OPEN ACCESS

Edited by:

Penghua Wang,

University of Connecticut Health

Center, United States

Reviewed by:

Huanle Luo,

SYSU, China

Tao Lin,

UCONN Health, United States

${ }^{*}$ Correspondence:

Michael Hust

m.hust@tu-bs.de

Specialty section:

This article was submitted to

Clinical Microbiology,

a section of the journal

Frontiers in Cellular

and Infection Microbiology

Received: 06 May 2021

Accepted: 21 June 2021

Published: 07 July 2021

Citation:

Roth KDR, Wenzel EV, Ruschig M,

Steinke S, Langreder N, Heine PA,

Schneider K-T, Ballmann R, Fühner V,

Kuhn P, Schirrmann T, Frenzel A,

Dübel S, Schubert M, Moreira GMSG,

Bertoglio F, Russo G and Hust M

(2021) Developing Recombinant

Antibodies by Phage Display Against

Infectious Diseases and Toxins for

Diagnostics and Therapy.

Front. Cell. Infect. Microbiol. 11:697876.

doi: 10.3389/fcimb.2021.697876

\section{Developing Recombinant Antibodies by Phage Display Against Infectious Diseases and Toxins for Diagnostics and Therapy}

Kristian Daniel Ralph Roth ${ }^{1}$, Esther Veronika Wenzel ${ }^{1,2}$, Maximilian Ruschig ${ }^{1}$, Stephan Steinke ${ }^{1}$, Nora Langreder ${ }^{1}$, Philip Alexander Heine ${ }^{1}$, Kai-Thomas Schneider ${ }^{1}$, Rico Ballmann ${ }^{1}$, Viola Fühner ${ }^{1}$, Philipp Kuhn ${ }^{3}$, Thomas Schirrmann ${ }^{3}$, André Frenzel ${ }^{3}$, Stefan Dübel ${ }^{1,2,3}$, Maren Schubert ${ }^{1}$, Gustavo Marçal Schmidt Garcia Moreira ${ }^{1}$, Federico Bertoglio ${ }^{1}$, Giulio Russo ${ }^{1,2}$ and Michael Hust ${ }^{1,3^{*}}$

1 Institut für Biochemie, Biotechnologie und Bioinformatik, Abteilung Biotechnologie, Technische Universität Braunschweig,
Braunschweig, Germany, ${ }^{2}$ Abcalis GmbH, Braunschweig, Germany, ${ }^{3}$ YUMAB GmbH, Braunschweig, Germany

Antibodies are essential molecules for diagnosis and treatment of diseases caused by pathogens and their toxins. Antibodies were integrated in our medical repertoire against infectious diseases more than hundred years ago by using animal sera to treat tetanus and diphtheria. In these days, most developed therapeutic antibodies target cancer or autoimmune diseases. The COVID-19 pandemic was a reminder about the importance of antibodies for therapy against infectious diseases. While monoclonal antibodies could be generated by hybridoma technology since the 70ies of the former century, nowadays antibody phage display, among other display technologies, is robustly established to discover new human monoclonal antibodies. Phage display is an in vitro technology which confers the potential for generating antibodies from universal libraries against any conceivable molecule of sufficient size and omits the limitations of the immune systems. If convalescent patients or immunized/infected animals are available, it is possible to construct immune phage display libraries to select in vivo affinity-matured antibodies. A further advantage is the availability of the DNA sequence encoding the phage displayed antibody fragment, which is packaged in the phage particles. Therefore, the selected antibody fragments can be rapidly further engineered in any needed antibody format according to the requirements of the final application. In this review, we present an overview of phage display derived recombinant antibodies against bacterial, viral and eukaryotic pathogens, as well as microbial toxins, intended for diagnostic and therapeutic applications.

Keywords: phage display, infectious disease, recombinant antibodies, scFv antibodies, VHH antibodies 


\section{INTRODUCTION}

Antibodies are indispensable tools for basic research (Colwill and Gräslund, 2011), diagnostics (Kourea and Kotoula, 2016) and therapy (Kaplon and Reichert, 2021). In the past - and still today polyclonal antibodies (blood serum) are produced in animals like horses (von Behring and Kitasato, 1890). The hybridoma technology was a milestone in antibody generation because it allowed the production of monoclonal antibodies (Köhler and Milstein, 1975). Despite these antibodies are monoclonal, cell secreted antibodies are not always monospecific, as unveiled by the results of a multicentric study on the detrimental effects of genetic diversity in individual hybridoma clones (Bradbury et al., 2018). Of 185 randomly selected hybridomas analyzed in this study, almost one third was found to contain additional productive heavy or light chains, resulting in antibodies with reduced affinity and more than one specificity. Other limitations of the hybridoma technology are the possible instability of the tetraploid, but also often aneuploid hybridoma cell lines (Pauza et al., 1993), the restriction of the immune system which prevents the generation of antibodies against highly conserved or selfantigens and most important the limitations to directly generate human antibodies (Winter and Milstein, 1991). The hybridoma technology most commonly provides murine antibodies for use in research and diagnostics. But, the therapeutic applications of murine antibodies are very limited because repeated administration of murine antibodies can cause a human antimouse antibody reaction (HAMA), which can lead also to severe side effects such as anaphylactic shock (Courtenay-Luck et al., 1986). While various humanization strategies are available to reduce the immunogenicity, these approaches are often laborious (Almagro and Fransson, 2008; Lo K.-M. et al., 2014). The human hybridoma technology allows the generation of human antibodies, (Cole et al., 1984; Hammond, 2010), but this approach will not be able to deliver antibodies against any targets because specific B-cells from humans would be needed and this is limited by ethical constraints. An alternative for human antibody generation is the use of transgenic animals in which the animal antibody gene repertoire is substituted with the corresponding human gene repertoire, but also this technology is limited by the restrictions of the immune system. This approach was successfully used for several approved therapeutic antibodies (Jakobovits, 1995; Lonberg and Huszar, 1995; Fishwild et al., 1996; Nelson et al., 2010).

A technology which allows to generate fully human antibodies right away, hence avoiding the side effects originating from HAMA, is antibody phage display. Because this approach uses an in vitro selection process, it does not have to rely on immunization and associated limitations, and can use entirely human gene repertoires. Phage display is based on the work of Georg P. Smith on filamentous phage, which infects E. coli and it is the most commonly used antibody display approach nowadays (Smith, 1985). Referring to the pan and the method of gold diggers, the antibody selection process was called "panning" (Parmley and Smith, 1988).

Around 1990/91, the M13 phage display technology was further developed for human antibody generation in parallel at three research sites: DKFZ in Heidelberg (Germany), MRC Laboratory of Molecular Biology in Cambridge (UK) and at the Scripps Research Institute in La Jolla (USA) (McCafferty et al., 1990; Barbas et al., 1991; Breitling et al., 1991; Clackson et al., 1991). For the expression of the antibody::pIII (phage protein III) fusion proteins via phage display, two different genetic approaches have been developed. Initially, the antibody genes were directly inserted into the M13 phage genome and fused upstream of the wildtype pIII gene (gIII) (McCafferty et al., 1990). Due to a better genetic stability and opportunity for independent regulation of phage and antibodies production, today the most successful system is based on phagemids. These are independent plasmids which provide the genes encoding the antibody::pIII fusion proteins and contain a phage morphogenetic signal for packaging of the phagemid into the phage particles (Breitling et al., 1991). In both phage display systems, the antibody fragments are always displayed on the phage surface and the corresponding antibody gene is packaged into the same phage particle. This successful technology was awarded with the Nobel Prize for Chemistry in 2018. For antibody phage display, the most common used antibody formats are the single chain fragment variable (scFv) (Vaughan et al., 1996; Schofield et al., 2007; Hust et al., 2011) or fragment antigen binding (Fabs) (de Haard et al., 1999; Hoet et al., 2005). Other used formats are human VH domains (dAbs), immunoglobulins of sharks (IgNARs) and the variable domains of camel heavy chains (VHHs) (Muyldermans, 2001; Nuttall et al., 2001; Holt et al., 2003; Nuttall et al., 2004; Muyldermans et al., 2009). The use of immune camel, llama or alpaca libraries gained popularity in the last five years. For veterinary research, chicken antibody libraries are often used (Fehrsen et al., 2005; Foord et al., 2007; Wemmer et al., 2010). The diversity of chicken antibody genes is the result of gene conversion. Here, the N- and C-terminal parts of chicken's VH and VL are always identical, which facilitates antibody gene amplification and library cloning (Parvari et al., 1988; Chiliza et al., 2008).

In the antibody selection process (panning), in most cases, the target molecules is immobilized on a solid surface, like plastic surfaces - normally used for ELISA - such as polystyrene tubes or microtiter plate wells, the latter of which is the most simple and commonly used method (Hust et al., 2002; Russo et al., 2018), affinity chromatography column matrixes (Breitling et al., 1991) or magnetic beads (Sawyer et al., 1997). An alternative is the use of biotinylated targets for a selection in solution followed by a "pull-down" with streptavidin beads (Schütte et al., 2009; Wenzel et al., 2020b). After incubating the entire diversity of the phage display library with these immobilized antigens, the tremendous excess of non- or weak-binding antibody phage particles are removed by stringent washing. Afterwards, the bound antibody phage will be eluted, mainly by trypsinization or by $\mathrm{pH}$ shift, and used for E. coli infection. Subsequently, the phagemid bearing E. coli will be infected with a helperphage to produce new antibody phage particles with an enriched fraction of antigen specific antibody phage clones. Usually 3-5 panning rounds are performed before screening. Specific binders can be identified in a screening process using monoclonal soluble antibodies or 
monoclonal antibody phage by e.g. ELISA (Frenzel et al., 2014), WB (Hust et al., 2002) or flow cytometer (Ayriss et al., 2007). The antibody fragment genes can be subcloned to produce antibodies in any desired antibody format, e.g. IgG or scFv-Fc (Hoet et al., 2005; Dübel et al., 2010; Hust et al., 2011; Jäger et al., 2013; Frenzel et al., 2014). Figure 1 shows an overview on the phage display antibody selection process. An overview about phage display in comparison to other display technologies is given by Valldorf et al. (2021).

Depending the origin of the $\mathrm{V}$-gene repertoires, there are two types of libraries: immune libraries and universal libraries. Immune libraries are constructed from convalescent patients or immunized donors. This library type is most used to obtain an antibody against a particular target, e.g. an infectious pathogen like Ebola virus (Maruyama et al., 1999a) or diphtheria toxin (Wenzel et al., 2020a). The advantage of this library type is that the $\mathrm{V}$-genes contain hypermutations and are already affinitymatured for the targeted pathogen.

The alternatives are universal libraries - in the past also named "single-pot" libraries - made of naïve, semi-synthetic or synthetic gene repertoires. This library type allows to isolate antibody fragments binding to virtually every possible target without the need for an immunization or the availability of patients' blood. (Winter et al., 1994; Dübel et al., 2010; Frenzel et al., 2017). In a pandemic situation, this provides a source for immediate antibody generation against a new arising pathogen, independently from the availability of material from patients (Bertoglio et al., 2021b). The Naïve libraries are cloned from rearranged $\mathrm{V}$ genes derived from B cells ( $\operatorname{IgM}$ ) of non-immunized donors. Examples for naïve libraries are the HAL scFv libraries (Hust et al., 2011; Kügler et al., 2015) and Fab library constructed by de Haard and colleagues (de Haard et al., 1999).
Semi-synthetic libraries are cloned from unrearranged $\mathrm{V}$ genes from pre-B cells (germline cells) (Griffiths et al., 1994) or in most cases from one antibody framework (Pini et al., 1998). In this defined framework one or several CDRs, but always the CDR H3, are randomized, e.g. by using DNA-primers covering the CDR H3 section. The semi-synthetic libraries Tomlinson I and J libraries are often used and are the best example for semisynthetic libraries. These libraries have a VH3-23 and Kappa IKV1-39 framework combined with randomized CDR2 and CDR3 (de Wildt et al., 2000). For the FAB310 antibody gene library, a combination of naïve and synthetic repertoire was used. Here, the Fd fragment $(\mathrm{VH}+\mathrm{CH} 1)$ contains randomized CDR1 and CDR2 in the human VH3-23 framework and a naïve CDR3 regions from autoimmune patients. The $\mathrm{Fd}$ fragments were combined with light chains also from autoimmune patients (Hoet et al., 2005). The transition of semi-synthetic to synthetic libraries is not strict. In general, complete synthetic libraries are made of human frameworks and here all CDR cassettes are synthetic, the best examples are the HUCAL libraries (Hayashi et al., 1994; Knappik et al., 2000; Tiller et al., 2013). Universal libraries have a theoretical diversity higher than $10^{10}$ independent clones (Schofield et al., 2007; Glanville et al., 2009; Lloyd et al., 2009; Tiller et al., 2013; Kügler et al., 2015).

In vitro display methods, like phage display, differ from classical animal immunization approaches to obtain polyclonals or hybridomas, in the possibility to directly generate sequence defined monoclonal antibodies. Additionally, the phage display antibody selection process occurs entirely in vitro and its customization allows to pre-filter antibodies with the intended binding properties, such as epitope specificity, binding at defined $\mathrm{pH}$ and temperatures, or absence of unwanted cross-reactivities. An alternative method that allows to generate sequence defined
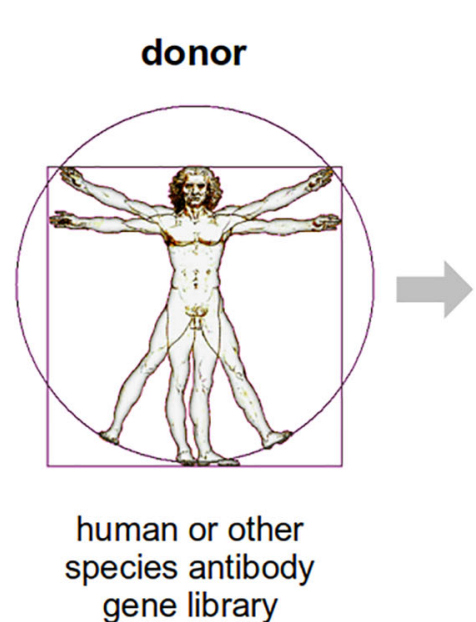

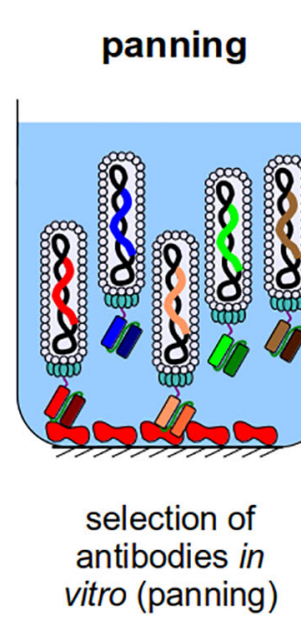

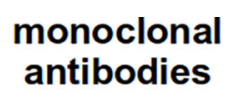
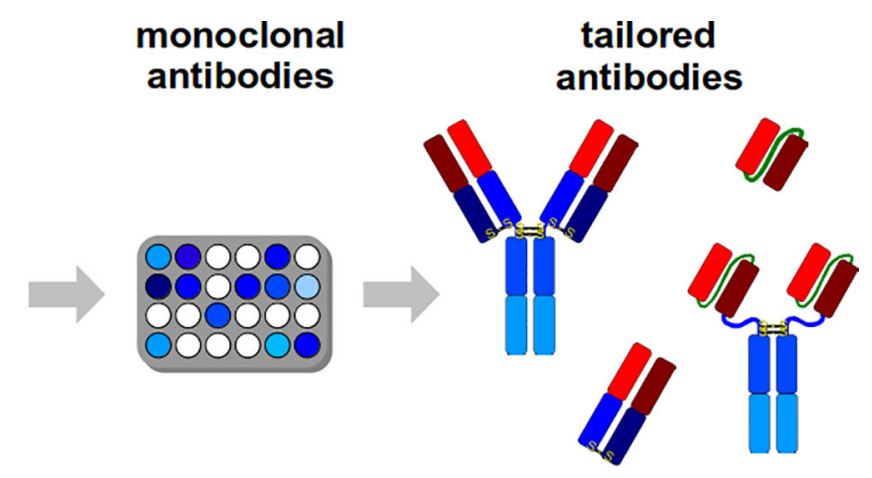
identification of monoclonal binders by e.g. ELISA

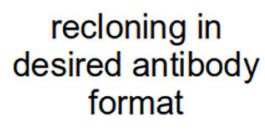

FIGURE 1 | Schematic illustration of the antibody generation process. For the antibody generation, human phage display libraries or libraries from other species are used. These libraries will be used for the in vitro selection (panning) on a target molecule. In short: the antibody phage particles will be incubated with target molecule (in the illustration, a target molecule was immobilized in a microtitre plate well and a scFv phage display library is used), the non and weak binding antibody phage particles will be washed away and the binding antibody phage will be eluted (the procedure will be repeated 3-5 times) and further analyzed. In the next step, monoclonal binders will be identified, e.g. by ELISA. Finally, the selected antibody fragments can be recloned, because the corresponding gene is packaged in the phage particles, and produced in any antibody format tailored to the final application. 
antibodies is the microfluidics-based B-cell selection method (Seah et al., 2018). B-cells secreted antibodies binding to labeled antigen material can be assessed at single cell level in droplets of buffer solution. This method, very laborious and technically demanding, is restricted to the availability of patient or immunized animal B-cells. Additionally, this approach provides a lower degree of flexibility in the number of assays which can be performed in the initial antibody screening phase. The upside of this method is the possibility to discover antibodies already in the IgG format. These features made this method particularly popular for the discovery of therapeutic antibodies from B-cells of disease-recovered patients. This is the case of the FDA approved Neutralizing antibodies to Ebola virus glycoprotein Ebanga (Ansuvimab-zykl) (https://www.fda.gov/ drugs/drug-safety-and-availability/fda-approves-treatment-ebolavirus), the anti-HIV neutralizing antibodies under clinical evaluation (Spencer et al., 2021) or the anti-SARS-CoV-2 antibodies REGN10933 and REGN10987 (Hansen et al., 2020).

To date, 106 monoclonal antibodies and antibody conjugates have been approved by EMA and/or FDA (status March 2021), 87 antibodies are in clinical phase 2 or 3 and 122 antibodies are in phase 1 or IND filed (Source: antibodysociety.org, status April 2020). Most approved antibodies are for the treatment of autoimmune diseases and cancer. The annual sales of therapeutic antibodies exceeded 98 billion US\$ in 2017 and the market will be predicted with 137-200 billion US\$ in 2022 (Grilo and Mantalaris, 2019). The mode of action of therapeutic antibodies are numerous and include neutralization of substances e.g. cytokines like tumor necrosis factor alpha (TNF- $\alpha$ ) (Alonso-Ruiz et al., 2008) or toxins (RasettiEscargueil et al., 2017), human cell binding and modulation of the host immune system (Chatenoud and Bluestone, 2007), blocking of receptors which are overexpressed on cancer cells like epidermal growth factor receptor (EGFR) (Peeters et al., 2009) or combinations of these mode of actions (Adams and Weiner, 2005). Currently, eight recombinant antibodies or antibody cocktails are approved for the direct treatment of pathogens or toxins. The first recombinant antibody approved for the treatment of an infectious disease was Palivizumab. It is a classical humanized antibody approved in 1998 for the treatment of Respiratory syncytial virus (RSV) bronchiolitis (Malley et al., 1998). For anthrax treatment, the human antibody Raxibacumab was developed. This antibody is derived from a human phage display library (made by Cambridge Antibody Technology in cooperation with Human Genome Science) and was approved in 2012 (Mazumdar, 2009; Kummerfeldt, 2014). A second antibody for post-exposure treatment of anthrax, the antibody Obiltoxaximab, has been approved in 2020 (Henning et al., 2018). A further approved antibody against toxins is Bezlotoxumab, approved in 2016. This antibody neutralizes the Clostridioides difficile toxin TcdB (Babcock et al., 2006; Johnson and Gerding, 2019). The anti-HIV antibody Ibalizumab has been approved in 2018. The mode of action is very unique for an antiviral antibody, because it blocks cell entry by binding to the human receptor CD4 on the target cells instead of binding to the virus (Beccari et al., 2019). The anti-rabies antibody Rabishield to replace anti-rabies serum therapies has been approved 2018 in
India (Wang et al., 2011; Gogtay et al., 2018). End of 2020, two products were approved for the treatment of Ebola: the threeantibody cocktail REGN-EB3 (Atoltivimab/maftivimab/ odesivimab) (Pascal et al., 2018) and the single antibody mAb114 (Ansuvimab-zykl) (Corti et al., 2016). These antibodies showed a good efficiency in clinical trials against Ebola virus especially in comparison to Remdesivir (Mulangu et al., 2019). In the COVID-19 pandemic, the anti-SARS-CoV-2 antibody cocktail Casirivimab (REGN10933)/Imdevimab (REGN10987) (Baum et al., 2020; Hansen et al., 2020) and the antibody Bamlanivimab (LY-CoV555) (Chen et al., 2021) got a conditional marketing authorization in Europe and an Emergency use authorization (EUA) in the USA for nonhospitalized patients with mild to moderate symptoms. The FDA also authorized the antibody cocktail Bamlanivimab and Etesevimab (JS016, CB6) (Shi et al., 2020) in the USA for the same indication. For the treatment of hospitalized patients with moderate to severe symptoms, phage display derived antibody COR-101 (STE90-C11) against SARS-CoV-2 (Bertoglio et al., 2021a) is in clinical phase $1 \mathrm{~b} / \mathrm{II}$.

In the next sections, we provide an overview of recombinant antibodies derived from phage display against bacterial and viral pathogens, eukaryotic pathogens (parasites, fungi) and toxins, as well as detailed examples for diagnostics and therapy.

\section{RECOMBINANT ANTIBODIES AGAINST BACTERIA}

Toxins are the most frequent antigenic target of therapeutic antibodies used to fight bacterial pathogens. This topic is thoroughly discussed in a dedicated paragraph: "targeting of toxins with recombinant antibodies". Excluding toxin antigens, antibodies raised against bacteria are predominantly used in diagnostics (Skottrup et al., 2011; Ferrara et al., 2012) and to assess the presence of contamination in environmental samples (Griep et al., 1998; Mechaly et al., 2008). As of today, microbiologic bacteria identification by cultivation remains the benchmark approach for the diagnostic of several pathogenic bacterial species, including Mycobacterium tuberculosis (Norbis et al., 2014), Salmonella Typhimurium (Kuhn et al., 2012), or Listeria monocytogenes (Gasanov et al., 2005).

The many drawbacks of these methods are the low throughput and high costs caused by their inherently long experimental duration, the higher risk of exposure to pathogenic organisms and the need of highly trained personnel. Real-time PCR and other molecular diagnostics approaches have been introduced to reduce the time needed for the identification of many bacteria (Liang et al., 2018), while offering high detection sensitivity and specificity. Nevertheless, such methods most often depend on the availability of laboratory infrastructure and, if portable, are less amenable to high throughput parallelized measurements ( $\mathrm{Xu}$ et al., 2020). Similarly, mass spectrometry is able to provide high sensitivity, however, this technology requires expensive devices and trained personnel (Dixon et al., 2015). On the 
other hand, antibody-based detection methods such as ELISA and immunochromatography, are faster, simpler, and well-suited for high-throughput. These features, together with the lower costs compared to other techniques, contributed to the success of these diagnostic approaches world-wide, including developing countries, where resources may be scarce and laboratories sparsely distributed over the territory.

Up to date, a vast plethora of antibodies for diagnostic applications has been generated via phage-display against different bacterial proteins or carbohydrates (Table 1). Interestingly, research on this field seems to be in constant rise, as $44 \%$ of these antibodies have been generated only in the past five years.

In the following paragraphs, we offer detailed examples on antibodies against different bacterial pathogens that were generated using phage display.

Mycobacterium tuberculosis (Mtb) is the bacteria responsible for a lung infection known as Tuberculosis (TB). This pathogen specifically attacks and replicates inside the macrophage cells in the alveoli, causing fatigue, fever and coughing (Fu and Fu-Liu, 2002). As of 2021, this disease affected approximately 10 million people and caused 1.5 million deaths worldwide per year (World Health Organization, 2021). TB early diagnosis is essential to improve treatment and limit disease spread. The protein secreted by Mtb in the highest amounts, Antigen 85 (Ag85), represents an ideal target for diagnostics (Wiker and Harboe, 1992). Ag85 is an oligomeric protein composed of three relatively small (30-32 $\mathrm{kDa}$ ) homologue proteins (Ag85A, Ag85B and Ag85C) (Wiker et al., 1992). In a novel approach described by Ferrara et al. (2012), a combination of antibody display techniques was successfully adopted to select Ag85 complex-specific antibodies. A universal phage display naïve $\mathrm{scFv}$-library with a nominal diversity of $\sim 10^{11}$ unique antibodies was used for initial selection on Ag85, obtaining a sub-library of $10^{5}$ pre-selected antibodies. Second, the selected antigen-specific scFv genes were used for the generation of yeast-display antibody sub-library. Upon completion of yeast based antibody generation, each clone was tested in FACS for its ability to specifically recognize the antigen target resulting in the discovery of 192 clones having the desired properties. Sequence analysis revealed that 111 of these antibodies were unique and could be used in further $A b$ characterization. Chessboard antibody combination testing resulted in the identification of 7 antibody pairs that detect as little as $22.7 \mathrm{nM} \mathrm{Ag85}$ in patient sera or $6.1 \mathrm{nM}$ in serum freeconditions. The uniqueness of this work relies in the fact that each validated antibody was specific for the Ag85-complex only. Other approaches were aimed at discovering subunit-specific antibodies, as in the case of Fuchs et al. Here, the naïve HAL7/8 phage display libraries were incubated with recombinant Ag85B subunit (Fuchs et al., 2014). The resulting antibodies were shown to have, in sandwich ELISA or lateral flow test, an antigen protein limit of detection of respectively $10 \mathrm{ng} / \mathrm{mL}$ and $<5 \mathrm{ng} /$ $\mathrm{mL}$. Nevertheless, when using bacterial cell extracts or filtered culture material, immunodetection could be only performed in ELISA or western blot. The authors concluded that the absence of an antibody affinity improvement step may have been the reason for their results. This supposition found indirect confirmation in a different study by Sixholo and colleagues (Sixholo et al., 2011) describing the selection of antibodies against the Mtb $16 \mathrm{kDa}$ heat shock protein $\mathrm{X}$ (HspX) from chicken semi-synthetic Nkuku antibody gene library. By the repetition of four panning rounds against recombinant antigen material, three unique scFv's were confirmed to bind HspX in ELISA. On purpose, the clone with the weakest binding was chosen for in vitro affinity maturation by different methods. In the first approach, a mutant library of the parental antibody gene was generated by error-prone PCR, resulting in a diversity of $\sim 3 \times 10^{7}$ unique scFv clones. Repeating the antibody selection using this library under more stringent conditions, led to the discovery of three mutant scFv's with increased binding affinity. Direct binding comparison in ELISA showed that the newly generated antibodies produced a signal $\sim 11$ times higher than the parental clone. The result was confirmed by the improved association and dissociation kinetics in SPR analysis. All affinity-improved antibody genes contained mutated amino acids in both CDR and framework regions. In the second approach, a glycine residue alone was replaced to the common 15-mer linker connecting the $\mathrm{VH}$ to $\mathrm{VL}$, resulting in tetramer formation (Schmiedl et al., 2006). The avidity effect leading to cooperative binding resulted in a binding signal increase of $\sim 14$ times in ELISA. Antibodies against Mtb were also generated by Hamidon and colleagues (Hamidon et al., 2018) utilizing a different approach. A patient immune TB library with a nominal diversity of $10^{9}$ different $\mathrm{scFv}$ antibodies could be generated starting from the B-cell material from six individuals infected with TB. This immune library was used to select antibodies against $\mathrm{Mtb} \alpha$-crystalline, resulting in three unique antigen-specific clones validated for antigen binding in ELISA and Western Blot assays.

Periodontitis is a disease where inflammation of the dental gum results in its progressive retraction and, if not cured on time, loss of teeth. One of the major pathogens involved in gum infection is Porphyromonas gingivalis (Socransky et al., 1998). The RgpB cysteine proteases secreted by this pathogen is one of the causing factors of the gum inflammation and constitutes a valid biomarker candidate (Imamura, 2003). Skottrup et al. (2011) generated antibodies against immobilized RgpB from a naive library of camelid antibodies with a diversity of $\sim 5 \times 10^{7}$ different clones. Such antibodies consist of a monomeric VHH domain $(\sim 15 \mathrm{kDa})$, which offer multiple advantages for diagnostics, in particular high yields in E. coli production systems, good stability and small epitope accessibility. This library yielded an elite antibody clone with 362 pM affinity towards the recombinant $\operatorname{RgpB}$, also specific to the antigen presented on cells. While not inhibiting RgpB catalytic activity, this antibody showed in subtractive inhibition ELISA a limit of detection equal to $\sim 8 \times 10^{6}$ cells $/ \mathrm{mL}$ of saliva.

In the field of foodborne gastrointestinal infection causing pathogens, Salmonella Typhimurium is probably the most studied bacteria (Jacobsen et al., 2011). In the attempt to generate antibodies for the detection of this pathogen, Meyer et al. (2012) utilized ORFeome phage display for biomarker 
TABLE 1 | Recombinant antibodies derived by phage display against pathogenic bacteria.

\begin{tabular}{|c|c|c|c|c|c|c|}
\hline Bacteria & Target & $\begin{array}{l}\text { Library } \\
\text { Type }\end{array}$ & $\begin{array}{l}\text { Antibody } \\
\text { Format }\end{array}$ & $\begin{array}{l}\text { Antibody } \\
\text { Origin }\end{array}$ & Application & Reference \\
\hline Acinetobacter baumannii & Bap & Immune & $\mathrm{VHH}$ & camel & ELISA, WB, in vivo neutralization & (Payandeh et al., 2014) \\
\hline Bacillus anthracis & S-layer protein EA1 & immune & $\mathrm{VHH}$ & llama & ELISA, WB & $\begin{array}{l}\text { (Walper et al., 2012; } \\
\text { Anderson et al., 2018) }\end{array}$ \\
\hline Bacillus anthracis & live bacteria & immune & scFv & mice & ELISA, WB, IF & (Mechaly et al., 2008) \\
\hline Bacillus anthracis & protective antigen (PA) & naïve & scFv & human & ELISA, Inhibition assay & (Ahn et al., 2019) \\
\hline Bordetella pertussis & $\begin{array}{l}\text { filamentous hemagglutinin, } \\
\text { pertactin }\end{array}$ & immune & scFv & mice & $\begin{array}{l}\text { ELISA, in vitro inhibition, in vivo } \\
\text { studies }\end{array}$ & (Hussein et al., 2007) \\
\hline Brucella melitensis & radiated bacteria & immune & scFv & mice & ELISA & (Hayhurst et al., 2003) \\
\hline Campylobacter jejuni & whole cells & immune & ScFv & rabbit & ELISA, WB & (Nzuma et al., 2018) \\
\hline Chlamydophila psittaci & $\begin{array}{l}2.4[2.8] 2.4 \text {-linked Kdo } \\
\text { tetrasaccharide }\end{array}$ & immune & scFv & mice & ELISA, IF & (Gerstenbruch et al., 2010) \\
\hline Chlamydia trachomatis & elementary bodies & naïve & scFv & human & ELISA, WB, IF & $\begin{array}{l}\text { (Sheets et al., 1998; } \\
\text { Lindquist et al., 2002) }\end{array}$ \\
\hline Chlamydia trachomatis & unknown & immune & $\mathrm{VHH}$ & camel & unknown & (Tillib et al., 2017) \\
\hline Clostridium botulinum & RhoA/B & naïve & scFv & human & WB, immunofluorescence & (Rohrbeck et al., 2016) \\
\hline Clostridium difficile & $\begin{array}{l}\text { different surface proteins } \\
\text { (including FliC and FliD) }\end{array}$ & $\begin{array}{l}\text { semi- } \\
\text { synthetic }\end{array}$ & $\mathrm{scFv}$ & human & ELISA, WB, in vitro motility assay & (Shirvan and Aitken, 2016) \\
\hline Clostridium difficile & Surface layer proteins (SLPs) & immune & $\mathrm{VHH}$ & Llama & ELISA, WB, in vitro motility assay & (Kandalaft et al., 2015) \\
\hline Escherichia coli & live E. coli F17 + & immune & $\mathrm{VHH}$ & camel & ELISA & (Salhi et al., 2020) \\
\hline Francisella tularensis & lipopolysaccharide (LPS) & immune & scFv, IgG & rabbit & ELISA, WB, IF, in vitro neutralization & (Mechaly et al., 2019) \\
\hline Klebsiella pneumoniae & $\begin{array}{l}\text { different strains of K. pneumonia } \\
\text { (possibly MrkA) }\end{array}$ & naive & $\begin{array}{l}\text { scFv, } \\
\text { scFv-Fc, } \\
\operatorname{lgG}\end{array}$ & human & ELISA, OPK, IF, in vivo protection & (Wang Q. et al., 2016) \\
\hline Haemophilus influenzae & capsular polysaccharide & immune & $\mathrm{Fab}$ & human & ELISA & (Reason et al., 1997) \\
\hline Helicobacter pylori & urease & $\begin{array}{l}\text { semi- } \\
\text { synthetic }\end{array}$ & $\mathrm{scFv}$ & human & ELISA, WB, WB & (Fouladi et al., 2019) \\
\hline Helicobacter pylori & bacterial lysate & immune & scFv & human & ELISA & (Reiche et al., 2002) \\
\hline Lactobacillus acidophilus & S-layer protein & naïve & $\mathrm{scFv}$ & human & FACS, WB & (Close et al., 2013) \\
\hline Lawsonia intracellularis & live bacteria & $\begin{array}{l}\text { semi- } \\
\text { synthetic }\end{array}$ & $\mathrm{scFv}$ & human & ELISA, IF & $\begin{array}{l}\text { (Dezorzová-Tomanová } \\
\text { et al., 2007) }\end{array}$ \\
\hline Legionella pneumophila & whole cells & naïve & scFv & human & ELISA, biosensor & (Kuhn et al., 2017) \\
\hline Leptospira spec. & LipL21 & naïve & $\mathrm{scFv}$ & human & ELISA & (Mohd Ali et al., 2021) \\
\hline Listeria monocytogenes & internalin B & $\begin{array}{l}\text { immune/ } \\
\text { naïve }\end{array}$ & $\mathrm{VHH}$ & $\begin{array}{l}\text { alpaca, } \\
\text { llama, } \\
\text { camel }\end{array}$ & ELISA & (Gene et al., 2015) \\
\hline Listeria monocytogenes & $\begin{array}{l}\text { pyruvate dehydrogenase } \\
\text { complex-enzyme } 2 \text { (PDC-E2) }\end{array}$ & naïve & $\begin{array}{l}\text { scFv, } \\
\text { scFv-Fc }\end{array}$ & human & ELISA, WB, IF & (Moreira et al., 2020) \\
\hline Listeria monocytogenes & heat-killed cells & naive & $\mathrm{VHH}$ & Llama & ELISA, WB & (Tu et al., 2016) \\
\hline Moraxella catarrhalis & HMW-OMP & $\begin{array}{l}\text { semi- } \\
\text { synthetic }\end{array}$ & scFv & human & ELISA, FACS, WB, in vitro inhibition & (Boel et al., 1998) \\
\hline Mycobacterium avium & cell lysate & immune & scFv & sheep & ELISA, WB, FACS, IF & (Berger et al., 2006) \\
\hline Mycobaterium bovis & HSP65 & $\begin{array}{l}\text { semi- } \\
\text { synthetic }\end{array}$ & $\begin{array}{l}\text { scFv,scFv- } \\
\operatorname{lgY}-F_{C}\end{array}$ & chicken & ELISA, WB & (Wemmer et al., 2010) \\
\hline Mycobacterium leprea & PGLI-M3 & naiive? & scFv & human & ELISA, immunohistochemistry & (Lima et al., 2020) \\
\hline $\begin{array}{l}\text { Mycobacterium } \\
\text { tuberculosis }\end{array}$ & antigen 16kDa (HspX) & $\begin{array}{l}\text { semi- } \\
\text { synthetic }\end{array}$ & scFv & chicken & ELISA & (Sixholo et al., 2011) \\
\hline $\begin{array}{l}\text { Mycobacterium } \\
\text { tuberculosis }\end{array}$ & antigen 85B & naïve & $\begin{array}{l}\text { scFv,scFv- } \\
\text { FC }\end{array}$ & human & ELISA, WB, lateral flow strip assay & (Fuchs et al., 2014) \\
\hline $\begin{array}{l}\text { Mycobacterium } \\
\text { tuberculosis }\end{array}$ & antigen 85 & naïve & $\begin{array}{l}\text { scFv,scFv- } \\
\text { FC }\end{array}$ & human & ELISA & (Ferrara et al., 2012) \\
\hline $\begin{array}{l}\text { Mycobacterium } \\
\text { tuberculosis }\end{array}$ & LAM & immune & scFv & $\begin{array}{l}\text { Rabbit/ } \\
\text { chicken }\end{array}$ & Sandwich-ELISA & (Kawasaki et al., 2019) \\
\hline $\begin{array}{l}\text { Mycobacterium } \\
\text { tuberculosis }\end{array}$ & $\alpha$-crystalline antigen & immune & scFv & human & ELISA & (Hamidon et al., 2018) \\
\hline $\begin{array}{l}\text { Mycobacterium } \\
\text { tuberculosis }\end{array}$ & LAM & immune & scFvlgG & rabbit & ELISA, WB, dot blot, flow cytometry & (Yan et al., 2020) \\
\hline Neisseria meningitidis & $\mathrm{NadA}$ & Immune & $\mathrm{VHH}$ & Ilama & $\begin{array}{l}\text { Dot blot, WB, } I H C \text {, blocking assay, in } \\
\text { vitro model }\end{array}$ & (Kulkarni et al., 2020) \\
\hline Porphyromonas gingivalis & RgpB & naïve & $\mathrm{VHH}$ & camel & ELISA & (Skottrup et al., 2011) \\
\hline Pseudomonas aeruginosa & SpuE & naïve & scFv & human & ELISA & (Zhang Y. et al., 2019) \\
\hline Pseudomonas aeruginosa & flagelar capping protein (FliD) & naïve & $\begin{array}{l}\text { scFv, } \\
\text { scFv-Fc }\end{array}$ & human & WB & (Postel et al., 2016) \\
\hline
\end{tabular}


TABLE 1 | Continued

\begin{tabular}{|c|c|c|c|c|c|c|}
\hline Bacteria & Target & $\begin{array}{l}\text { Library } \\
\text { Type }\end{array}$ & $\begin{array}{l}\text { Antibody } \\
\text { Format }\end{array}$ & $\begin{array}{l}\text { Antibody } \\
\text { Origin }\end{array}$ & Application & Reference \\
\hline Ralstonia solanacearum & LPS & naïve & scFv & human & ELISA, IF, WB & (Griep et al., 1998) \\
\hline Salmonella Typhimurium & OmpD & naïve & scFv & human & ELISA & (Meyer et al., 2011) \\
\hline Salmonella Typhimurium & 5 different immunogenic proteins & naïve & scFv & human & ELISA & (Meyer et al., 2012) \\
\hline Staphylococcus aureus & FnBPA, ClfA & immune & scFv & bovine & ELISA, WB, inhibition assay & $\begin{array}{l}\text { (Wang M. et al., 2015, } \\
\text { Wang M. et al., 2016) }\end{array}$ \\
\hline Staphylococcus aureus & cells & immune & $\begin{array}{l}\text { scFvscFv- } \\
\text { Fc }\end{array}$ & human & ELISA, dot blot & (Nian et al., 2016) \\
\hline $\begin{array}{l}\text { Streptococcus } \\
\text { pneumoniae }\end{array}$ & Pep27 & synthetic & scFv & human & ELISA & (Kim et al., 2018) \\
\hline Streptococcuspneumoniae & PspA & synthetic & scFv & human & WB & (Jang et al., 2017) \\
\hline $\begin{array}{l}\text { Streptococcus mutans \& } \\
\text { sobrinus }\end{array}$ & live cells & synthetic & Fab & human & $\begin{array}{l}\text { ELISA, IF, Flow cytometry, in vitro } \\
\text { biofilm assay, in vivo model }\end{array}$ & (Alam et al., 2018) \\
\hline Vibrio cholera & LPS & immune & $\mathrm{VHH}$ & camel & ELISA, in vivo challenge & $\begin{array}{l}\text { (Ebrahimizadeh et al., } \\
\text { 2013) }\end{array}$ \\
\hline Vibrio parahaemolyticus & VP1694 & immune & scFv & mice & ELISA, WB & (Wang R. et al., 2014) \\
\hline Vibrio parahaemolyticus & OmpU & $\begin{array}{l}\text { semi- } \\
\text { synthetic }\end{array}$ & $\mathrm{sdAb}$ & human & ELISA, in vitro inhibition & (Yu et al., 2020) \\
\hline Yersinia pestis & $\mathrm{F} 1$ & naïve & scFv & human & ELISA & (Lillo et al., 2011) \\
\hline
\end{tabular}

ELISA, enzyme linked immunosorbent assays; IHC, immunohistochemistry; IF, immuno fluorescence; FACS, fluorescence-activated cell sorting; WB, western blot.

discovery. Starting from bacterial genomic material, a random protein fragments library was screened using sera from Salmonella infected animals. In a second step, the antigens corresponding to the newly discovered immunogenic proteins were used to select human antibodies from the naïve HAL gene libraries. Antibodies are also potent tools for the monitoring of a vaccination campaign and discrimination of infected from vaccinated subjects. For the development of DIVA (Differentiating Infected from Vaccinated Animals) vaccines against S. Typhimurium, Selke and colleagues (Selke et al., 2007) generated an engineered bacterial strain lacking the marker protein OmpD (outer membrane protein D). A serological test using OmpD-specific antibodies constitutes a tool to discriminate infected animal from vaccinated ones. Meyer et al. (2011) generated scFv antibodies against OmpD for antigen detection in competitive ELISA on swine serum.

Another very prominent foodborne pathogen is Listeria monocytogenes. This bacterial infection, listeriosis, can cause severe illness, including meningitis and sepsis when reaching the systemic circulation. As of today, 13 different $L$. monocytogenes serotypes have been discovered, of which type $4 \mathrm{~b}, 1 / 2 \mathrm{a}$ and $1 / 2 \mathrm{~b}$ have shown to be the most virulent (Datta and Burall, 2018). Contaminated food also contains non-pathogenic Listeria species, making the diagnosis more difficult. Indeed, their faster growth rate during the enrichment step required for bacteria detection is the major cause of false-negative results in Listeria monocytogenes food diagnostics (Besse et al., 2010). Hence, species-specific immunodiagnostic tools constitute a necessary resource to improve both $L$. monocytogenes as well as Listeria spp. detection. Gene and colleagues (Gene et al., 2015) used naive and immune camelid antibody libraries for the selection via phage display of diagnostic nanobodies against internalin B (InIB), a protein which is strongly involved in host-cell invasion. Two of the five generated nanobodies, R303 and R3-30, showed picomolar binding affinities to InIB, representing a valuable resource for bacteria immunodetection in poorly concentrated samples. A recent study from Moreira et al. (2020) described the use in combination of different phage display techniques to identify new Listeria spp. protein biomarkers and rise antibodies against them. Initially, the human naïve antibody display phage library HAL9/10 was used to generate antibodies against different cell fractions from L. monocytogenes (cell wall, membrane, and cytoplasm). This way, four binders were isolated, which allowed the identification of a novel target for Listeria spp. detection named pyruvate dehydrogenase complex-enzyme 2 (PDC-E2) by using both immunomagnetic separation/mass spectrometry (IMS-MS) and ORFeome phage display. One of these antibodies was also used in immunofluorescence on non-permeabilized cells confirming the surface localization of the target. Antibody selection against PDC-E2 recombinant antigen yielded 16 additional antibodies. These 20 antibodies were finally tested in indirect ELISA against a panel of 17 Listeria species (including the most virulent $L$. monocytogenes serotypes $4 \mathrm{~b}, 1 / 2 \mathrm{a}$, and $1 / 2 \mathrm{~b}$ ) and 16 non-Listeria species. Two antibodies, GSM313-E9 and GSM313-H8, provided $100 \%$ sensitivity and specificity for Listeria spp. detection. Moreover, the binding region (epitope) of 18 out of the 20 antibodies was identified via single-gene phage display for epitope mapping, enabling to define the lipoyl domains of PDC-E2 as the major contributors for the detection through this target.

\section{RECOMBINANT ANTIBODIES AGAINST VIRUSES}

Viruses are in every kind of environment and are able to infect any sort of host. New viral species are continuously discovered and therefore much research has been devoted during the recent 
decades to generate vast sets of antibodies against viruses, both from universal and immune libraries using phage display technology. Target for selection of antibodies ranged from peptides and recombinant viral proteins to complete viral or pseudoviral particles, leading to the isolation of antibodies against human pathogenic viruses such as Sin nombre virus (Velappan et al., 2007), Dengue virus (Cabezas et al., 2008; Saokaew et al., 2014), Influenza virus (Lim et al., 2008; Sui et al., 2009), VEEV (Kirsch et al., 2008), Norovirus (HigoMoriguchi et al., 2014), SARS coronavirus (Sui et al., 2004), SARS-CoV-2 (Bertoglio et al., 2021b) or Hepatitis C (Songsivilai and Dharakul, 1998) from naïve antibody gene libraries. Alternatively, another source of monoclonal antibodies has been immune antibody gene libraries constructed from hosts infected with e.g. Hantavirus (Liang et al., 2001; Koch et al., 2003), WEEV (Hülseweh et al., 2014), HIV (Mohammadzadeh et al., 2014; Trott et al., 2014), SARS (Kang et al., 2006), Yellow fever virus (Daffis et al., 2005) or Influenza virus (Throsby et al., 2008; Sun et al., 2009). Additionally, semi-synthetic libraries have been used to generate antibodies against e.g. Influenza virus (Avnir et al., 2014). Plant viruses have also been addressed for antibody selections (Ziegler et al., 1995; Hust et al., 2002; Orecchia et al., 2008), beside human and animal viruses.

Virus-specific antibodies have also been selected from libraries originating from different species such as those from macaque (Rülker et al., 2012), chimpanzee (Goncalvez et al., 2008), llama (Fatima et al., 2014), mouse (Liu H. et al., 2014), chicken (van Wyngaardt et al., 2004) and human origin (Tikunova et al., 2012).

The predominant format harnessed for initial selection of antibodies against viruses has been scFv format (Gould et al., 2005; Wu et al., 2014), although Fab (Wyrzucki et al., 2014; Zhao et al., 2014) and VHH libraries (Fatima et al., 2014) were often used. In a peculiar case, Xiao et al. used the antibody $\mathrm{CH} 2$ domain as scaffold to generate binders against gp120 of HIV (Xiao et al., 2009). In the case of HIV, some unique aspects could be highlighted as for example that the neutralizing anti-gp41 antibody $\mathrm{HK} 20$ has a higher neutralization potency as scFv or Fab compared to IgG, indicating that the IgG format has more difficult access to the epitope, due to the formats bigger steric hindrance (Sabin et al., 2010). Another noteworthy example is the anti-gp41 VHH 2H10, where a CDR3 tryptophan is not involved in epitope binding, but resulted essential for virus neutralization (Lutje Hulsik et al., 2013).

In the following paragraphs, we present detailed examples for antibody generation and engineering using phage display against different viral taxa.

Vaccinia virus is the arketypal virus within the genus of Orthopoxvirus. This virus is with 300x $230 \mathrm{nM}$ a large DNA virus with a genome of about $0,2 \mathrm{Mb}$ (Malkin et al., 2003). Among the species included in Orthopoxvirus genus, there are monkeypox virus, cowpox virus and especially variola virus, the causative agent of smallpox in humans. Occurrence of natural smallpox has been eradicated in 1977 thanks to a massive WHO vaccination program, which started ten years earlier. However, since no vaccination of the general population is nowadays conducted and the use of variola virus as potential threat following intentional release has renewed the research interest for safe and effective smallpox vaccines, due to case fatality rates of $30 \%$ or more among unvaccinated subjects (Henderson et al., 1999). It is assumed that immunity against one poxvirus provides broad immunity against most of the viral family members given the high similarity shared among orthiopoxviruses (Earl et al., 2004; Berhanu et al., 2008). Using an immune scFv phage display library constructed from vaccinia virus immunized patients, human vaccinia specific antibodies were isolated. In vitro plaque-reduction neutralization tests proved that seven of these antibodies were able to neutralize both, vaccinia and cowpox virus. Five of them, additionally neutralized monkeypox virus (Tikunova et al., 2012). Another set of antibodies were selected from a Fab immune library derived from chimpanzee, vaccinated with vaccinia virus. After conversion into a chimeric chimpanzee/human IgG format, antibody 8AH8AL, binding to vaccinia protein $\mathrm{B} 5$, was neutralizing in vitro for vaccinia and smallpox virus. Its protective effect was assessed in mice challenged with vaccinia virus even when the monoclonal antibody was administered 2 days after challenge. In this model, $8 \mathrm{AH} 8 \mathrm{AL}$ provided significantly greater protection than that of the previously isolated rat anti-B5 antibody 19C2 (Chen et al., 2006). Since experimental work with smallpox virus is extremely restricted and essentially not allowed, vaccinia had to be used as model.

Ebola Virus and Marburg Virus, two members of the Filoviridae family, cause severe hemorrhagic fevers and extremely high mortality of up to $90 \%$ in infected humans. Besides the obvious public health concern associated with its natural outbreaks, Ebola virus might be considered a potential agent of biological warfare and bio-terrorism (Goodchild et al., 2011). Phage display-derived human antibodies targeting Ebola virus were selected from an immune library originated from survivors of the 1995 Ebola virus outbreak in Kikwit, Democratic Republic of Congo (Maruyama et al., 1999b). Nucleoprotein, envelope glycoprotein and secreted envelope glycoprotein binders have been isolated in this study. Antibody (KZ52), recognizing the envelope glycoprotein, neutralized in vitro both, as Fab (50\% neutralization at $0.4 \mu \mathrm{g} / \mathrm{mL})$ as well as full IgG (90\% neutralization at $2.6 \mu \mathrm{g} / \mathrm{mL}$ ) (Maruyama et al., 1999a). Follow-up studies demonstrated effective protection in vivo in a guinea pig Ebola challenge model, upon administration of the antibody up to one hour post viral challenge (Parren et al., 2002). Unfortunately, KZ52 showed no protection in macaques challenged with Ebola, even though the antibody was given in a two-dose regimen with the first dose one day prior viral challenge and the second after three days the former dose (Oswald et al., 2007). Further examples of antibodies selected through phage display against Filoviridae family members encompass a murine scFv and two shark IgNAR $\mathrm{V}$ immune libraries generated against inactivated Zaire Ebola virus to yield several antibodies specific for the viral matrix protein VP40 and the viral nucleoprotein (Goodchild et al., 2011). Of note, this work is the first example of a successful targeted IgNAR V isolation from a shark immune library. The antibody 
combination $\mathrm{X} 10 \mathrm{~B} 1 / \mathrm{X} 10 \mathrm{H} 2$ generated against the glycoprotein of Ebola Sudan virus (SUDV) showed $100 \%$ in vivo protection in scFv-Fc format in a mice challenge model. After 35 days post infection, the mice were challenged again with SUDV and all mice survived showing the development of an own protective immune answer against SUDV (Froude et al., 2017). These antibodies were also tested as IgG and the $\mathrm{X} 10 \mathrm{H} 2$ antibody was successfully employed in a cocktail with the non-phage display derived antibody 16F6 (Herbert et al., 2020). Recombinant antibodies against Marburg virus were generated using human synthetic libraries (Amatya et al., 2019) or macaque immune libraries (Froude et al., 2017). The macaque antibodies showed in vitro neutralization and up to $100 \%$ in vivo protection against wt Ci67 Marburg virus in a prophylactic mice challenge model using $100 \mu \mathrm{g} \mathrm{scFv-Fc/mice.}$

Flaviviridae family member Dengue virus (DENV) causes at least 100 million symptomatic infections each year and became a major health and economic burden in over 50 countries worldwide (Moreland et al., 2010; de Alwis et al., 2012; Moreland et al., 2012). Its genome encompasses a single open reading frame, contained in the $\sim 11 \mathrm{~kb}$ positive strand RNA. The four circulating serotypes of DENV show approximately 70\% sequence homology (Moreland et al., 2012; Zhao et al., 2014). DENV infection can result in clinical symptoms that include dengue fever, dengue hemorrhagic fever (DHF) and dengue shock syndrome (DSS) (Yamanaka et al., 2021), which is presumably promoted by antibody-dependent enhancement (ADE) (Taylor et al., 2015). ADE results from partially or nonneutralizing anti-dengue IgG antibodies from a former infection mainly of another dengue serotype. The presence of $\mathrm{ADE}$ is associated with the onset of DHF that can be fatal (Halstead, 2014). Two Fabs, namely 5H2 and 5D9, were isolated from a chimpanzee immune library and neutralized dengue type 4 virus in a plaque reduction neutralization test (Men et al., 2004). In another example, human $\mathrm{scFv}$ antibodies specific to dengue virus envelope protein were selected by panning against recombinant full length envelope protein and its domain III (Saokaew et al., 2014). Because DENV envelope protein plays an essential role in virion assembly and viral entry, scFvs selected in this study were shown to block DENV infection in vitro (Saokaew et al., 2014). Dengue nonstructural protein 5 (NS5) is involved in viral replication and host immune response modulation. A naïve human Fab-phage library was screened for NS5-specific antibodies using various NS5 variants from Dengue Virus serotypes 1-4 as antigens for panning and characterization (Zhao et al., 2014). Alternating the use of NS5 derived from different dengue serotypes for each selection round, this strategy allowed the identification of two monoclonals that are crossreactive against all four dengue serotypes. Another study presented antibodies selected against antigen Dengue virus particles directly captured from supernatant of infected Vero cells. Here, highly serotype specific antibodies were generated. Seven out of nine antibodies were specific to only one DENV serotype. One Dengue-3 selected clone cross-reacted with Dengue 1, whereas another clone showed pancross-reactivity despite being selected on Dengue 2 particles. Interestingly, all of the obtained antibodies recognized several strains of distinct genotypes within the corresponding serotype (Cabezas et al., 2008). Antibody C9 was isolated after panning against dengue envelope protein using a mouse/human chimeric Fab library. The antibody crossreacts with DENV1-3 and neutralizes DENV2 in cell-based assays after conversion into full length IgG (Moreland et al., 2012). Besides scFv and Fab, also variable domain heavy-chain antibodies (VHH antibodies) have been selected using phage display technology to target DENV2 NS1 protein. After four rounds of panning, 20 hits were selected (Fatima et al., 2014). A VHH antibody combination was developed which allows the detection of NS1 of all four Dengue strains (Shriver-Lake et al., 2018). For the therapy of dengue, the application of full-length antibodies like IgG may not provide the best solution for dengue therapy in the context of ADE. Antibodies with a silent Fc part or antibody fragments would be the preferred option for the development of therapeutic antibodies against dengue.

Venezuelan equine encephalitis virus (VEEV), an alphavirus of the Togoviridae family, causes both equine epidemics and also encephalitis in humans (Johnson and Martin, 1974; Weaver et al., 2004). Much research addressed the generation of neutralizing antibodies against VEEV since it is classified as Category B agent by the Centers for Disease Control and Prevention (CDC). An immune library from human donors was used as source for selection of mAbs targeting both VEEV envelope glycoproteins E1 and E2 (Hunt et al., 2010). The isolated Fabs L1A7 and F5 were neutralizing in vitro, with F5 being 300 times more effective than L1A7. Subsequently, F5 in full IgG format was employed to generate neutralization-escape variants of VEEV for epitope mapping purposes. Another study harnessed an immune macaque library to generate human-like antibodies. Among these antibodies, scFv-Fc ToR67-3B4 was protective in mice when administered $6 \mathrm{~h}$ post viral challenge with VEEV Trinidiad strain, allowing 80 to $100 \%$ survival after a challenge with 100 -fold $\mathrm{LD}_{50}$. Counterintuitively, scFv-Fc ToR67-3B4 was able to neutralize other VEEV strains in vitro, but not Trinidad one. This tests proved that in vitro neutralization is not mandatory for an antibody to be actually protective in more complex infection models (Rülker et al., 2012). A further study described the antibody selection from a human naïve scFv gene library using complete, active VEEV particles as target. Specific detection of the VEEV strains TC83, $\mathrm{H} 12 / 93$, and 230 by the isolated antibodies was verified. Remarkably, none of the selected $\mathrm{scFv}$ phage clones showed cross-reactivity with Alphavirus species of the Eastern equine encephalitis virus (EEEV) and Western equine encephalitis virus (WEEV) antigenic complex or with Chikungunya virus (CHIKV), making them ideal tools for immunological detection and diagnostic of Alphavirus species (Kirsch et al., 2008). From WEEV immunized macaques, two different scFv antibody gene libraries were constructed. Reformatted as scFvFc, three antibodies originating from these libraries specifically bound WEEV in ELISA with little or absent cross-reactivity with other alphaviruses. Additionally, their neutralization potency was assessed in vitro. This was indeed the first study in which 
in vitro neutralizing antibodies against WEEV were developed. About $1 \mathrm{ng} / \mathrm{mL}$ of the best antibody (ToR69-3A2) neutralized $50 \%$ of $5 \times 10^{4}$ TCID50/mL WEEV (Hülseweh et al., 2014). Four anti-WEEV antibodies from this study were also tested in an in vivo WEEV aerosol challenge approach. A dose dependent protection was measured. Interestingly, not only the best neutralizing antibody ToR69-3A2 was protective in vivo, but also the non-neutralizing antibody ToR68-2C3. The mode of action of the non-neutralizing antibodies cannot be the blocking of the virus host cell receptor interaction, but protection may results from complement-mediated lysis, antibody-dependent cell-mediated lysis of infected cells or opsonization followed by uptake by phagocytes (Burke et al., 2018). Single domain antibodies generated against E3E2 of WEEV from a llama immune library allowed the development of a MagPlex sandwich immunoassay to detect specifically WEEV and discriminate from other alphaviruses (Liu et al., 2018).

Influenza viruses are the etiologic agents of seasonal flu, a worldwide spread disease. In recent years, the "bird flu" (H5N1) and the pandemic "swine flu" (a variant of H1N1) moved into the spotlight of public attention and also of research focus, given the global spread of these variants. Due to many genetic events, such as e.g. antigenic drift and shift, new influenza variants will keep occurring in the future and will challenge vaccine and diagnostic development (Webster and Govorkova, 2014; Trombetta et al., 2015; Keilman, 2019). Sui et al. (2009) selected antibodies from a naïve scFv library against the $\mathrm{H} 5$ hemagglutinin ectodomain. Hemagglutinin is a trimer and the extracelluar part consist of a stalk domain and a globular head domain (Krammer and Palese, 2013). They identified ten antibodies binding to the trimeric $\mathrm{H} 5$, nine of which shared the same germline framework (VH1-69). These antibodies were converted into IgG1 and were protective in mice at dose of 10 or $15 \mathrm{mg} / \mathrm{kg}$ in both a prophylactic and therapeutic challenge models, respectively. Very remarkably, some antibodies crossneutralized $\mathrm{H} 1, \mathrm{H} 2, \mathrm{H} 5, \mathrm{H} 6, \mathrm{H} 8$, and $\mathrm{H} 9$ influenza strains. These phage display derived antibodies are good candidates for broadspectrum influenza immunotherapy (Sui et al., 2009).

Rabies is caused by the rabies virus which infects the central nervous system, always resulting in fatal disease, before Louis Pasteur developed the rabies vaccination. The current postexposure therapy is based both on vaccination and polyclonal anti-rabies sera (Goudsmit et al., 2006; Briggs, 2012; Crowcroft and Thampi, 2015). From two different immune scFv libraries, 147 unique recombinant antibodies were selected against the rabies glycoprotein (Kramer et al., 2005). The neutralization of the selected mAbs was tested in vitro using 27 different street rabies virus isolates and the best neutralizing antibodies were further investigated in vivo in a hamster rabies (Bakker et al., 2005). This antibody was further analyzed with another human antibody, termed CR57, derived by somatic cell hybridization technique, in combination (Dietzschold et al., 1990), both in in vitro and in vivo models (Goudsmit et al., 2006). In a clinical phase 1 study, the safety and efficacy of the mAb cocktail (named CL184) was tested (Bakker et al., 2008) and subsequently in phase 2 studies. The antibodies were renamed Rafivirumab
(CR57) and Foravirumab (CR4098). The in vivo efficacy in a hamster model was demonstrated with several rabies isolates (Franka et al., 2017). The antibody Rabishield, which is not derived by phage display, has been approved in 2018 (Wang et al., 2011; Gogtay et al., 2018).

The emergence of new viral species able to leak from their animal reservoirs and lastly infect the human host has been described several times in the last decades and has led to either local epidemics or global pandemics. In this regard, Henipavirus and Betacoronavirus genera, respectively, are emblematic examples of zoonotic viral diseases that posed serious threats to human health. The generation of monoclonal antibodies through phage display targeting these pathogens has been mainly investigated towards the development of new therapeutic agents, even though in the case of SARS-CoV-2 monoclonal antibodies are of foremost interest also for diagnostic purposes.

Henipaviruses known to be pathogenic to the human host are Hendra virus $(\mathrm{HeV})$ and Nipah virus $(\mathrm{NiV})$, that caused small outbreaks in Australia and Malaysia, respectively, first recognized during 1990 (Weatherman et al., 2018). Bats are the animal reservoir of these viruses and their transmission to human beings is either mediated through amplifying hosts, like pigs or horses, or direct, as documented in NiV Bangladesh 2001 outbreak, through contact between same contaminated food (Halpin et al., 2011; Weatherman et al., 2018). The infection of these negative-stranded RNA viruses causes mainly severe respiratory and neurological symptoms and sequelae with high mortality rate (Wong and Tan, 2012). The initial contact of these virus to host cells is mediated by attachment to glycoprotein $\mathrm{G}$ (also known as RBP -Receptor Binding Protein-), that binds the cellular surface proteins ephrinB2 or ephrinB3 (Bonaparte et al., 2005; Negrete et al., 2005; Negrete et al., 2006; Navaratnarajah et al., 2020). The soluble forms of $\mathrm{HeV}$ G protein was used to isolate 17 antibodies from a phage display human Fab naïve library (Zhu et al., 2006), to date the only report of phage displayderived anti-NiV/-HeV antibodies. Seven of them were further investigated and given the $80 \%$ sequence similarity between $G$ proteins of $\mathrm{HeV}$ and $\mathrm{NiV}$, some of them resulted in effective cross-recognition of the two viral species. Fab m102 was further improved through light chain shuffling, $\mathrm{VH}$ random mutagenesis and IgG1 conversion demonstrating cross-neutralization of both $\mathrm{HeV}$ and NiV and normal serum half-life in ferrets (Zhu et al., 2008). Further testing of this monoclonal antibody demonstrated its efficacy in NiV-infected ferrets (Bossart et al., 2009). For African green monkeys challenged with $\mathrm{HeV}$ (Bossart et al., 2011) and NiV (Geisbert et al., 2014), further evidence suggests that the therapeutic window in African green monkeys is different based on the NiV viral strain used (Mire et al., 2016). Its safety was also recently demonstrated in a Phase I first-inhuman clinical trial (Playford et al., 2020), establishing the security criteria necessary to proceed to verify its effectiveness in infected humans in further clinical trials.

The Betacoronavirus genus (single-stranded, positive-sense RNA viruses) has clearly demonstrated its potential as source of worldwide health threats during the beginning of the new 
millennium, with SARS-CoV and SARS-CoV-2, both emerging from China in late 2002 and late 2019, respectively (Ksiazek et al., 2003; Lu et al., 2020). Furthermore, smaller outbreaks were caused by MERS virus in Saudi Arabia, during 2012 as it was first isolated, and South Korea (2015) (Zaki et al., 2012; Memish et al., 2020). Unlike the latter virus that keeps circulating in camelids (Sabir et al., 2016; Kandeil et al., 2019), SARS-CoV and SARS-CoV-2 originated from bats (Guan et al., 2003; Zhou et al., 2020) and spread worldwide. If the first SARS-CoV-caused pandemic was contained by summer 2003 (Cherry, 2004), COVID-19 pandemics is still lashing the entire world with recurring waves of infection. Phage display-derived antibodies are among the multiple approaches quickly deployed to generate monoclonal antibodies directed to SARS-CoV-2 (Jiang et al., 2020). In this emergence scenario, anti-nucleocapsid protein antibodies have been generated through phage display for diagnostic purposes (Kim et al., 2021). However, the most efforts have been focused on spike protein, and specifically to the receptor binding domain (RBD), to directly block the interaction with the host receptor, aiming to select neutralizing antibodies for novel therapeutics development. Various formats, e.g. IgG, Fab, VHH and bispecifics, from mainly human, either naïve or immune, libraries have been investigated and their neutralization efficiency was mostly studied in vitro, with some mAbs that were also tested in animal models ( $\mathrm{Li}$ et al., 2020a; Li et al., 2020b; Noy-Porat et al., 2020; Sun Z. et al., 2020; Zeng et al., 2020; Bertoglio et al., 2021a; Bertoglio et al., 2021b; Bracken et al., 2021; Ku et al., 2021; Lim et al., 2021). At the moment of writing, the only anti-SARS-CoV-2 phage-display derived antibody known to enter clinical trials is STE90-C11 (COR-101) (ClinicalTrials.gov ID: NCT04674566) (Bertoglio et al., 2021a).

A summary of antibodies generated by phage display against viruses is presented in Table 2 .

\section{EUKARYOTIC PATHOGENS}

A huge number of antibodies against a broad range of eukaryotic pathogens has been generated by phage display. These recombinant antibodies are directed against very different parasites, e.g. Taenia solium (Ribeiro et al., 2013), protozoa, e.g. Cryptosporidium parvum (Boulter-Bitzer et al., 2009; Boulter-Bitzer et al., 2010), Plasmodium falciparum (Roeffen et al., 2001; Lundquist et al., 2006) or Toxoplasma gondii (Hoe et al., 2005) and fungi such as Aspergillus fumigatus (Schütte et al., 2009). Beside human pathogens also veterinary pathogens like Myxobolus rotundus (Zhang J. Y. et al., 2006) (a fish pathogen) or Babesia gibsoni (a dog pathogen) (Hirose et al., 2009) and plant pathogens like Aspergillus niger (Ascione et al., 2004), Fusarium verticilloides (Hu et al., 2012) or Sclerotinia sclerotiorum (Yang et al., 2009) are of interest.

The majority of the antibodies to these targets are derived from human antibody gene libraries, but libraries derived also from mouse (Fu et al., 1997), chicken (Hu et al., 2012), camel (Saerens et al., 2008) or macaque (Schütte et al., 2009) have been successfully applied to select recombinant antibodies against eukaryotic pathogens.

Detailed examples for the recombinant antibodies against several eukaryotic pathogens derived from phage display are given the following paragraphs.

Allergic bronchopulmonary aspergillosis, saprophytic aspergilloma, chronic necrotizing aspergillosis and the invasive aspergillosis which is highly lethal are caused by Aspergillus fumigatus and are the most important Aspergillus-related diseases (Broderick et al., 1996; Latgé, 1999). As one possible consequence of a hematopoietic stem cell transplantation or solid organ transplantation, an invasive aspergillosis can occur in these immunocompromised patients (Rüping et al., 2008). Therefore, an early diagnosis of aspergillosis is crucial for a successful treatment. The development of a panel of human antibodies binding to Crf2 was described by Schütte et al. (2009). The glycosyol hydrolase Crf2 is located in the cell wall of the growing hyphae. Two kind of antibody gene libraries were used: a macaque immune library and the human naive antibody libraries HAL4/7 (Hust et al., 2011). In addition, two different antibody selection strategies were performed: A) a panning on recombinant antigen immobilized on immunostrips. B) a panning in solution using biotinylated antigen. Six antibodies were selected from the human naïve libraries and ten from the macaque immune library. It was observed, that all antibodies generated by panning in solution bound to conformational epitopes and the antibodies generated on directly immobilized Crf2 bound to linear epitopes. Seven antibodies bound to the native antigen Crf2 on growing hyphae of Aspergillus fumigatus shown by histopathological immunofluorescence microscopy. These antibodies didn't show cross reactions with other Aspergillus species or Candida albicans. It was shown that antiCrf2 antibody MS112-IIB1 was able to neutralize the enzymatic activity of Crf2, but was not able to reduce the fungal growth in a rat model of invasive pulmonary aspergillosis (Chauvin et al., 2019).

Besides the diagnosis in patients, the preventive diagnosis of Aspergillus pathogens in agricultural products is of importance. Therefore, Wang et al. developed a nanobody-polyclonal antibody Sandwich-ELISA (Wang T. et al., 2017). To obtain polyclonal antibodies and for the construction of a camelid immune library, rabbits or alpacas, respectively, were immunized with extracellular antigens and mycelia lysate of A. flavus, a strain with high levels of aflatoxin. Panning resulted in one $\mathrm{VHH}$ nanobody against the extracellular antigens and two nanobodies against the mycelia lysate. The developed SandwichELISA is detecting aflatoxin producing strains of the Aspergillus spp. in agricultural products before the fungi can produce high levels of aflatoxin and is therefore suited for early detection.

Malaria is one of the most common mosquito-borne diseases caused by five different species of Plasmodium, $P$. falciparum, $P$. vivax, P. malariae, P. ovale and P. knowlesi (Cox-Singh et al., 2008). In humans $P$. falciparum is responsible for most malariarelated deaths globally, while $P$. vivax is the most widespread parasite (Popovici and Ménard, 2015). The parasites infect erythrocytes and destroy these cells at the end of the 
TABLE 2 | Recombinant antibodies derived by phage display against viruses.

\begin{tabular}{|c|c|c|c|c|c|c|}
\hline Virus & Target & $\begin{array}{l}\text { Library } \\
\text { Type }\end{array}$ & $\begin{array}{l}\text { Antibody } \\
\text { Format }\end{array}$ & Antibody Origin & Application & Reference \\
\hline Australian bat Lyssavirus & possibly ABLV -G & naive & Fab, lgG & human & ELISA, in vitro neutralization & (Weir et al., 2021) \\
\hline Blue tongue virus & complete virus & $\begin{array}{l}\text { semi- } \\
\text { synthetic }\end{array}$ & $\mathrm{scFv}$ & chicken & ELISA & $\begin{array}{l}\text { (van Wyngaardt } \\
\text { et al., 2004; Fehrsen } \\
\text { et al., 2005) }\end{array}$ \\
\hline $\begin{array}{l}\text { Broad bean mottle virus } \\
\text { (BBMV) }\end{array}$ & complete virus & immune & $\mathrm{VHH}$ & camel & ELISA, in vitro neutralization & $\begin{array}{l}\text { (Ghannam et al., } \\
\text { 2015) }\end{array}$ \\
\hline Bovine viral diarrhea virus & $\begin{array}{l}\text { nonstructural protein } 5 \\
\text { (NS5B) }\end{array}$ & immune & $\mathrm{VHH}$ & camel & ELISA, intrabodies & (Duan et al., 2020) \\
\hline Bovine viral diarrhea virus & envelope 2 (E2) & immune & $\mathrm{VHH}$ & camel & ELISA, in vitro neutralization & (Li et al., 2017) \\
\hline Canine Parvovirus & VLP of CPV-VP2 & immune & scFv & chicken & $\begin{array}{l}\text { ELISA, WB, ICA, virus suppression } \\
\text { assay }\end{array}$ & (Ge et al., 2020) \\
\hline $\begin{array}{l}\text { Chikungunya virus } \\
\text { (CHIKV) }\end{array}$ & VLPs with E1 and E2 & immune & $F a b, \lg G$ & human & $\begin{array}{l}\text { ELISA, in vitro neutralization, in vivo } \\
\text { protection }\end{array}$ & (Fong et al., 2014) \\
\hline Dengue & envelope protein $\mathrm{E}$ & naïve & scFv & human & $\begin{array}{l}\text { ELISA, Immunofluorescent assay, } \\
\text { in vitro neutralization }\end{array}$ & $\begin{array}{l}\text { (Saokaew et al., } \\
\text { 2014) }\end{array}$ \\
\hline Dengue & nonstructural protein 5 (NS5) & naiive & Fab & human & ELISA, WB, dot blot, & (Zhao et al., 2014) \\
\hline Dengue & $\begin{array}{l}\text { Dengue virus envelope } \\
\text { protein }\end{array}$ & naïve & Fab, IgG & $\begin{array}{l}\text { human, mouse } \\
\text { (panel of } \\
\text { hybridoma } \\
\text { clones) }\end{array}$ & ELISA, WB, IHC & $\begin{array}{l}\text { (Moreland et al., } \\
\text { 2012) }\end{array}$ \\
\hline Dengue & NS3 & naïve & Fab & human & ELISA, in vitro neutralization & $\begin{array}{l}\text { (Moreland et al., } \\
\text { 2010) }\end{array}$ \\
\hline Dengue & NS1 & $\begin{array}{l}\text { naïve(Non- } \\
\text { immune) }\end{array}$ & $\mathrm{VHH}$ & Ilama & $\begin{array}{l}\text { ELISA, lateral flow } \\
\text { immunochromatograpic assay }\end{array}$ & (Fatima et al., 2014) \\
\hline Duck hepatitis A virus & VP1 & immune & $\mathrm{VHH}$ & camel & ELISA, IF, dot-blot & (Xue et al., 2019) \\
\hline Duck hepatitis A virus & VP3 & immune & $\mathrm{scFv}$ & mice & ELISA, in vivo neutralization & (Wang et al., 2018) \\
\hline Ebola & $\begin{array}{l}\text { nucleoprotein, envelope } \\
\text { glycoprotein, secreted } \\
\text { envelope glycoprotein }\end{array}$ & immune & Fab, lgG & human & $\begin{array}{l}\text { ELISA, immunostaining, } \\
\text { immunoprecipitation, in vitro } \\
\text { neutralization }\end{array}$ & $\begin{array}{l}\text { (Maruyama et al., } \\
\text { 1999a) }\end{array}$ \\
\hline Ebola & nucleoprotein & synthetic & scFv, IgG & human & ELISA, WB & $\begin{array}{l}\text { (Shingarova et al., } \\
\text { 2007) }\end{array}$ \\
\hline Ebola (Zaire) & $\begin{array}{l}\text { viral matrix protein VP40, } \\
\text { nucleoprotein }\end{array}$ & immune & scFv, IgNAR & mice, shark & ELISA, WB & $\begin{array}{l}\text { (Goodchild et al., } \\
\text { 2011) }\end{array}$ \\
\hline Ebola (Zaire) & VP35 & $\begin{array}{l}\text { semi- } \\
\text { synthetic }\end{array}$ & scFv & human & ELISA, WB, intrabody & (Flego et al., 2019) \\
\hline Ebola (Sudan) & glycoprotein (GP) & immune & $\begin{array}{l}\text { scFv, scFv- } \\
\text { Fc }\end{array}$ & macaque & $\begin{array}{l}\text { ELISA, in vitro neutralization, in vivo } \\
\text { protection }\end{array}$ & $\begin{array}{l}\text { (Froude et al., 2018; } \\
\text { Herbert et al., 2020) }\end{array}$ \\
\hline Ebola (Zaire) & glycoprotein (GP) & immune & $\mathrm{VHH}$ & Ilama & ELISA & (Liu et al., 2017) \\
\hline Ebola (Zaire) & $\begin{array}{l}\text { VP35, interferon inhibitory } \\
\text { domain }\end{array}$ & naïve & $\begin{array}{l}\text { scFv } \\
\text { (transbody) }\end{array}$ & human & ELISA, IF, WB & $\begin{array}{l}\text { (Seesuay et al., } \\
\text { 2018) }\end{array}$ \\
\hline Ectromelia virus (ECTV) & $\begin{array}{l}\text { ECTV, variola virus, vaccinia } \\
\text { virus, cow pox virus }\end{array}$ & immune & scFv & human & ELISA, in vitro neutralization, WB & $\begin{array}{l}\text { (Khlusevich et al., } \\
\text { 2018) }\end{array}$ \\
\hline Enterovirus 71 (EV71) & virion protein 2 (VP2) & naïve & scFv & mice & ELISA, WB & $\begin{array}{l}\text { (Thanongsaksrikul } \\
\text { et al., 2018) }\end{array}$ \\
\hline Enterovirus 71 & inactivated EV71 virions & immune & $\mathrm{Fab}$ & human & ELISA, in vitro neutralization & (Chen et al., 2017) \\
\hline
\end{tabular}


TABLE 2 | Continued

\begin{tabular}{|c|c|c|c|c|c|c|}
\hline Virus & Target & $\begin{array}{l}\text { Library } \\
\text { Type }\end{array}$ & $\begin{array}{l}\text { Antibody } \\
\text { Format }\end{array}$ & Antibody Origin & Application & Reference \\
\hline $\begin{array}{l}\text { Enterovirus 71/ } \\
\text { coxsackievirus A16 } \\
\text { (CVA16) }\end{array}$ & VP4 & immune & scFv, IgG & mice & WB, in vitro neutralization & (Zhang et al., 2016) \\
\hline Enterovirus 71 & VP4 & naïve & scFv & human & ELISA, WB, IF, in vitro neutralization & $\begin{array}{l}\text { (Phanthong et al., } \\
\text { 2020) }\end{array}$ \\
\hline Epstein-Barr virus & LMP1 & naïve & Fab & human & $\begin{array}{l}\text { ELISA, WB, IF, FACS, in vitro } \\
\text { inhibition }\end{array}$ & (Zhang et al., 2013) \\
\hline $\begin{array}{l}\text { Foot-and-mouth disease } \\
\text { virus (FMDV) }\end{array}$ & 3ABC & immune & scFv & chicken & ELISA, WB & (Foord et al., 2007) \\
\hline $\begin{array}{l}\text { Foot-and-mouth disease } \\
\text { virus }\end{array}$ & $146 S$ & immune & $\mathrm{VHH}$ & llama & ELISA & $\begin{array}{l}\text { (Harmsen et al., } \\
\text { 2017) }\end{array}$ \\
\hline $\begin{array}{l}\text { Foot-and-mouth disease } \\
\text { virus }\end{array}$ & VP2 capsid protein & immune & scFv & mice & ELISA & (Salem et al., 2019) \\
\hline $\begin{array}{l}\text { Foot-and-mouth disease } \\
\text { virus }\end{array}$ & VLPS & immune & $\mathrm{VHH}$ & camel & ELISA, IF & $\begin{array}{l}\text { (Wang D. et al., } \\
\text { 2015) }\end{array}$ \\
\hline $\begin{array}{l}\text { Grapevine leafroll- } \\
\text { associated virus } 3\end{array}$ & coat protein & immune & scFv & mice & ELISA & $\begin{array}{l}\text { (Orecchia et al., } \\
\text { 2008) }\end{array}$ \\
\hline Grapevine virus B & virus particles & $\begin{array}{l}\text { semi- } \\
\text { synthetic }\end{array}$ & scFv & human & ELISA & $\begin{array}{l}\text { (Saldarelli et al., } \\
\text { 2005) }\end{array}$ \\
\hline $\begin{array}{l}\text { Haematopoietic necrosis } \\
\text { virus (IHNV) }\end{array}$ & n.d. & $\begin{array}{l}\text { naïve(non- } \\
\text { immune) }\end{array}$ & scFv & mouse & ELISA, WB, IHC & (Liu H. et al., 2014) \\
\hline Hantavirus & nucleoprotein & immune & $\mathrm{VHH}$ & Ilama & ELISA, WB & (Pereira et al., 2014) \\
\hline Hantavirus & virus particles & immune & $\mathrm{Fab}$ & human & $\mathrm{IF}, \mathrm{WB}$ & (Koch et al., 2003) \\
\hline HCMV & gycoprotein B and $\mathrm{H}$ & immune & scFv & human & ELISA, in vitro neutralization & $\begin{array}{l}\text { (Nejatollahi et al., } \\
\text { 2002) }\end{array}$ \\
\hline HCMV & Gp55 & immune & scFv & human & ELISA, in vitro neutralization & (Moazen et al., 2016) \\
\hline Hendra and Nipah virus & $\begin{array}{l}\text { attachment envelope } \\
\text { glycoprotein G }\end{array}$ & naïve & $\mathrm{Fab}, \operatorname{lgG}$ & human & $\begin{array}{l}\text { ELISA, immunoprecipitation, WB, in } \\
\text { vitro neutralization IF, in vivo } \\
\text { neutralization }\end{array}$ & $\begin{array}{l}\text { (Zhu et al., 2006; } \\
\text { Zhu et al., 2008) }\end{array}$ \\
\hline Hepatitis A & Hepatitis A Capsid & immune & $\mathrm{Fab}, \lg \mathrm{G}$ & chimpanzee & ELISA, in vitro neutralization & $\begin{array}{l}\text { (Schofield et al., } \\
\text { 2002) }\end{array}$ \\
\hline Hepatitis A & HBsAG & naïve & scFv & human & ELISA & $\begin{array}{l}\text { (Zhang J.-L et al., } \\
\text { 2006) }\end{array}$ \\
\hline Hepatitis C & NS5B & naïve & scFv & human & ELISA, IF, in vitro neutralization & $\begin{array}{l}\text { (Thueng-in et al., } \\
\text { 2014) }\end{array}$ \\
\hline Hepatitis C & core, E1, E2 & immune & scFv & human & ELISA & (Chan et al., 1996) \\
\hline Hepatitis C & core protein & immune & $\mathrm{Fab}$ & human & ELISA & (Barban et al., 2000) \\
\hline Hepatitis C & E2 glycoprotein & immune & $\mathrm{Fab}$ & human & ELISA & (Burioni et al., 2001) \\
\hline Hepatitis C & NS5A & naïve & $\begin{array}{l}\text { ScFv } \\
\text { (transbodies) }\end{array}$ & human & ELISA, WB, IF, in vitro neutralization & $\begin{array}{l}\text { (Glab-Ampai et al., } \\
\text { 2017) }\end{array}$ \\
\hline Hepatitis C & NS3/4A & naïve & $\begin{array}{l}\text { scFv } \\
\text { (transbodies) }\end{array}$ & human & ELISA, IF, in vitro neutralization & $\begin{array}{l}\text { (Jittavisutthikul et al., } \\
\text { 2016) }\end{array}$ \\
\hline Hepatitis E & ORF2 protein & immune & $\mathrm{Fab}$ & chimpanzee & ELISA, WB & $\begin{array}{l}\text { (Schofield et al., } \\
\text { 2000) }\end{array}$ \\
\hline Herpes simplex virus & HSV1, -2 lysate & immune & Fab & human & $\begin{array}{l}\text { in vitro inhibition, immuno } \\
\text { precipitaton }\end{array}$ & (Burioni et al., 1994) \\
\hline Herpes simplex virus & glycoprotein gD, gB & $\begin{array}{l}\text { presumably } \\
\text { immune }\end{array}$ & Fab & human & ELISA, immuno precipitation & (Sanna et al., 1995) \\
\hline Herpes simplex virus & virus lysate? & immune & $\mathrm{Fab}$ & human & ELISA, IF & (Cattani et al., 1997) \\
\hline HIV-1 & Integrase & immune & scFv & rabbit & ELISA, WB, IF, in vitro neutralization & (da Silva et al., 2012) \\
\hline HIV-1 & gp140 & immune & $\begin{array}{l}\text { scFv, scFv- } \\
\text { FC }\end{array}$ & human & $\begin{array}{l}\text { ELISA, WB, immunoprecipitation, in } \\
\text { vitro neutralization }\end{array}$ & (Trott et al., 2014) \\
\hline HIV-1 & gp140 & immune & Fab, IgG & human & ELISA, WB, in vitro neutralization & $\begin{array}{l}\text { (Choudhry et al., } \\
\text { 2007) }\end{array}$ \\
\hline HIV-1 & gp140 & immune & $\mathrm{VHH}$ & Ilama & ELISA, in vitro neutralization & $\begin{array}{l}\text { (Strokappe et al., } \\
\text { 2012) }\end{array}$ \\
\hline HIV-1 & gp120 & synthetic & $\mathrm{CH} 2$ domain & human & ELISA, in vitro neutralization & (Xiao et al., 2009) \\
\hline HIV-1 & p24 & immune & ScFv & mouse & ELISA & $\begin{array}{l}\text { (Mohammadzadeh } \\
\text { et al., 2014) }\end{array}$ \\
\hline HIV-1 & gp41 & synthetic & Fab & human & WB, in vitro neutralization & $\begin{array}{l}\text { (Gustchina et al., } \\
\text { 2007) }\end{array}$ \\
\hline HIV-1 & gp41 & naïve & scFv & human & ELISA, in vitro neutralization & (Miller et al., 2005) \\
\hline
\end{tabular}


TABLE 2 | Continued

\begin{tabular}{|c|c|c|c|c|c|c|}
\hline Virus & Target & $\begin{array}{l}\text { Library } \\
\text { Type }\end{array}$ & $\begin{array}{l}\text { Antibody } \\
\text { Format }\end{array}$ & Antibody Origin & Application & Reference \\
\hline HIV-1 & gp120 & immune & Fab & human & ELISA, in vitro neutralization, IF & (Sun et al., 2017) \\
\hline HIV-1 & gp140 & immune & $\mathrm{VHH}$ & camel & ELISA, in vitro neutralization & (Koch et al., 2017) \\
\hline HIV-1 & gp140 trimer & immune & $\mathrm{scFv}$ & human & ELISA, in vitro neutralization & (He et al., 2017) \\
\hline HIV-1 & RSC3 core protein & immune & scFv & human & ELISA, in vitro neutralization & (Kumar et al., 2017) \\
\hline HIV-2 & gp125 protein & immune & $\mathrm{Fab}$ & human & ELISA, in vitro neutralization & (Björling et al., 1999) \\
\hline Human metapneumovirus & F ectodomain & $\begin{array}{l}\text { presumably } \\
\text { immune }\end{array}$ & Fab & human & $\begin{array}{l}\text { ELISA, IF, in vitro neutralization, in } \\
\text { vivo protection }\end{array}$ & (Williams et al., 2007) \\
\hline Influenza A (IAV) & HA (stem region) & $\begin{array}{l}\text { semi- } \\
\text { synthetic }\end{array}$ & scFv & human(IGHV1-69) & ELISA, in vitro neutralization & (Avnir et al., 2014) \\
\hline Influenza A & HA ectodomain & naïve & scFv & human & $\begin{array}{l}\text { ELISA, Flow cytometry, } \\
\text { immunoprecipitation, in vitro } \\
\text { neutralization, in vivo protection }\end{array}$ & (Sui et al., 2009) \\
\hline Influenza A (H2N2) & HA (stem region) & $\begin{array}{l}\text { presumably } \\
\text { immune }\end{array}$ & $\mathrm{Fab}$ & human & ELISA, in vitro neutralization & $\begin{array}{l}\text { (Wyrzucki et al., } \\
\text { 2014) }\end{array}$ \\
\hline Influenza A & HA2 & $\begin{array}{l}\text { semi- } \\
\text { synthetic }\end{array}$ & scFv & human & ELISA, WB, in vitro neutralization & (Li et al., 2016) \\
\hline Influenza A (H1N1) & $\mathrm{HA}$ & immune & scFv & mice & ELISA & (Rajput et al., 2015) \\
\hline Influenza A (H1N1/H5N1) & $\mathrm{HA}$ & immune & $\begin{array}{l}\mathrm{VHH}, \\
\text { bivalent } \\
\mathrm{VHH}\end{array}$ & alpaca & ELISA, in vitro neutralization & (Hufton et al., 2014) \\
\hline Influenza A (H5N1) & $\mathrm{HA}$ & $\begin{array}{l}\text { semi- } \\
\text { synthetic }\end{array}$ & scFv & human & ELISA & (Wu et al., 2014) \\
\hline Influenza A (H5N1) & $\mathrm{HA}$ & naïve & scFv & human & $\begin{array}{l}\text { ELISA, in vitro neutralization, in vivo } \\
\text { protection }\end{array}$ & $\begin{array}{l}\text { (Maneewatch et al., } \\
\text { 2009) }\end{array}$ \\
\hline Influenza A (H5N1) & $\mathrm{HA}$ & immune & Fab & chicken & $\mathrm{IF}$, in vitro neutralization, WB & $\begin{array}{l}\text { (Pitaksajjakul et al., } \\
\text { 2010) }\end{array}$ \\
\hline Influenza A (H5N1) & nucleoprotein (NP) & immune & $\mathrm{scFv}$ & mice & ELISA, WB, in vitro inhibition & $\begin{array}{l}\text { (Sengupta et al., } \\
\text { 2014) }\end{array}$ \\
\hline Influenza A (H5N1) & HAcleavage site & immune & Fab & mice & ELISA, IF & (Dong et al., 2013) \\
\hline Influenza A (H5N1) & NS1 & naïve & scFv & human & ELISA, in vitro neutralization, IF & $\begin{array}{l}\text { (Yodsheewan et al., } \\
\text { 2013) }\end{array}$ \\
\hline Influenza A (H5N1) & complete inactivated virus & immune & $\mathrm{VHH}$ & camel & ELISA & (Zhu et al., 2014) \\
\hline Influenza A (H3N2) & $\begin{array}{l}\text { peptides (neutralizing } \\
\text { epitope) }\end{array}$ & $\begin{array}{l}\text { semi- } \\
\text { synthetic }\end{array}$ & scFv & human & ELISA & $\begin{array}{l}\text { (Vashisht et al., } \\
\text { 2019) }\end{array}$ \\
\hline Influenza A & M2-cytoplasmatic domain & naïve & scFvscFv-Fc & human & WB, IHC & $\begin{array}{l}\text { (Velappan et al., } \\
\text { 2020) }\end{array}$ \\
\hline Influenza B & $\mathrm{HA}$ & immune & $\mathrm{VHH}$ & alpaca & ELISA & $\begin{array}{l}\text { (Ramage et al., } \\
\text { 2019) }\end{array}$ \\
\hline Influenza B & whole virus & immune & Fab & human & ELISA, WB, IF, in vitro neutralization & (Hirano et al., 2018) \\
\hline $\begin{array}{l}\text { Japanese encephalitis } \\
\text { virus }\end{array}$ & $\begin{array}{l}\text { domains I,II,III of envelope } \\
\text { protein }\end{array}$ & immune & Fab, lgG & chimpanzee & $\begin{array}{l}\text { ELISA, immunoprecipitation, in vitro } \\
\text { neutralization, in vivo protection }\end{array}$ & $\begin{array}{l}\text { (Goncalvez et al., } \\
\text { 2008) }\end{array}$ \\
\hline $\begin{array}{l}\text { Japanese encephalitis } \\
\text { virus }\end{array}$ & envelope Protein & immune & Fab & human & $\begin{array}{l}\text { ELISA, immunoprecipitation, in vitro } \\
\text { neutralization }\end{array}$ & $\begin{array}{l}\text { (Arakawa et al., } \\
\text { 2007) }\end{array}$ \\
\hline Marburg virus & glycoprotein (GP) & immune & $\begin{array}{l}\text { scFv, scFv- } \\
\text { FC }\end{array}$ & macaque & $\begin{array}{l}\text { WB, in vitro neutralization, in vivo } \\
\text { protection }\end{array}$ & (Froude et al., 2017) \\
\hline Marburg virus & VP35 & synthetic & Fab & human & ELISA & (Amatya et al., 2019) \\
\hline Measles virus & virus lysate & $\begin{array}{l}\text { immune } \\
\text { (Puumala } \\
\text { hantavirus) }\end{array}$ & $\mathrm{Fab}$ & human & ELISA, in vitro neutralization & $\begin{array}{l}\text { (de Carvalho Nicacio } \\
\text { et al., 2002) }\end{array}$ \\
\hline MERS & S2 domain & synthetic & Fab, IgG & human & ELISA, IF, sandwich ELISA & (Kim et al., 2019) \\
\hline MERS & nucleoprotein (NP) & naïve & scFv & human & ELISA & (Lim et al., 2019) \\
\hline Norovirus & Norovirus VLPS & $\begin{array}{l}\text { semi- } \\
\text { synthetic }\end{array}$ & scFv & human & ELISA, WB & (Huang et al., 2014) \\
\hline Norovirus & $\begin{array}{l}\text { P-domain of the Gl.1 major } \\
\text { capsid protein }\end{array}$ & $\begin{array}{l}\text { semi- } \\
\text { synthetic }\end{array}$ & scFv & human & ELISA, dot-blot & (Hurwitz et al., 2017) \\
\hline Norovirus & VLPs with VP1 and VP2 & immune & $\mathrm{VHH}$ & llama & ELISA, WB, in vitro inhibition, IF & $\begin{array}{l}\text { (Garaicoechea et al., } \\
\text { 2015) }\end{array}$ \\
\hline Norovirus & VLPS & naïve & scFv & human & ELISA, in vitro inhibition & $\begin{array}{l}\text { (Higo-Moriguchi } \\
\text { et al., 2014) }\end{array}$ \\
\hline Norwalk virus & VLPS & immune & $\mathrm{Fab}, \operatorname{lgG}$ & chimpanzee & ELISA, FACS, IF, in vitro inhibition & (Chen et al., 2013) \\
\hline Paramyxovirus & glycoproteins F and HN & synthetic & Fab, sAb & human & $\begin{array}{l}\text { ELISA, in vitro neutralization, } \\
\text { immunoprecipitation }\end{array}$ & (Welch et al., 2014) \\
\hline
\end{tabular}


TABLE 2 | Continued

\begin{tabular}{|c|c|c|c|c|c|c|}
\hline Virus & Target & $\begin{array}{l}\text { Library } \\
\text { Type }\end{array}$ & $\begin{array}{l}\text { Antibody } \\
\text { Format }\end{array}$ & Antibody Origin & Application & Reference \\
\hline Plum pox virus & Nla protease & $\begin{array}{l}\text { semi- } \\
\text { synthetic }\end{array}$ & scFv & human & WB, dotblot & (Hust et al., 2002) \\
\hline Poliovirus & capsid proteins VP1 and VP3 & immune & Fab, IgG & chimpanzee & $\begin{array}{l}\text { ELISA, in vitro neutralization, in vivo } \\
\text { protection }\end{array}$ & (Chen et al., 2011) \\
\hline Polyomavirus JC (JCV) & VLPS & synthetic & $\mathrm{Fab}, \lg \mathrm{G}$ & human & ELISA & (Chen et al., 2015) \\
\hline Porcine circovirus type 2 & Cap protein & immune & $\mathrm{VHH}$ & camel & ELISA & (Mu et al., 2021) \\
\hline $\begin{array}{l}\text { Porcine epidemic diarrhea } \\
\text { virus }\end{array}$ & $\begin{array}{l}\text { PEDV S1 domain of spike } \\
\text { protein }\end{array}$ & immune & $\mathrm{VHH}$ & camel & ELISA, IF & (Bao et al., 2019) \\
\hline $\begin{array}{l}\text { Porcine epidemic diarrhea } \\
\text { virus }\end{array}$ & nucleocapsid (N) protein & immune & $\mathrm{VHH}$ & camel & ELISA & (Ma et al., 2019) \\
\hline $\begin{array}{l}\text { Porcine epidemic diarrhea } \\
\text { virus }\end{array}$ & spike protein & immune & scFv & pig & ELISA, IF, in vivo protection & (Zhang et al., 2019a) \\
\hline $\begin{array}{l}\text { Porcine reproductive and } \\
\text { respiratory syndrome } \\
\text { virus (PRRSV) }\end{array}$ & $\begin{array}{l}\text { non-structural protein } 4 \\
\text { (NSP4) }\end{array}$ & immune & $\begin{array}{l}\mathrm{VHH} \\
\text { (intrabody) }\end{array}$ & camel & ELISA, IF, in vitro neutralization & (Liu et al., 2016) \\
\hline $\begin{array}{l}\text { Porcine reproductive and } \\
\text { respiratory syndrome } \\
\text { virus (PRRSV) }\end{array}$ & Nsp9 & iummune & $\mathrm{VHH}$ & camel & ELISA, IF, in vitro inhibition & (Liu et al., 2015) \\
\hline Puumala hantavirus & $\mathrm{N}$ protein, G2 protein & immune & Fab & human & ELISA & $\begin{array}{l}\text { (Salonen et al., } \\
\text { 1998) }\end{array}$ \\
\hline Puumala hantavirus & gycoprotein G2 & immune & $\mathrm{Fab}$ & human & ELISA, IF, in vitro neutralization & $\begin{array}{l}\text { (de Carvalho Nicacio } \\
\text { et al., 2000) }\end{array}$ \\
\hline Rabies virus & glycoprotein & $\begin{array}{l}\text { semi- } \\
\text { synthetic }\end{array}$ & scFvscFv-Fc & human & ELISA, WB, in vitro neutralization & (Ray et al., 2001) \\
\hline Rabies virus & glycoprotein & immune & scFv, IgG & human & $\begin{array}{l}\text { ELISA, flow cytometry, in vitro } \\
\text { neutralization }\end{array}$ & $\begin{array}{l}\text { (Bakker et al., 2005; } \\
\text { Kramer et al., 2005) }\end{array}$ \\
\hline Rabies virus & n.d. & immune & Fab & human & ELISA & (Houimel, 2014) \\
\hline Rabies virus & glycoprotein (antigenic site II) & immune & Fab, lgG & human & $\begin{array}{l}\text { ELISA, immunostaining, WB, in } \\
\text { vitro neutralization, in vivo } \\
\text { protection }\end{array}$ & (Sun et al., 2012) \\
\hline Rabies virus & inactivated RABV & naïve & $\begin{array}{l}\text { VHH, VHH } \\
\text { pentamer }\end{array}$ & lama & $\begin{array}{l}\text { ELISA, in vitro neutralization, in vivo } \\
\text { protection }\end{array}$ & (Boruah et al., 2013) \\
\hline $\begin{array}{l}\text { Respiratory syncytial virus } \\
\text { (RSV) }\end{array}$ & F protein & synthetic & $\mathrm{Fab}, \operatorname{lgG}$ & human & ELISA, in vitro neutralization & (Chen et al., 2016) \\
\hline Rotavirus & NSP4 & $\begin{array}{l}\text { semi- } \\
\text { synthetic }\end{array}$ & scFv & human & ELISA, WB & $\begin{array}{l}\text { (Rodríguez-Díaz } \\
\text { et al., 2004) }\end{array}$ \\
\hline Rotavirus & VP8* $^{*}$ & $\begin{array}{l}\text { semi- } \\
\text { synthetic }\end{array}$ & scFv & human & ELISA, WB, in vitro inhibition & $\begin{array}{l}\text { (Monedero et al., } \\
\text { 2004) }\end{array}$ \\
\hline SARS-CoV & S1 domain of spike protein & naïve & scFv & human & ELISA, in vitro neutralization & (Sui et al., 2004) \\
\hline SARS-COV & S protein & immune & Fab, lgG & human & $\begin{array}{l}\text { ELISA, IF, immuno blot, in vitro } \\
\text { neutralization }\end{array}$ & (Liang et al., 2005) \\
\hline SARS-CoV & S protein & immune & scFv & chicken & ELISA, IF & (Lee et al., 2007) \\
\hline SARS-CoV-2 & S protein (RBD) & naïve & $\begin{array}{l}\text { scFv, scFv- } \\
\text { Fc, lgG }\end{array}$ & human & $\begin{array}{l}\text { ELISA, in vitro inhibition, in vitro } \\
\text { neutralization }\end{array}$ & $\begin{array}{l}\text { (Bertoglio et al., } \\
\text { 2021b) }\end{array}$ \\
\hline SARS-CoV-2 & S protein (RBD) & immune & $\begin{array}{l}\text { scFv, scFv- } \\
\text { Fc, IgG }\end{array}$ & human & $\begin{array}{l}\text { ELISA, in vitro inhibition, in vitro } \\
\text { neutralization, in vivo protection }\end{array}$ & $\begin{array}{l}\text { (Bertoglio et al., } \\
\text { 2021a) }\end{array}$ \\
\hline SARS-CoV-2 & S protein (RBD) & naïve & $\begin{array}{l}\text { scFv, scFv- } \\
\text { FC }\end{array}$ & human & ELISA, in vitro neutralization & $\begin{array}{l}\text { (Noy-Porat et al., } \\
\text { 2020) }\end{array}$ \\
\hline SARS-CoV-2 & S protein (RBD) & synthetic & $\mathrm{VHH}$ & humanized & in vitro neutralization & (Chi et al., 2020) \\
\hline SARS-CoV-2 & S protein (RBD) & synthetic & $\mathrm{Fab}$ & human & ELISA, in vitro neutralization & (Zeng et al., 2020) \\
\hline SARS-CoV-2 & S protein (RBD) & immune & $\begin{array}{l}\text { VHH, VHH- } \\
\text { FC }\end{array}$ & alpaca & ELISA, in vitro inhibition, IF & (Ma et al., 2021) \\
\hline SARS-CoV-2 & S protein (RBD) & $\begin{array}{l}\text { semi- } \\
\text { synthetic }\end{array}$ & $\begin{array}{l}\text { scFv, scFv- } \\
\text { Fc, lgG }\end{array}$ & human & ELISA, WB & (Parray et al., 2020) \\
\hline SARS-CoV-2 & S protein (RBD) & immune & $\mathrm{VH}$ & human & ELISA, FACS, in vitro neutralization & (Sun et al., 2020) \\
\hline SARS-CoV-2 & $S$ protein $(R B D)$ & synthetic & $\mathrm{VH}$ & human & ELISA, in vitro neutralization & $\begin{array}{l}\text { (Bracken et al., } \\
\text { 2021) }\end{array}$ \\
\hline SARS-CoV-2 & S protein (RBD) & synthetic & $\begin{array}{l}\text { Fab, } \\
\text { bispecific } \\
\text { Fab+VH }\end{array}$ & human & in vitro neutralization & (Lim et al., 2021) \\
\hline SARS-CoV-2 & S protein (RBD) & naïve & scFv & human & $\begin{array}{l}\text { ELISA, in vitro neutralization, in vitro } \\
\text { inhibition, in vivo protection }\end{array}$ & (Ku et al., 2021) \\
\hline
\end{tabular}


TABLE 2 | Continued

\begin{tabular}{|c|c|c|c|c|c|c|}
\hline Virus & Target & $\begin{array}{l}\text { Library } \\
\text { Type }\end{array}$ & $\begin{array}{l}\text { Antibody } \\
\text { Format }\end{array}$ & Antibody Origin & Application & Reference \\
\hline SARS-CoV-2 & $\mathrm{RBD}$ & immune & Fab, IgG & human & $\begin{array}{l}\text { ELISA, in vitro neutralization assay, } \\
\text { in vivo protection, }\end{array}$ & (Zhou et al., 2021) \\
\hline SARS-CoV-2 & $\mathrm{RBD}$ & $\begin{array}{l}\text { semi- } \\
\text { synthetic }\end{array}$ & Fab & human & ELISA, in vitro neutralization & $\begin{array}{l}\text { (Slezak and } \\
\text { Kossiakoff, 2021) }\end{array}$ \\
\hline SARS-CoV-2 & $\mathrm{RBD}$ & immune & $\mathrm{VHH}$ & alpaca & $\begin{array}{l}\text { ELISA, in vitro inhibition, in vitro } \\
\text { neutralization }\end{array}$ & (Gai et al., 2021) \\
\hline SARS-CoV-2 & NP & immune & $\begin{array}{l}\text { scFv, scFv- } \\
\text { Fc }\end{array}$ & chicken & $\begin{array}{l}\text { ELISA, dotblot, lateral flow strip } \\
\text { assay }\end{array}$ & (Kim et al., 2021) \\
\hline SARS-CoV-2 & NP & immune & $\mathrm{Fab}, \lg \mathrm{G}$ & human & ELISA, WB & (Zhang et al., 2020) \\
\hline $\begin{array}{l}\text { Simian immunodeficiency } \\
\text { virus (SIV) }\end{array}$ & gp120 & immune & $\mathrm{Fab}$ & rhesus macaque & ELISA, in vitro neutralization & $\begin{array}{l}\text { (Glamann et al., } \\
\text { 1998) }\end{array}$ \\
\hline $\begin{array}{l}\text { Simian immunodeficiency } \\
\text { virus (SIV) }\end{array}$ & gp120/gp140 & immune & $\begin{array}{l}\text { scFv, scFv- } \\
\text { Fc }\end{array}$ & rhesus macaque & WB, in vitro neutralization & (Ita et al., 2017) \\
\hline Sin Nombre Virus & SNV-N & naïve & ScFv & human & ELISA, WB, dot-blot & $\begin{array}{l}\text { (Velappan et al., } \\
\text { 2007) }\end{array}$ \\
\hline Swine Influenza Virus & SIV-NP & immune & $\mathrm{VHH}$ & camel & ELISA, WB & (Du et al., 2019) \\
\hline $\begin{array}{l}\text { Transmissible } \\
\text { gastroenteritis virus }\end{array}$ & TGEV whole virus & immune & scFv & pig & in vitro neutralization, IF, WB & (Zhang et al., 2019b) \\
\hline Usutu virus & USUV A, USUV B & immune & scFv & chicken & ELISA, WB, in vitro neutralization & $\begin{array}{l}\text { (Schoenenwald } \\
\text { et al., 2020) }\end{array}$ \\
\hline $\begin{array}{l}\text { Vaccinia virus, Variola } \\
\text { Virus }\end{array}$ & Vaccinia B5 envelope protein & immune & Fab, lgG & chimpanzee & $\begin{array}{l}\text { ELISA, in vitro neutralization, in vivo } \\
\text { protection }\end{array}$ & (Chen et al., 2006) \\
\hline Vaccinia virus & virus particles & immune & scFv, IgG & human & $\begin{array}{l}\text { inhibition ELISA, in vitro } \\
\text { neutralization }\end{array}$ & (Shin et al., 2019) \\
\hline Vaccinia virus & inactivated virus particles, L1 & immune & $\mathrm{VHH}$ & llama & MAGPIX assay, FACS & (Walper et al., 2014) \\
\hline VEEV & virus particles & immune & scFv & mice & ELISA & (Duggan et al., 2001) \\
\hline VEEV & $\mathrm{E} 1 / \mathrm{E} 2$ & naïve & $\begin{array}{l}\text { scFv, scFv- } \\
\text { FC }\end{array}$ & human & ELISA, WB, IHC & (Kirsch et al., 2008) \\
\hline VEEV & E1 & immune & $\begin{array}{l}\text { scFv, scFv- } \\
\text { Fc }\end{array}$ & macaque & $\begin{array}{l}\text { ELISA, WB, IHC, in vitro } \\
\text { neutralization, in vivo protection }\end{array}$ & (Rülker et al., 2012) \\
\hline WEEV & virus particles & immune & $\begin{array}{l}\text { scFv, scFv- } \\
\text { FC }\end{array}$ & macaque & $\begin{array}{l}\text { ELISA, } \mathrm{IHC} \text {, in vitro neutralization, in } \\
\text { vivo protection }\end{array}$ & $\begin{array}{l}\text { (Hülseweh et al., } \\
\text { 2014; Burke et al., } \\
\text { 2018) }\end{array}$ \\
\hline WEEV & E2/E3E2 & immune & $\mathrm{VHH}$ & Ilama & ELISA (MagPlex assay) & (Liu et al., 2018) \\
\hline West nile virus & $\begin{array}{l}\text { domain I and II of WNV } \\
\text { envelope protein }\end{array}$ & naïve & scFv & human & $\begin{array}{l}\text { ELISA, in vitro neutralization, in vivo } \\
\text { protection }\end{array}$ & (Gould et al., 2005) \\
\hline West nile virus & $\begin{array}{l}\text { domain IIII of WNV envelope } \\
\text { protein }\end{array}$ & immune & $\mathrm{Fab}$ & human & $\begin{array}{l}\text { ELISA, IF, in vitro neutralization, in } \\
\text { vivo protection (failed) }\end{array}$ & (Duan et al., 2009) \\
\hline West nile virus & envelope (E) & naïve & $\begin{array}{l}\text { scFv, scFv- } \\
\text { Fc }\end{array}$ & human & ELISA, WB, in vitro neutralization & (Rizzo et al., 2020) \\
\hline $\begin{array}{l}\text { White spot syndrome } \\
\text { virus }\end{array}$ & virus particles & immune & scFv & mice & ELISA, in vitro neutralization & (Yuan et al., 2006) \\
\hline Yellow fever virus & domain II of envelope protein & immune & scFv, IgG & human & $\begin{array}{l}\text { ELISA,WB, immunoprecipitation, in } \\
\text { vitro neutralization, in vivo } \\
\text { protection }\end{array}$ & $\begin{array}{l}\text { (Daffis et al., 2005; } \\
\text { Lu et al., 2019) }\end{array}$ \\
\hline Zika virus & envelope domain III & naïve & $\mathrm{Fab}$ & human & $\begin{array}{l}\text { in vitro neutralization, in vivo } \\
\text { protection }\end{array}$ & (Wu et al., 2017) \\
\hline Zika virus & envelope (E) & immune & scFv & chicken & ELISA, WB, FACS, in vitro inhibition & (Mwale et al., 2020) \\
\hline Zika virus & NS1 & Immune & $\mathrm{VHH}$ & llama & ELISA & $\begin{array}{l}\text { (Delfin-Riela et al., } \\
\text { 2020) }\end{array}$ \\
\hline
\end{tabular}

ELISA, enzyme linked immunosorbent assays; HA, hemagglutinin; HCMV, Human cytomegalovirus; HIV, Human immunodeficiency virus; IF, immuno fluorescence microscopy; IHC,

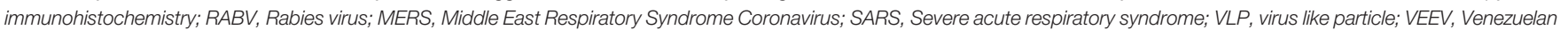
equine encephalitis virus; WB, western blot; WEEV, Western equine encephalitis virus. 
replication cycle. In tropical and subtropical countries there are approximately 3.2 billion people at risk of malaria (Tolle, 2009; Muerhoff et al., 2010). Because the life cycle of Plasmodium consists of different development stages, different targets of $P$. falciparum were addressed for antibody generation. Roeffen et al. (2001) targeted Pfs48/45, a surface protein of P. falciparum which is expressed during macrogamete and zygote stages. Pfs48/ 45 is also a potential vaccine candidate because transmissionblocking anti-Pfs48/45 antibodies taken up by the mosquito during the blood meal and block the oocyte development within the mosquito's intestinal tract (Rener et al., 1983; Kumar and Carter, 1984; Vermeulen et al., 1985). To generate anti-Pfs48/45 antibodies, two human immune libraries were constructed from B-lymphocytes derived from $P$. falciparum patients with transmission-blocking immunity.

The antibody selection was performed in immunotubes with immobilized extract of gametocytes. To specifically generate antibodies against $\mathrm{Pfs} 48 / 45$, the scFv-phage were eluted by competition using a cocktail of four rat monoclonal Abs recognizing distinct epitopes on Pfs48/45 (epitopes I, IIb, III and V). Remarkably, one epitope, the epitope III of Pfs $48 / 45$, was bound by all of the generated antibodies. Human monoclonal antibodies against the Block 2 region of Plasmodium falciparum merozoite surface protein-1 (PfMSP-1) were isolated by phage display from a scFv immune library of a malaria patient (Sowa et al., 2001). A Fab-immune library was constructed using lymphocytes of thirteen adults with acquired immunity to malaria. Finally, three Fabs (RAM1, 2 and 3) were isolated by panning on the merozite surface protein 3 (MSP-3 194-257) (Lundquist et al., 2006). This protein is involved in the binding of heme and the antibodies promote the depletion of Plasmodium by monocytes (Oeuvray et al., 1994; Imam et al., 2014). Therefore, the N-terminal fragment of MSP-3 was also tested in clinical vaccines trials (Audran et al., 2005). Binding of the antibodies to native parasite protein was demonstrated for all three antibodies in immunofluorescence microscopy and immunoblot. The native MSP-3 was bound by RAM1 and RAM2 in fixed and permeabilized cells. The anti-MSP-3 antibodies were produced as IgG1 and also in the IgG3 format and tested in an antibody-dependent cellular inhibition assay (ADCI). The IgG3 format of RAM1 showed an inhibition rate that is comparable to affinity-purified polyclonal anti-MSP-3 211 237 antibodies derived from human immune donors. In contrast, the IgG1 format also showed a lower inhibition in this assay compared to IgG3 (Lundquist et al., 2006). In 2021, SeidelGreven et al. (2021) presented a monoclonal antibody directed against AMA-1, the apical membrane antigen 1. As anti-AMA-1 antibodies show a high prevalence in immune individuals it is not only an interesting target for therapeutics but also one of the major blood-stage vaccine candidates. A human malaria Fabimmune library was used to select antibodies against a set of three AMA-1 variants. To improve the affinity and functional activity a light chain shuffling was performed. After subcloning

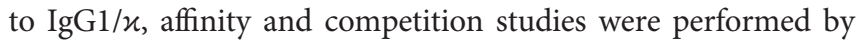
surface plasmon resonance (SPR) spectroscopy. In addition to an immunofluorescence assay (IFA), the antibodies were tested in an in vitro growth assay. Here, all antibodies were able to inhibit the growth of four different P. falciparum strains including 3D7. Therefore, those antibodies might be the fundament for the development of an antibody cocktail for therapeutic or prophylactic anti-malaria approaches. In 2014, Leow et al. (2014) aimed to find new antibodies with higher thermal stability. As degradation of antibodies due to high temperatures in the endemic countries are affecting the shelf life of malaria rapid diagnostic tests (RDTs). Therefore, they performed a panning with a naïve human scFv library on the histidine-rich protein 2 (PfHRP2) of P. falciparum. PfHRP2 is a biomarker used in most RDTs, as it is abundantly expressed in erythrocytes across all asexual stages and is released during the rupture of the red blood cells. Additionally, it remains detectable in the blood for up to 28 days. Isolated binders were cloned into the IgG format, produced in CHO cells and were compared to a commercial antibody. The selected antibodies showed comparable specificity and sensitivity, with higher thermal stability, making them candidates for a field test in a prototype test kit. To further cope with the degradation issues, Leow et al. (2018) created a shark immune library consisting of VNARs. The variable domain of the shark antibodies is known to have a high thermal stability and therefore is a potential alternative for the RDTs. A wobbegong shark (Orectolobus ornatus) was immunized with different malaria proteins (PfHRP2, PfpLDH and Pvaldolase), used for the construction of a VNAR single domain library and antibodies were selected against all three proteins. Pvaldolase and $\mathrm{pLDH}$ are used for diagnosis of non $P$. falciparum malaria infections and $P$. vivax infections. Specificity and sensitivity of the anti-PfHRP2 antibodies were demonstrated by Sandwich-ELISA and dot blot analysis. Further engineering could lead to a new generation of RDTs.

Table 3 gives an overview of antibodies generated by phage display against eukaryotic pathogens.

\section{ANTIBODIES AGAINST TOXINS}

The Center for Disease Control and Prevention (CDC) classifies several bacterial toxins and/or the pathogens producing these toxins as category $\mathrm{A}$ or $\mathrm{B}$ agent as they are a high risk to national security and public health (see: https://www.niaid.nih.gov/ research/emerging-infectious-diseases-pathogens). Thus, these toxins are a relevant target for development of diagnostics and therapeutics (Froude et al., 2011). Here, antibody phage display technology is a powerful tool to select diagnostic as well as neutralizing antibodies against complete active toxins or certain domains by using human naïve antibody libraries with high diversity (Indrawattana et al., 2010; Amaro et al., 2011; Neri et al., 2011). The aim of such neutralizing antibodies is in most cases to block the interaction of the toxin to its cellular target, by binding to the cell binding domain of the toxin. However, neutralization of the toxicity is also possible by antibodies directed against other domains like the translocation domain or the enzymatic domain (Fühner et al., 2018; Wenzel et al., 2020a). Immunization of animals with toxoids, non-toxic 
TABLE 3 | Recombinant antibodies derived by phage display against eukaryotic pathogens.

\begin{tabular}{|c|c|c|c|c|c|c|}
\hline Eukaryotic pathogen & Target & $\begin{array}{l}\text { Library } \\
\text { Type }\end{array}$ & $\begin{array}{l}\text { Antibody } \\
\text { Format }\end{array}$ & $\begin{array}{l}\text { Antibody } \\
\text { Origin }\end{array}$ & Application & Reference \\
\hline Alexandrium minutum & Whole cell/surface epitopes & naïve & $\begin{array}{l}\text { nanobody/ } \\
\text { fluobody }\end{array}$ & lama & IF & (Mazzega et al., 2019) \\
\hline Aspergillus flavus & $\begin{array}{l}\text { extracellular antigens \& } \\
\text { mycelia lysate }\end{array}$ & immune & nanobody & alpaca & ELISA (sandwich), WB & (Wang T. et al., 2017) \\
\hline Aspergillus fumigatus & Crf2 & $\begin{array}{l}\text { immune/ } \\
\text { naïve }\end{array}$ & $\begin{array}{l}\text { scFv,scFv- } \\
\text { FC }\end{array}$ & $\begin{array}{l}\text { macaque/ } \\
\text { human }\end{array}$ & ELISA, IF & (Schütte et al., 2009) \\
\hline Aspergillus niger & glucose oxidase & $\begin{array}{l}\text { semi- } \\
\text { synthetic }\end{array}$ & scFv & human & ELISA & (Ascione et al., 2004) \\
\hline Babesia gibsoni & P50 & $\begin{array}{l}\text { semi- } \\
\text { synthetic }\end{array}$ & scFv & human & ELISA, IF & (Hirose et al., 2009) \\
\hline Balamuthia mandrillaris & whole cell/surface antigens & naïve & $\mathrm{scFv}$ & human & ELISA, IHC & (Siddiqui et al., 2016) \\
\hline Botrytis cinerea & $\begin{array}{l}\text { fungal glucosylceramides } \\
\text { (fGlcCer) }\end{array}$ & immune & $\mathrm{VHH}$ & llama & ELISA, in vitro activity assay & (De Coninck et al., 2017) \\
\hline Brugia malayi & $\mathrm{BmR1}$ & $\begin{array}{l}\text { naïve, } \\
\text { immune }\end{array}$ & scFv & human & ELISA, WB & (Rahumatullah et al., 2017) \\
\hline Brugia malayi & BmSXP & immune & scFv & human & ELISA, WB & $\begin{array}{l}\text { (Rahumatullah et al., 2015; } \\
\text { Rahumatullah et al., 2019) }\end{array}$ \\
\hline Candida albicans & Als3p and other & naïve & scFv & human & $\begin{array}{l}\text { ELISA, IF, WB, in vitro } \\
\text { neutralization }\end{array}$ & $\begin{array}{l}\text { (Haidaris et al., 2001; Bliss et al., } \\
\text { 2003; Laforce-Nesbitt et al., 2008) }\end{array}$ \\
\hline Cryptosporidium parvum & P23 & $\begin{array}{l}\text { semi- } \\
\text { synthetic }\end{array}$ & scFv & human & ELISA & (Boulter-Bitzer et al., 2009) \\
\hline Cryptosporidium parvum & S16 & $\begin{array}{l}\text { semi- } \\
\text { synthetic }\end{array}$ & scFv & human & ELISA & (Boulter-Bitzer et al., 2010) \\
\hline Echinococcus granulosus & $\mathrm{AgB}$ & immune & scFv & human & ELISA & (Rahumatullah et al., 2020) \\
\hline Fasciola hepaticum & cathepsin L1 & immune & scFv & rat & ELISA, WB & (Norbury et al., 2019a) \\
\hline Fasciola hepaticum & cathepsin B2 & naïve & scFv & mice & ELISA, WB & (Norbury et al., 2019b) \\
\hline Fusarium oxysporum & cell wall-bound protein & immune & ScFv & chicken & $\begin{array}{l}\text { ELISA, IF, scFv-AFP (anti- } \\
\text { fungal peptide) fusion protein }\end{array}$ & (Peschen et al., 2004) \\
\hline Fusarium verticillioides & cell wall-bound proteins & immune & scFv & chicken & ELISA, IF & (Hu et al., 2012) \\
\hline Fusarium verticillioides & $\begin{array}{l}\text { soluble cell wall-bound } \\
\text { proteins }\end{array}$ & immune & $\begin{array}{l}\text { scFv,scFv- } \\
\text { AP }\end{array}$ & chicken & ELISA, IF, WB & (Hu et al., 2013) \\
\hline Haemonchus contortus & $\begin{array}{l}\text { excretory/secretory (ES) } \\
\text { products }\end{array}$ & immune & $\mathrm{scAb}$ & sheep & $\begin{array}{l}\text { IF, transepithelial resistance } \\
\text { assay }\end{array}$ & (Rehman et al., 2016) \\
\hline Leishmania infantum & $\beta$-tubulin & naïve & scFv & human & ELISA, WB & (Costa et al., 2019) \\
\hline Myxobolus rotundus & spore protein & immune & scFv & mice & ELISA, in vitro neutralization & (Zhang J. Y. et al., 2006) \\
\hline Neospora caninum & rNcSRS2 & immune & $\mathrm{Fab}$ & mice & ELISA, IF & (Dong et al., 2014) \\
\hline Onchocerca volvulus & Ov16 & synthetic & Fab, IgG & human & $\begin{array}{l}\text { ELISA, rapid diagnostic } \\
\text { platform }\end{array}$ & (Golden et al., 2016) \\
\hline Paranosema locustae & alpha-/beta-hydrolase & immune & $\begin{array}{l}\text { scFv, mini } \\
\text { antibody }\end{array}$ & mice & WB, IF & (Dolgikh et al., 2017) \\
\hline Plasmodium chabaudi & AMA-1 & immune & scFv & mice & ELISA, WB & (Fu et al., 1997) \\
\hline Plasmodium falciparum & MSP-1 & immune & scFv & human & ELISA, IF & (Sowa et al., 2001) \\
\hline Plasmodium falciparum & MSP-3 & immune & Fab,lgG & human & ELISA, IF, WB, FACS & (Lundquist et al., 2006) \\
\hline Plasmodium falciparum & Pfs48/45 & immune & scFv & human & ELISA, WB & (Roeffen et al., 2001) \\
\hline Plasmodium falciparum & $\begin{array}{l}\text { PfHRP2, PfpLDH and } \\
\text { Pvaldolase }\end{array}$ & $\begin{array}{l}\text { Immune/ } \\
\text { sdAb }\end{array}$ & VNAR & shark & ELISA, dot blot & (Leow et al., 2018) \\
\hline Plasmodium falciparum & PfHRP2 & naïve & scFv & human & $\begin{array}{l}\text { ELISA (sandwich), WB, dot } \\
\text { blot }\end{array}$ & (Leow et al., 2014) \\
\hline Plasmodium falciparum & AMA-1 & immune & Fab, IgG & human & ELISA, IF, in vitro inhibition & (Seidel-Greven et al., 2021) \\
\hline Plasmodium yoelii & MSP1 & immune & scFv & mice & $\begin{array}{l}\text { ELISA, WB, in vivo } \\
\text { protection }\end{array}$ & (Vukovic et al., 2002) \\
\hline Schisostoma japonicum & $\begin{array}{l}\text { Schisostoma japonicum } \\
\text { cercariaeschistosomules }\end{array}$ & immune & scFv & buffalo & $\begin{array}{l}\text { IF, WB, ELISA, protein } \\
\text { microarray }\end{array}$ & $\begin{array}{l}\text { (Hosking et al., 2015a; Hosking } \\
\text { et al., 2015b) }\end{array}$ \\
\hline Schizophyllum commune & $\begin{array}{l}\text { beta-(1,6)-Branched beta- } \\
(1,3)-\text { D-Glucan Schizophyllan }\end{array}$ & immune & scFv & mice & ELISA & (Josewski et al., 2017) \\
\hline Strongyloides stercoralis & rNIE & immune & scFv & human & ELISA, WB & (Rahumatullah et al., 2021) \\
\hline Sclerotinia sclerotiorum & SSPG1d & immune & scFv & mice & ELISA, WB & (Yang et al., 2009) \\
\hline $\begin{array}{l}\text { Strongyloides } \\
\text { venezuelensis }\end{array}$ & HSP60 & $\begin{array}{l}\text { presumably } \\
\text { naïve }\end{array}$ & scFv & human & ELISA, IF & (Levenhagen et al., 2015) \\
\hline Taenia solium & TS14 & immune & $\mathrm{VHH}$ & camel & ELISA, WB & (Deckers et al., 2009) \\
\hline Taenia solium & $\begin{array}{l}\text { T. solium metacestodes, } \\
\text { peptides }\end{array}$ & naïve & scFv & human & ELISA, IF & (Ribeiro et al., 2013) \\
\hline
\end{tabular}


TABLE 3 | Continued

\begin{tabular}{|c|c|c|c|c|c|c|}
\hline Eukaryotic pathogen & Target & $\begin{array}{l}\text { Library } \\
\text { Type }\end{array}$ & $\begin{array}{l}\text { Antibody } \\
\text { Format }\end{array}$ & $\begin{array}{l}\text { Antibody } \\
\text { Origin }\end{array}$ & Application & Reference \\
\hline Trypanosoma cruzi & $P 2 B$ & immune & scFv & human & ELISA, WB & (Grippo et al., 2011) \\
\hline Trypanosoma evansi & different surface proteins & immune & $\mathrm{VHH}$ & camel & ELISA, FACS & (Saerens et al., 2008) \\
\hline $\begin{array}{l}\text { Trypanosoma evansi, } \\
\text { brucei, T. congolense, T. } \\
\text { vivax }\end{array}$ & different surface proteins & immune & $\mathrm{VHH}$ & alpaca & WB, IHC & (Obishakin et al., 2014) \\
\hline Toxoplasma gondii & TgMIC2 & immune & scFv & mice & ELISA, WB & (Hoe et al., 2005) \\
\hline Toxoplasma gondii & tachyzoites & immune & scFv & mice & $\begin{array}{l}\text { ELISA, WB, IF, in vitro } \\
\text { invasion, attachment assays }\end{array}$ & (Lim et al., 2018) \\
\hline
\end{tabular}

ELISA, enzyme linked immunosorbent assays; IHC, immuno histo chemistry; IF, immuno fluorescence microscopy; FACS, fluorescence-activated cell sorting; WB, Western blot.

subunits or selected toxin domains allows for the isolation of high-affinity antibodies with immune antibody libraries. Especially well-suited for the construction of such immune antibody libraries are macaques as there $\mathrm{V}$-genes are very similar to their human counterparts (Chassagne et al., 2004; Pelat et al., 2007; Pelat et al., 2009; Rülker et al., 2012; Miethe et al., 2014; Miethe et al., 2015). Alternatively, also B-cells from vaccinated humans can be used in cases where an approved vaccine is available (Wenzel et al., 2020a).

So far, neutralizing antibodies have been successfully selected against several toxins, classified as category A agents, such as botulinum toxins causing botulism from Clostridium botulinum (Amersdorfer et al., 2002; Conway et al., 2010; Hu et al., 2010; Miethe et al., 2014) and anthrax toxins from Bacillus anthracis (Pelat et al., 2007) and also against different category B agents, such as staphylococcal enterotoxin B (Larkin et al., 2010; Chen et al., 2019). We focused on toxins produced by microorganisms and did not include e.g. plant toxins like the potential biowarfare agent ricin (Pelat et al., 2009) or anti-venom, e.g. anti-snake toxin, antibodies (Laustsen et al., 2018).

One microorganism with the high-risk to be potential used as a bioweapon is the Gram-positive, anaerobic, spore-forming bacterium Clostridium botulinum and other Clostridium spp. that produce the most toxic substances known: eight different serotypes $(\mathrm{A}-\mathrm{H})$ of botulinum neurotoxin (BoNT). Five of these serotypes (A, B, E, rarely $\mathrm{F}$, only one case of $\mathrm{H}$ ) cause human botulism. Human botulism results in flaccid muscle paralysis what requires intensive hospital care and passive immunization (Arnon et al., 2001; Barash and Arnon, 2014). The most toxic substance is serotype A with a $\mathrm{LD}_{50}$ of about $1 \mathrm{ng} / \mathrm{kg}$ by intravenous route, about $10 \mathrm{ng} / \mathrm{kg}$ by the pulmonary route and about $1 \mu \mathrm{g} / \mathrm{kg}$ for the oral route (Dembek et al., 2007). BoNTs consist of a $50 \mathrm{kDa}$ light chain and a $100 \mathrm{kDa}$ heavy chain linked by a disulfide bound. Receptor-mediated endocytosis followed by translocation of the light chain across the membrane into the neuronal cytosol is facilitated by two functional domains (Hc and $\mathrm{Hn}$ ) of the heavy chain. The light chain contains the catalytic domain responsible for the BoNT toxicity. Currently botulism is treated by the application of anti-botulism immunoglobulins, such equine serum or the human serum BabyBIG against type A and B. Yet the availability of BabyBIG is limited while equine serum may cause serum sickness and hypersensitivity. Here, antibody phage display technology has been used to generate toxin-neutralizing antibodies against each serotype. One single domain antibodies ( $\mathrm{VHH}$ ) was selected by phage display of a llama immunized with a cocktail of seven BoNT toxoids (A-F) (Conway et al., 2010; Shriver-Lake et al., 2017). Other VHH have been isolated from immunized alpacas and were produced as $\mathrm{VHH}-\mathrm{Fc}$ fusion. These antibodies were protective against LD50 BoNT/A and showed protection over 14 days after antibody administration (Godakova et al., 2019). Furthermore, a human antibody gene library could be generated after in vitro immunization with BoNT/A ( $\mathrm{Hu}$ et al., 2010). Macaque immune libraries were used to isolate neutralizing $\mathrm{scFv}$ against the light chains (Lc) and heavy chains (Hc) of BoNT/A, -B and -E with $\mathrm{nM}$ affinities against by the EU AntibotABE project (Chahboun et al., 2011; Miethe et al., 2014; Avril et al., 2015; Rasetti-Escargueil et al., 2015). These antibodies were germlinehumanized and the in vivo protection was analyzed in non-lethal and lethal mice challenge experiments. For BoNT/A and BoNT/ $\mathrm{B}$ neutralizing anti-Lc and anti-Hc antibody showed only limited protection, but the combination of anti-LC and anti-HC antibodies showed a synergistic effect and $100 \%$ protection when using $2.5 \mu \mathrm{g} /$ mice (Miethe et al., 2016). Interestingly, no neutralizing antibodies against the $\mathrm{Hc}$ of BoNT/E were selected, but the neutralizing anti-Lc antibody alone showed full in vivo protection using only $2.5 \mathrm{ng}$ IgG/mice (Derman et al., 2016).

Another serious infectious disease is anthrax caused by toxins of Bacillus anthracis, an aerobic, Gram-positive, spore-forming bacterium found in soils all over the world. Bacillus anthracis secretes the lethal toxin (LT) consisting of the lethal factor (LF) and the protective antigen (PA); while the edema toxin (ET) is formed by the edema factor (EF) and PA (Liu S. et al., 2014). In the pathogenesis of anthrax only LT is essential (Inglesby et al., 2002). Production and dissemination as aerosol of anthrax toxin is easily possible highlighting its potential as a bioweapon (Oncü et al., 2003). Vaccines are currently based on the subunit PA to induce the generation of neutralizing antibodies. For treatment, commercial monoclonal antibodies against PA, such as Raxibacumab, are commonly used in combination with antibiotics (Kummerfeldt, 2014). Raxibacumab was approved by the FDA in 2012 to treat inhalational anthrax. However, as PA could be mutated and modified to escape neutralizing PA antibodies while still maintaining biological activity, the use of anti-PA antibodies alone presents a security issue. An alternative and additional target presents the LF domain. Such an antibody 
against the LF domain is 2LF, isolated from an immune library via antibody phage display technology (Pelat et al., 2007). Also a synergistic effect of the combination of an anti-PA together with an anti-LF antibody is to be expected and would improve the efficacy of the therapy.

Staphylococcal enterotoxin B (SEB) from Staphylococcus aureus is an example for a bacterial toxin classified as category $B$ agent, that could potentially cause foodborne illness. Staphylococcus aureus produces in total twenty-one types of staphylococcal enterotoxins leading to food poisoning with abdominal cramps, diarrhea and vomiting (Thomas et al., 2006; Ono et al., 2008). The most potent toxin secreted by $S$. aureus is $\mathrm{SEB}$, a single $28 \mathrm{kDa}$ polypeptide. As a superantigen, it stimulates $\mathrm{T}$ cells leading to an overproduction of cytokines, resulting in fever, hypertension and in some cases death. Phage display was employed to identify the epitope of a SEB specific monoclonal antibody using a peptide phage library (Urushibata et al., 2010) and to generate recombinant antibodies from a murine immune library (Singh et al., 2010). Additionally, synthetic human Fab libraries was used to generate human monoclonal antibodies blocking SEB binding to MHC-II (Larkin et al., 2010) and neutralizing SEB in vitro and in vivo (Chen et al., 2019). In contrast to the therapeutic use, phage display was applied to generate nanobodies against SEB from camel immune and naive libraries useful as a diagnostic tool. These nanobodies were either directly coupled with alkaline phosphatase in a sandwich-ELISA (Sun T. et al., 2020), or used for western-blot and ELISA in an indirect detection system (Zanganeh et al., 2019).

In the late 1970ies, Clostridioides difficile was discovered as the pathogen causing antibiotic treatment associated diarrhea (CDAD) (Bartlett et al., 1978). Only strains expressing at least Toxin B $(\mathrm{TcdB})$ mostly together with Toxin A (TcdA) result in disease and typical symptoms of CDAD (Bartlett et al., 1978). Only strains expressing at least Toxin $B(\operatorname{TcdB})$, mostly together with Toxin A (TcdA), result in disease and typical symptoms of CDAD (Natarajan et al., 2013). TcdA and TcdB are homologous multidomain single-chain proteins of 308 and $270 \mathrm{kDa}$, respectively. Both toxins share the same domain architecture. The N-terminus harbors the catalytic domain, a glucosyltransferase (GTD) acting on small Rho-GTPases (Just et al., 1995; Busch et al., 1998), followed by a cysteine protease domain (CPD) catalyzing the proteolytic autoprocessing and upon translocation releasing the GTD into the cytosol (Egerer et al., 2007; Reineke et al., 2007). Pore formation and translocation of the N-terminal portion of the toxin is facilitated by the translocation domain (TLD) (Genisyuerek et al., 2011). The C-terminus of TcdA and $\mathrm{TcdB}$ composes repetitive elements that combine long and short repeats in so called CROPs (Combined Repetitive Oligo Peptides). The CROPs are responsible for the first contact of the toxin with the target cells by interaction with carbohydrate structures on the cell surface (von Eichel-Streiber et al., 1992).

Due to increasing CDAD case numbers and epidemic outbreaks (Rupnik et al., 2009; Depestel and Aronoff, 2013), these two toxins were targets of several antibody-generationcampaigns (Babcock et al., 2006; Marozsan et al., 2012). In 2011,
Hussack and coworkers were the first to report the successful generation of anti TcdA antibodies by phage display using a llama derived immune library. Four VHH antibodies (A4.2, A5.1, A20.1, and A26.8), showed potent neutralization of the cytopathic effects of TcdA on fibroblast cells in an in vitro assay (Hussack et al., 2011). Similarly, Yang et al. used an alpaca derived immune library to generate six and eleven unique $\mathrm{VHH}$ antibodies against TcdA and $\mathrm{TcdB}$, respectively. The single domain antibodies showing the most potent neutralizing activity and highest affinity to nonoverlapping epitopes were combined in a tetravalent bispecific antibody format designated as "ABA". The heterotetramer ABA consists of two copies of the anti TcdB VHH E3 as well as the one copy of each of the anti TcdA VHHs AH3 and AA6 in the following order: AH3/E3/E3/AA6. ABA was shown to bind to TcdA and TcdB simultaneously and one single injection of ABA was enough to reverse fulminant $\mathrm{CDAD}$ in mice. In another antibody generation campaign, the naïve $s c F v$ libraries HAL9/10 (Kügler et al., 2015) were used to isolate the first fully human, phage display derived antibodies against $\mathrm{TcdB}$. Using various TcdB fragments for the panning process, partially combined with preincubation steps, 31 unique antibodies were generated directed against a broad range of epitopes. The antibodies were tested in an in vitro neutralization assay using Vero cells. Interestingly, the two most potent antibodies bound to the same, formerly unknown, epitope within the glycosyltransferase domain of TcdB (Fühner et al., 2018).

Diphtheria toxin (DT) is a typical A-B-toxin with an A subunit (catalytic domain) and a B subunit that contains the cell binding domain and the translocation domain. DT is produced by a corynephage $\beta$ infected pathogenic Corynebacterium stain, mainly Corynebacterium diphtheriae (Murphy, 1996). To date, the only approved therapeutic is a serum from horses immunized with diphtheria toxin, as invented by Emil von Behring and Shibasaburo Kitasato over 100 years ago (von Behring and Kitasato, 1890). Antibodies were generated by phage display from immune libraries of boost vaccinated donors. Neutralizing antibodies against all three domains of DT were selected. The best antibodies showed an in vitro neutralizing antibody with a relative potency of $454 \mathrm{IU} / \mathrm{mg}$ at $4 \mathrm{xMCDt}$ (minimal cytopathic dose). When using higher toxin concentration, the neutralization efficacy was highly reduced, but when using two or three antibodies in combinations the neutralization was restored. An in vivo potency of $79.4 \mathrm{IU} / \mathrm{mg}$ was achieved in an intradermal challenge assay (Wenzel et al., 2020a).

An Overview of recombinant antibodies against toxins are given in Table 4.

\section{CONCLUSION}

A large number of recombinant antibodies for application in diagnostics and therapy were already generated by phage display against viral, bacterial and eukaryotic pathogens as well as toxins. Antibody phage display allows the generation of antibodies originating from several species, including human, camel, llama, alpaca, chimpanzee, macaque, pig, mice, chicken or shark. These antibodies are derived from two types of library 
TABLE 4 | Recombinant antibodies derived by phage display against toxins.

\begin{tabular}{|c|c|c|c|c|c|c|c|}
\hline Toxin & Species & Target & $\begin{array}{l}\text { library } \\
\text { type }\end{array}$ & $\begin{array}{l}\text { Antibody } \\
\text { Format }\end{array}$ & $\begin{array}{l}\text { Antibody } \\
\text { Origin }\end{array}$ & Application & Reference \\
\hline $\begin{array}{l}\text { Adenylate cyclase } \\
\text { toxin (ACT) }\end{array}$ & $\begin{array}{l}\text { Bordetella } \\
\text { pertussis }\end{array}$ & $\begin{array}{l}\text { C-terminal repeat-in- } \\
\text { toxin }(R T X) \text { domain } \\
\text { of } A C T\end{array}$ & immune & scFv & mice & ELISA, in vitro inhibition & $\begin{array}{l}\text { (Wang X. et al., } \\
\text { 2015) }\end{array}$ \\
\hline Alpha-toxin & $\begin{array}{l}\text { Clostridium } \\
\text { perfringens }\end{array}$ & type A alpha-toxin & $\begin{array}{l}\text { semi- } \\
\text { synthetic }\end{array}$ & ScFv & human & $\begin{array}{l}\text { ELISA, in vitro inhibition, in vivo } \\
\text { protection }\end{array}$ & $\begin{array}{l}\text { (Wang D. et al., } \\
\text { 2017) }\end{array}$ \\
\hline Anthrax toxin & Bacillus anthracis & lethal factor (LF) & immune & scFv & macaque & $\begin{array}{l}\text { ELISA, in vitro toxin } \\
\text { neutralization, in vivo protection }\end{array}$ & (Pelat et al., 2007) \\
\hline Anthrax toxin & Bacillus anthracis & $\begin{array}{l}\text { protective antigen } \\
(\mathrm{PA})\end{array}$ & naïve & scFv & human & $\begin{array}{l}\text { in vitro toxin neutralization, in vivo } \\
\text { protection }\end{array}$ & (Mazumdar, 2009) \\
\hline Anthrax toxin & Bacillus anthracis & $\begin{array}{l}\text { protective antigen } \\
\text { (PA) }\end{array}$ & immune & $\mathrm{VHH}$ & camel & ELISA & (Shali et al., 2018) \\
\hline Anthrax toxin & Bacillus anthracis & lethal factor (LF) & immune & $\begin{array}{l}\text { VHH, bispecific } \\
\text { VHH }\end{array}$ & alpaca & ELISA, WB, in vivo protection & (Vrentas et al., 2016) \\
\hline Anthrax toxin & Bacillus anthracis & $\begin{array}{l}\text { protective antigen } \\
(\mathrm{PA})\end{array}$ & immune & $\begin{array}{l}\text { VHH, bispecific } \\
\text { VHH }\end{array}$ & alpaca & $\begin{array}{l}\text { ELISA, in vitro inhibition, in vivo } \\
\text { protection }\end{array}$ & (Moayeri et al., 2015) \\
\hline $\begin{array}{l}\text { Botulinum } \\
\text { Neurotoxin }\end{array}$ & $\begin{array}{l}\text { Clostridium } \\
\text { botulinum }\end{array}$ & $\begin{array}{l}\text { serotype A - light } \\
\text { chain }\end{array}$ & immune & scFv & macaque & ELISA, in vitro toxin inhibition & $\begin{array}{l}\text { (Chahboun et al., } \\
\text { 2011) }\end{array}$ \\
\hline $\begin{array}{l}\text { Botulinum } \\
\text { Neurotoxin }\end{array}$ & $\begin{array}{l}\text { Clostridium } \\
\text { botulinum }\end{array}$ & $\begin{array}{l}\text { serotype A - light } \\
\text { chain }\end{array}$ & immune & scFv,scFv-Fc & macaque & $\begin{array}{l}\text { ELISA, WB, in vitro toxin } \\
\text { inhibition, ex vivo toxin } \\
\text { neutralization }\end{array}$ & (Miethe et al., 2014) \\
\hline $\begin{array}{l}\text { Botulinum } \\
\text { Neurotoxin }\end{array}$ & $\begin{array}{l}\text { Clostridium } \\
\text { botulinum }\end{array}$ & $\begin{array}{l}\text { serotype A - light } \\
\text { chain }\end{array}$ & immune & $\mathrm{VHH}$ & camel & ELISA, WB, in vitro neutralization & $\begin{array}{l}\text { (Thanongsaksrikul } \\
\text { et al., 2010) }\end{array}$ \\
\hline $\begin{array}{l}\text { Botulinum } \\
\text { Neurotoxin }\end{array}$ & $\begin{array}{l}\text { Clostridium } \\
\text { botulinum }\end{array}$ & $\begin{array}{l}\text { serotype A - heavy } \\
\text { chain }\end{array}$ & immune & scFv & murine & $\begin{array}{l}\text { ELISA, ex vivo toxin } \\
\text { neutralization }\end{array}$ & $\begin{array}{l}\text { (Amersdorfer et al., } \\
\text { 1997) }\end{array}$ \\
\hline $\begin{array}{l}\text { Botulinum } \\
\text { Neurotoxin }\end{array}$ & $\begin{array}{l}\text { Clostridium } \\
\text { botulinum }\end{array}$ & $\begin{array}{l}\text { serotype A - heavy } \\
\text { chain }\end{array}$ & immune & scFv & human & $\begin{array}{l}\text { ELISA, ex vivo toxin } \\
\text { neutralization }\end{array}$ & $\begin{array}{l}\text { (Amersdorfer et al., } \\
\text { 2002) }\end{array}$ \\
\hline $\begin{array}{l}\text { Botulinum } \\
\text { Neurotoxin }\end{array}$ & $\begin{array}{l}\text { Clostridium } \\
\text { botulinum }\end{array}$ & $\begin{array}{l}\text { serotype A - heavy } \\
\text { chain }\end{array}$ & naïve & scFv & human & $\begin{array}{l}\text { ELISA, ex vivo toxin } \\
\text { neutralization }\end{array}$ & $\begin{array}{l}\text { (Amersdorfer et al., } \\
\text { 2002) }\end{array}$ \\
\hline $\begin{array}{l}\text { Botulinum } \\
\text { Neurotoxin }\end{array}$ & $\begin{array}{l}\text { Clostridium } \\
\text { botulinum }\end{array}$ & $\begin{array}{l}\text { serotype A - heavy } \\
\text { chain }\end{array}$ & immune & scFv & macaque & $\begin{array}{l}\text { ELISA, ex vivo toxin } \\
\text { neutralization }\end{array}$ & (Avril et al., 2015) \\
\hline $\begin{array}{l}\text { Botulinum } \\
\text { Neurotoxin }\end{array}$ & $\begin{array}{l}\text { Clostridium } \\
\text { botulinum }\end{array}$ & serotype A + B & immune & scFv-Fc, lgG & macaque & $\begin{array}{l}\text { ELISA, in vivo mouse paralysis } \\
\text { assay, in vivo protection }\end{array}$ & (Miethe et al., 2016) \\
\hline $\begin{array}{l}\text { Botulinum } \\
\text { Neurotoxin }\end{array}$ & $\begin{array}{l}\text { Clostridium } \\
\text { botulinum }\end{array}$ & serotype A & immune & $\mathrm{VHH}, \mathrm{VHH}-\mathrm{FC}$ & alpaca & in vivo protection & $\begin{array}{l}\text { (Godakova et al., } \\
\text { 2019) }\end{array}$ \\
\hline $\begin{array}{l}\text { Botulinum } \\
\text { Neurotoxin }\end{array}$ & $\begin{array}{l}\text { Clostridium } \\
\text { botulinum }\end{array}$ & $\begin{array}{l}\text { serotype B - light } \\
\text { chain/heavy chain }\end{array}$ & immune & scFv,scFv-Fc & macaque & $\begin{array}{l}\text { ELISA, in vitro toxin inhibition, ex } \\
\text { vivo toxin neutralization, in vivo } \\
\text { protection }\end{array}$ & $\begin{array}{l}\text { (Rasetti-Escargueil } \\
\text { et al., 2015) }\end{array}$ \\
\hline $\begin{array}{l}\text { Botulinum } \\
\text { Neurotoxin }\end{array}$ & $\begin{array}{l}\text { Clostridium } \\
\text { botulinum }\end{array}$ & $\begin{array}{l}\text { serotype E - light } \\
\text { chain }\end{array}$ & immune & scFv,scFv-Fc & macaque & $\begin{array}{l}\text { ELISA, in vitro toxin inhibition, ex } \\
\text { vivo toxin neutralization, in vivo } \\
\text { protection }\end{array}$ & (Miethe et al., 2015) \\
\hline $\begin{array}{l}\text { Botulinum } \\
\text { Neurotoxin }\end{array}$ & $\begin{array}{l}\text { Clostridium } \\
\text { botulinum }\end{array}$ & $\begin{array}{l}\text { serotype E - light } \\
\text { chain }\end{array}$ & immune & scFv-Fc, lgG & macaque & $\begin{array}{l}\text { ELISA, in vivo mouse paralysis } \\
\text { assay, in vivo protection }\end{array}$ & (Derman et al., 2016) \\
\hline $\begin{array}{l}\text { Botulinum } \\
\text { Neurotoxin }\end{array}$ & $\begin{array}{l}\text { Clostridium } \\
\text { botulinum }\end{array}$ & $\begin{array}{l}\text { serotype E - heavy } \\
\text { chain }\end{array}$ & immune & $\mathrm{VHH}$ & dromedary & ELISA, in vivo protection & $\begin{array}{l}\text { (Bakherad et al., } \\
\text { 2013) }\end{array}$ \\
\hline $\begin{array}{l}\text { Botulinum } \\
\text { Neurotoxin }\end{array}$ & $\begin{array}{l}\text { Clostridium } \\
\text { botulinum }\end{array}$ & $\begin{array}{l}\text { serotype } A / B / C / D / E / \\
F\end{array}$ & immune & $\mathrm{VHH}$ & llama & ELISA, in vitro toxin inhibition & $\begin{array}{l}\text { (Conway et al., } \\
\text { 2010; Shriver-Lake } \\
\text { et al., 2017) }\end{array}$ \\
\hline C. difficile toxin & $\begin{array}{l}\text { Clostridioides } \\
\text { difficile }\end{array}$ & TcdA & immune & $\mathrm{VHH}$ & Ilama & ELISA, WB, in vitro neutralization & $\begin{array}{l}\text { (Hussack et al., } \\
\text { 2011) }\end{array}$ \\
\hline C. difficile toxin & $\begin{array}{l}\text { Clostridioides } \\
\text { difficile }\end{array}$ & TcdA, TcdB & immune & $\begin{array}{l}\text { VHH, bispecific } \\
\text { VHH }\end{array}$ & alpaca & $\begin{array}{l}\text { ELISA, in vitro toxin inhibition, in } \\
\text { vivo protection }\end{array}$ & (Yang et al., 2014) \\
\hline C. difficile toxin & $\begin{array}{l}\text { Clostridioides } \\
\text { difficile }\end{array}$ & TcdB & naïve & scFv-Fc & human & dot blot, in vitro neutralization & (Chung et al., 2018) \\
\hline C. difficile toxin & $\begin{array}{l}\text { Clostridioides } \\
\text { difficile }\end{array}$ & TcdB & naïve & scFv, scFv-Fc & human & ELiSA, in vitro neutralization & (Fühner et al., 2018) \\
\hline C. difficile toxin & $\begin{array}{l}\text { Clostridium } \\
\text { difficile }\end{array}$ & binary CDT toxin & immune & $\mathrm{VHH}, \mathrm{VHH}-\mathrm{FC}$ & llama & ELISA, in vitro toxin inhibition, IF & (Unger et al., 2015) \\
\hline Cry toxin & $\begin{array}{l}\text { Bacillus } \\
\text { thuringiensis }\end{array}$ & $\begin{array}{l}\text { Cry1Aa, Cry1Ab, } \\
\text { Cry1Ac, Cry1B, } \\
\text { Cry1C, Cry1F }\end{array}$ & immune & scFv & mice & ELISA, sandwich ELISA & (Dong et al., 2018) \\
\hline Cry toxin & $\begin{array}{l}\text { Bacillus } \\
\text { thuringiensis }\end{array}$ & Cry1E & immune & $d A b$ & human & ELISA, in vitro inhibition & (Xu et al., 2017a) \\
\hline
\end{tabular}


TABLE 4 | Continued

\begin{tabular}{|c|c|c|c|c|c|c|c|}
\hline Toxin & Species & Target & $\begin{array}{l}\text { library } \\
\text { type }\end{array}$ & $\begin{array}{l}\text { Antibody } \\
\text { Format }\end{array}$ & $\begin{array}{l}\text { Antibody } \\
\text { Origin }\end{array}$ & Application & Reference \\
\hline Cry toxin & $\begin{array}{l}\text { Bacillus } \\
\text { thuringiensis }\end{array}$ & Cry1F & immune & scFv & rabbit & ELISA & (Xu et al., 2017b) \\
\hline Cry toxin & $\begin{array}{l}\text { Bacillus } \\
\text { thuringiensis }\end{array}$ & Cry3A & immune & $\mathrm{VHH}$ & Ilama & ELISA & $\begin{array}{l}\text { (Zúñiga-Navarrete } \\
\text { et al., 2015) }\end{array}$ \\
\hline Cry toxin & $\begin{array}{l}\text { Bacillus } \\
\text { thuringiensis }\end{array}$ & Cry1Fa & immune & $\mathrm{VHH}$ & camel & sandwich ELISA & $\begin{array}{l}\text { (Wang P. et al., } \\
\text { 2014) }\end{array}$ \\
\hline Cry toxin & $\begin{array}{l}\text { Bacillus } \\
\text { thuringiensis }\end{array}$ & Cry1C d-endotoxins & $\begin{array}{l}\text { semi- } \\
\text { synthetic }\end{array}$ & ScFv & human & ELISA, in vitro toxin inhibition & $\begin{array}{l}\text { (Wang Y. et al., } \\
\text { 2012) }\end{array}$ \\
\hline Cry toxin & $\begin{array}{l}\text { Bacillus } \\
\text { thuringiensis }\end{array}$ & Cry1B toxin & immune & $\mathrm{VHH}$ & camel & ELISA & (Zhong et al., 2018) \\
\hline CyaA-hemolysin & $\begin{array}{l}\text { Bordetella } \\
\text { pertussis }\end{array}$ & CyaA-Hly & $\begin{array}{l}\text { semi- } \\
\text { synthetic }\end{array}$ & $\mathrm{VHH}$ & humanizedcamel & ELISA, WB, in vitro neutralization & (Malik et al., 2016) \\
\hline Diphtheria toxin & $\begin{array}{l}\text { Corynebacterium } \\
\text { diphtheriae }\end{array}$ & DT & immune & $\begin{array}{l}\text { scFv, scFv-Fc, } \\
\operatorname{lgG}\end{array}$ & human & $\begin{array}{l}\text { ELISA, in vitro neutralization, in } \\
\text { vivo neutralization }\end{array}$ & (Wenzel et al., 2020a) \\
\hline Enterotoxin B & Escherichia coli & EtxB & $\begin{array}{l}\text { semi- } \\
\text { synthetic }\end{array}$ & scFv & human & ELISA, in vitro toxin inhibition & (Chung et al., 2008) \\
\hline Epsilon toxin & $\begin{array}{l}\text { Clostridium } \\
\text { perfingens }\end{array}$ & Epsilon toxoid & $\begin{array}{l}\text { semi } \\
\text { synthetic }\end{array}$ & $\mathrm{scFv}, \mathrm{dAb}$ & human & ELISA & (Alibeiki et al., 2020) \\
\hline Mycotoxin & $\begin{array}{l}\text { Fusarium } \\
\text { verticillioides }\end{array}$ & fumonisin B1 & $\begin{array}{l}\text { semi- } \\
\text { synthetic }\end{array}$ & scFv & human & - & (Lauer et al., 2005) \\
\hline Mycotoxin & Fusarium spp. & trichothecenes HT-2 & immune & $\mathrm{Fab}$ & mice & TR-FRET Assay & (Arola et al., 2016) \\
\hline Mycotoxin & Aspergillus flavus & aflatoxin B1 & immune & $\mathrm{VHH}$ & alpaca & ELISA & (He et al., 2014) \\
\hline Mycotoxin & Fusarium spp. & deoxynivalenol & synthetic & scFv & human & ELISA, & (Leivo et al., 2020) \\
\hline Microcystin & $\begin{array}{l}\text { Microcystis } \\
\text { aeruginosa }\end{array}$ & ADDA & $\begin{array}{l}\text { semi- } \\
\text { synthetic }\end{array}$ & scFv & human & ELISA & $\begin{array}{l}\text { (McElhiney et al., } \\
\text { 2000) }\end{array}$ \\
\hline Microcystin & $\begin{array}{l}\text { Microcystis } \\
\text { aeruginosa }\end{array}$ & microcystin-LR & immune & ScFv & rabbit & ELISA & (Xu et al., 2019) \\
\hline Microcystin & $\begin{array}{l}\text { Microcystis } \\
\text { aeruginosa }\end{array}$ & microcystin-LR & immune & $\mathrm{VHH}$ & alpaca & ELISA, inhibition ELISA & (Xu et al., 2018) \\
\hline Mycolactone & $\begin{array}{l}\text { Mycobacterium } \\
\text { ulcerans }\end{array}$ & lipidic toxin A & naïve & scFv, scFv-Fc & human & ELISA, flow cytometry, & (Naranjo et al., 2019) \\
\hline Nodularin & $\begin{array}{l}\text { Nodularia } \\
\text { spumigena }\end{array}$ & NOD & $\begin{array}{l}\text { semi- } \\
\text { synthetic }\end{array}$ & $\begin{array}{l}\text { scFv, scFv- } \\
\text { alkaline } \\
\text { phosphatase }\end{array}$ & human & competition assay & (Akter et al., 2017) \\
\hline $\begin{array}{l}\text { Pseudomonas } \\
\text { aeruginosa } \\
\text { exotoxin A }\end{array}$ & $\begin{array}{l}\text { Pseudomonas } \\
\text { aeruginosa }\end{array}$ & ETA & naïve & ScFv & human & ELISA, WB, in vitro inhibition & (Santajit et al., 2019) \\
\hline $\begin{array}{l}\text { Pseudomonas } \\
\text { aeruginosa } \\
\text { exotoxin A }\end{array}$ & $\begin{array}{l}\text { Pseudomonas } \\
\text { aeruginosa }\end{array}$ & ExoA-DI & $\begin{array}{l}\text { semi- } \\
\text { synthetic }\end{array}$ & scFv & human & ELISA, WB & $\begin{array}{l}\text { (Shadman et al., } \\
\text { 2021) }\end{array}$ \\
\hline $\begin{array}{l}\text { Salmonella Typhi } \\
\text { Hemolysin E }\end{array}$ & Salmonella Typhi & hemolysin E antigen & naïve & scFv & human & ELISA, WB & (Lim et al., 2016) \\
\hline Shiga toxin & E.coli (STEC) & Stx2 & $\begin{array}{l}\text { semi- } \\
\text { synthetic }\end{array}$ & Fab & human & ELISA, WB, in vitro neutralization & (Luz et al., 2015) \\
\hline Shiga toxin & E.coli (EHEC) & Stx1, Stx2 & naïve & scFv & human & $\begin{array}{l}\text { ELISA, FACS, in vitro toxin } \\
\text { neutralization }\end{array}$ & (Neri et al., 2011) \\
\hline Shiga toxin & E.coli (STEC) & Stx1, Stx2 & immune & $\mathrm{VHH}$ & alpaca & $\begin{array}{l}\text { ELISA, in vitro toxin inhibition, in } \\
\text { vivo protection }\end{array}$ & $\begin{array}{l}\text { (Tremblay et al., } \\
\text { 2013) }\end{array}$ \\
\hline Shiga toxin & E.coli (STEC) & Stx2e & immune & $\mathrm{VHH}$ & llama & ELISA, in vitro neutralization & $\begin{array}{l}\text { (Lo A. W. H. et al., } \\
\text { 2014) }\end{array}$ \\
\hline $\begin{array}{l}\text { Staphylococcus } \\
\text { enterotoxin B }\end{array}$ & $\begin{array}{l}\text { Staphylococcus } \\
\text { aureus }\end{array}$ & SEB & immune & ScFv & mice & ELISA & (Singh et al., 2010) \\
\hline $\begin{array}{l}\text { Staphylococcus } \\
\text { enterotoxin B }\end{array}$ & $\begin{array}{l}\text { Staphylococcus } \\
\text { aureus }\end{array}$ & SEB & synthetic & Fab & human & $\begin{array}{l}\text { ELISA, WB, in vitro toxin } \\
\text { inhibition }\end{array}$ & (Larkin et al., 2010) \\
\hline $\begin{array}{l}\text { Staphylococcus } \\
\text { enterotoxin B }\end{array}$ & $\begin{array}{l}\text { Staphylococcus } \\
\text { aureus }\end{array}$ & SEB & synthetic & Fab, lgG & human & ELISA, in vivo protection & (Chen et al., 2019) \\
\hline $\begin{array}{l}\text { Staphylococcus } \\
\text { enterotoxin B }\end{array}$ & $\begin{array}{l}\text { Staphylococcus } \\
\text { aureus }\end{array}$ & SEB & naïve & $\begin{array}{l}\text { VHH, VHH- } \\
\text { alkaline } \\
\text { phosphatase } \\
\text { fusion }\end{array}$ & camel & $\begin{array}{l}\text { ELISA, chemiluminescent } \\
\text { immunoassay }\end{array}$ & (Sun T. et al., 2020) \\
\hline $\begin{array}{l}\text { Staphylococcus } \\
\text { enterotoxin B }\end{array}$ & $\begin{array}{l}\text { Staphylococcus } \\
\text { aureus }\end{array}$ & SEB & immune & $\mathrm{VHH}$ & camel & ELISA & $\begin{array}{l}\text { (Zanganeh et al., } \\
\text { 2019) }\end{array}$ \\
\hline
\end{tabular}


TABLE 4 | Continued

\begin{tabular}{|c|c|c|c|c|c|c|c|}
\hline Toxin & Species & Target & $\begin{array}{l}\text { library } \\
\text { type }\end{array}$ & $\begin{array}{l}\text { Antibody } \\
\text { Format }\end{array}$ & $\begin{array}{l}\text { Antibody } \\
\text { Origin }\end{array}$ & Application & Reference \\
\hline $\begin{array}{l}\text { Tetanus } \\
\text { neurotoxin }\end{array}$ & Clostridium tetani & tetantus toxoid & immune & $\mathrm{Fab}$ & macaque & ELISA & $\begin{array}{l}\text { (Chassagne et al., } \\
\text { 2004) }\end{array}$ \\
\hline $\begin{array}{l}\text { Tetanus } \\
\text { neurotoxin }\end{array}$ & Clostridium tetani & tetantus toxoid & naïve & scFv & human & ELISA, in vitro toxin inhibition & $\begin{array}{l}\text { (Indrawattana et al., } \\
\text { 2010) }\end{array}$ \\
\hline $\begin{array}{l}\text { Tetanus } \\
\text { neurotoxin }\end{array}$ & Clostridium tetani & TeNT heavy chain & immune & scFv, IgG & human & $\begin{array}{l}\text { ELISA, immunofluorescence, in } \\
\text { vitro inhibition }\end{array}$ & $\begin{array}{l}\text { (Wang H. et al., } \\
\text { 2016) }\end{array}$ \\
\hline $\begin{array}{l}\text { Tetanus } \\
\text { neurotoxin }\end{array}$ & Clostridium tetani & $\begin{array}{l}\text { tetanus neurotoxin } \\
(\text { TeNT) }\end{array}$ & immune & scFv & human & in vitro inhibition & (Khalili et al., 2015) \\
\hline $\begin{array}{l}\text { Tetanus } \\
\text { neurotoxin }\end{array}$ & Clostridium tetani & tetantus toxoid & naïve & $\mathrm{Fab}$ & human & ELISA, in vitro neutralization & $\begin{array}{l}\text { (Neelakantam et al., } \\
\text { 2014) }\end{array}$ \\
\hline $\begin{array}{l}\text { Tetanus } \\
\text { neurotoxin }\end{array}$ & Clostridium tetani & TeNT & Immune & ScFv, IgG & human & ELISA & $\begin{array}{l}\text { (Sadreddini et al., } \\
\text { 2015) }\end{array}$ \\
\hline $\begin{array}{l}\text { Toxic shock } \\
\text { syndrome toxin-1 }\end{array}$ & $\begin{array}{l}\text { Staphylococcus } \\
\text { aureus }\end{array}$ & TSST-1 & naïve & scFv & human & $\begin{array}{l}\text { T-cell activation assay, } \\
\text { interleukine gene expression }\end{array}$ & $\begin{array}{l}\text { (Rukkawattanakul } \\
\text { et al., 2017) }\end{array}$ \\
\hline $\begin{array}{l}\text { Vacuolating } \\
\text { cytotoxin A }\end{array}$ & $\begin{array}{l}\text { Helicobacter } \\
\text { pylori }\end{array}$ & p55 domain of VacA & $\begin{array}{l}\text { semi- } \\
\text { synthetic }\end{array}$ & ScFv & human & ELISA, WB, FACS & (Fahimi et al., 2018) \\
\hline $\begin{array}{l}\text { Vibrio } \\
\text { parahaemolyticus } \\
\text { hemolysin }\end{array}$ & $\begin{array}{l}\text { Vibrio } \\
\text { parahaemolyticus }\end{array}$ & $\mathrm{TLH}$ & immune & ScFv & mice & $\begin{array}{l}\text { ELISA, FACS, in vitro } \\
\text { neutralization }\end{array}$ & $\begin{array}{l}\text { (Wang R. et al., } \\
\text { 2012) }\end{array}$ \\
\hline $\begin{array}{l}\text { Vibrio vulnificus } \\
\text { toxin }\end{array}$ & Vibrio vulnificus & VvRtxA & $\begin{array}{l}\text { semi- } \\
\text { synthetic }\end{array}$ & scFv & human & ELISA, in vitro toxin inhibition, IF & (Hsu et al., 2011) \\
\hline
\end{tabular}

ELISA, enzyme linked immunosorbent assays; MS, mass spectrometry; WB, western blot.

sources: immune or universal libraries. Immune libraries are preferred when convalescent patients or immunized animals/ human donors are available. This approach offers the advantage to directly isolate affinity matured antibodies. Universal antibody gene libraries offer an alternative if immunization is not possible, ethically not feasible or patient samples are not available.

The COVID-19 pandemic should teach us to be prepared for the next pandemic, which beyond any doubt will come. We need permanent preparedness platforms which will react on novel pathogens arising worldwide and provide antibodies for diagnostics and as potential therapeutic lead candidates. This preparedness platforms should also have a budget for immediate start of GMP production and clinical phase I/II studies. In the most cases, new pathogens may have only a local impact, but this cannot be assured. Also these antibodies are always valuable tools for research and diagnostics of the pathogens.

We do not build a fire department when the house is already burning, we need to establish it in advance and maintain this service also in times without emergency. We have to think in the same way about infectious diseases and potential pandemics.

\section{REFERENCES}

Adams, G. P., and Weiner, L. M. (2005). Monoclonal Antibody Therapy of Cancer. Nat. Biotechnol. 23, 1147-1157. doi: 10.1038/nbt1137

Ahn, B.-E., Bae, H.-W., Lee, H.-R., Woo, S.-J., Park, O.-K., Jeon, J. H., et al. (2019). A Therapeutic Human Antibody Against the Domain 4 of the Bacillus Anthracis Protective Antigen Shows Protective Efficacy in a Mouse Model. Biochem. Biophys. Res. Commun. 509, 611-616. doi: 10.1016/j.bbrc.2018.12.146

Akter, S., Vehniäinen, M., Kankaanpää, H. T., and Lamminmäki, U. (2017). Rapid and Highly Sensitive Non-Competitive Immunoassay for Specific Detection of Nodularin. Microorganisms 5. doi: 10.3390/microorganisms5030058

\section{AUTHOR CONTRIBUTIONS}

All authors listed have made a substantial, direct, and intellectual contribution to the work, and approved it for publication.

\section{FUNDING}

We acknowledge funding from the European Community's Seventh Framework Program (FP7/2007-2013) under agreement no. 241832 granted to the AntiBotABE project (http://www.antibotabe.com) and funding received from the European Union's Horizon 2020 research and innovation programme under grant agreement No 101003650, funding from Federal State of Lower Saxony, Niedersächsisches Vorab (VWZN2889) and financial support of MWK Niedersachsen (14-76103-184 CORONA-2/20). We thank CNPq for supporting the scholarship of GMSGM. This review is an updated and revised version of a formerly published review (Kuhn et al., 2016).

Alam, M. K., Zheng, L., Liu, R., Papagerakis, S., Papagerakis, P., and Geyer, C. R. (2018). Synthetic Antigen-Binding Fragments (Fabs) Against S. Mutans and S. Sobrinus Inhibit Caries Formation. Sci. Rep. 8, 10173. doi: 10.1038/s41598-018-28240-0

Alibeiki, M., Golchin, M., and Tabatabaei, M. (2020). Development of a DoubleRecombinant Antibody Sandwich ELISA for Quantitative Detection of Epsilon Toxoid Concentration in Inactivated Clostridium Perfringens Vaccines. BMC Vet. Res. 16, 361. doi: 10.1186/s12917-020-02572-4

Almagro, J. C., and Fransson, J. (2008). Humanization of Antibodies. Front. Biosci. J. Virtual Libr. 13, 1619-1633.

Alonso-Ruiz, A., Pijoan, J. I., Ansuategui, E., Urkaregi, A., Calabozo, M., and Quintana, A. (2008). Tumor Necrosis Factor Alpha Drugs in Rheumatoid 
Arthritis: Systematic Review and Metaanalysis of Efficacy and Safety. $B M C$ Musculoskelet. Disord. 9, 52. doi: 10.1186/1471-2474-9-522

Amaro, I., Riaño-Umbarila, L., Becerril, B., and Possani, L. D. (2011). Isolation and Characterization of a Human Antibody Fragment Specific for Ts1 Toxin From Tityus Serrulatus Scorpion. Immunol. Lett. 139, 73-79. doi: 10.1016/ j.imlet.2011.05.002

Amatya, P., Wagner, N., Chen, G., Luthra, P., Shi, L., Borek, D., et al. (2019). Inhibition of Marburg Virus RNA Synthesis by a Synthetic Anti-VP35 Antibody. ACS Infect. Dis. 5, 1385-1396. doi: 10.1021/acsinfecdis.9b00091

Amersdorfer, P., Wong, C., Chen, S., Smith, T., Deshpande, S., Sheridan, R., et al. (1997). Molecular Characterization of Murine Humoral Immune Response to Botulinum Neurotoxin Type A Binding Domain as Assessed by Using Phage Antibody Libraries. Infect. Immun. 65, 3743-3752. doi: 10.1128/iai.65.9.37433752.1997

Amersdorfer, P., Wong, C., Smith, T., Chen, S., Deshpande, S., Sheridan, R., et al. (2002). Genetic and Immunological Comparison of Anti-Botulinum Type A Antibodies From Immune and non-Immune Human Phage Libraries. Vaccine 20, 1640-1648. doi: 10.1016/S0264-410X(01)00482-0

Anderson, G. P., Shriver-Lake, L. C., Walper, S. A., Ashford, L., Zabetakis, D., Liu, J. L., et al. (2018). Genetic Fusion of an Anti-BclA Single-Domain Antibody With Beta Galactosidase. Antibodies Basel Switz 7. doi: 10.3390/antib7040036

Arakawa, M., Yamashiro, T., Uechi, G., Tadano, M., and Nishizono, A. (2007). Construction of Human Fab (Gammal/Kappa) Library and Identification of Human Monoclonal Fab Possessing Neutralizing Potency Against Japanese Encephalitis Virus. Microbiol. Immunol. 51, 617-625. doi: 10.1111/j.13480421.2007.tb03948.x

Arnon, S. S., Schechter, R., Inglesby, T. V., Henderson, D. A., Bartlett, J. G., Ascher, M. S., et al. (2001). Botulinum Toxin as a Biological Weapon: Medical and Public Health Management. JAMA J. Am. Med. Assoc. 285, 1059-1070. doi: 10.1001/jama.285.8.1059

Arola, H. O., Tullila, A., Kiljunen, H., Campbell, K., Siitari, H., and Nevanen, T. K. (2016). Specific Noncompetitive Immunoassay for HT-2 Mycotoxin Detection. Anal. Chem. 88, 2446-2452. doi: 10.1021/acs.analchem.5b04591

Ascione, A., Flego, M., Zamboni, S., De Cinti, E., Dupuis, M. L., and Cianfriglia, M. (2004). Isolation and Characterization of the Human Monoclonal Antibodies C10 in Single-Chain Fragment Variable (scFv) Format to Glucose Oxidase From Aspergillus Niger. Hybrid. Hybridomics 23, 380-384. doi: 10.1089/hyb.2004.23.380

Audran, R., Cachat, M., Lurati, F., Soe, S., Leroy, O., Corradin, G., et al. (2005). Phase I Malaria Vaccine Trial With a Long Synthetic Peptide Derived From the Merozoite Surface Protein 3 Antigen. Infect. Immun. 73, 8017-8026. doi: 10.1128/IAI.73.12.8017-8026.2005

Avnir, Y., Tallarico, A. S., Zhu, Q., Bennett, A. S., Connelly, G., Sheehan, J., et al. (2014). Molecular Signatures of Hemagglutinin Stem-Directed Heterosubtypic Human Neutralizing Antibodies Against Influenza A Viruses. PLoS Pathog. 10, e1004103. doi: 10.1371/journal.ppat.1004103

Avril, A., Miethe, S., Popoff, M. R., Mazuet, C., Chahboun, S., Rasetti-Escargueil, C., et al. (2015). Isolation of Nanomolar Scfvs of non-Human Primate Origin, CrossNeutralizing Botulinum Neurotoxins A1 and A2 by Targeting Their Heavy Chain. BMC Biotechnol. 15, 86. doi: 10.1186/s12896-015-0206-0

Ayriss, J., Woods, T., Bradbury, A., and Pavlik, P. (2007). High-Throughput Screening of Single-Chain Antibodies Using Multiplexed Flow Cytometry. J. Proteome Res. 6, 1072-1082. doi: 10.1021/pr0604108

Babcock, G. J., Broering, T. J., Hernandez, H. J., Mandell, R. B., Donahue, K., Boatright, N., et al. (2006). Human Monoclonal Antibodies Directed Against Toxins A and B Prevent Clostridium Difficile-Induced Mortality in Hamsters. Infect. Immun. 74, 6339-6347. doi: 10.1128/IAI.00982-06

Bakherad, H., Mousavi Gargari, S. L., Rasooli, I., Rajabibazl, M., Mohammadi, M., Ebrahimizadeh, W., et al. (2013). In Vivo Neutralization of Botulinum Neurotoxins Serotype E With Heavy-Chain Camelid Antibodies (VHH). Mol. Biotechnol. 55, 159-167. doi: 10.1007/s12033-013-9669-1

Bakker, A. B. H., Marissen, W. E., Kramer, R. A., Rice, A. B., Weldon, W. C., Niezgoda, M., et al. (2005). Novel Human Monoclonal Antibody Combination Effectively Neutralizing Natural Rabies Virus Variants and Individual In Vitro Escape Mutants. J. Virol. 79, 9062-9068. doi: 10.1128/JVI.79.14.9062-9068.2005

Bakker, A. B. H., Python, C., Kissling, C. J., Pandya, P., Marissen, W. E., Brink, M. F., et al. (2008). First Administration to Humans of a Monoclonal Antibody Cocktail Against Rabies Virus: Safety, Tolerability, and Neutralizing Activity. Vaccine 26, 5922-5927. doi: 10.1016/j.vaccine.2008.08.050
Bao, F., Wang, L., Zhao, X., Lu, T., Na, A. M., Wang, X., et al. (2019). Preparation and Characterization of a Single-Domain Antibody Specific for the Porcine Epidemic Diarrhea Virus Spike Protein. AMB Express 9, 104. doi: 10.1186/ s13568-019-0834-1

Barash, J. R., and Arnon, S. S. (2014). A Novel Strain of Clostridium Botulinum That Produces Type B and Type H Botulinum Toxins. J. Infect. Dis. 209, 183191. doi: 10.1093/infdis/jit449

Barban, V., Fraysse-Corgier, S., Paranhos-Baccala, G., Petit, M., Manin, C., Berard, Y., et al. (2000). Identification of a Human Epitope in Hepatitis C Virus (HCV) Core Protein Using a Molecularly Cloned Antibody Repertoire From a NonSymptomatic, Anti-HCV-Positive Patient. J. Gen. Virol. 81, 461-469. doi: 10.1099/0022-1317-81-2-461

Barbas, C. F., Kang, A. S., Lerner, R. A., and Benkovic, S. J. (1991). Assembly of Combinatorial Antibody Libraries on Phage Surfaces: The Gene III Site. Proc. Natl. Acad. Sci. U. S. A. 88, 7978-7982. doi: 10.1073/pnas.88.18.7978

Bartlett, J. G., Chang, T. W., Gurwith, M., Gorbach, S. L., and Onderdonk, A. B. (1978). Antibiotic-Associated Pseudomembranous Colitis Due to Toxin-Producing Clostridia. N. Engl. J. Med. 298, 531-534. doi: 10.1056/NEJM197803092981003

Baum, A., Fulton, B. O., Wloga, E., Copin, R., Pascal, K. E., Russo, V., et al. (2020). Antibody Cocktail to SARS-CoV-2 Spike Protein Prevents Rapid Mutational Escape Seen With Individual Antibodies. Science 369, 1014-1018. doi: 10.1126/ science.abd0831

Beccari, M. V., Mogle, B. T., Sidman, E. F., Mastro, K. A., Asiago-Reddy, E., and Kufel, W. D. (2019). Ibalizumab, A Novel Monoclonal Antibody for the Management of Multidrug-Resistant HIV-1 Infection. Antimicrob. Agents Chemother. 63. doi: 10.1128/AAC.00110-19

Berger, S., Hinz, D., Bannantine, J. P., and Griffin, J. F. T. (2006). Isolation of HighAffinity Single-Chain Antibodies Against Mycobacterium Avium Subsp. Paratuberculosis Surface Proteins From Sheep With Johne's Disease. Clin. Vaccine Immunol. CVI 13, 1022-1029. doi: 10.1128/CVI.00163-06

Berhanu, A., Wilson, R. L., Kirkwood-Watts, D. L., King, D. S., Warren, T. K., Lund, S. A., et al. (2008). Vaccination of BALB/c Mice With Escherichia Coli-Expressed Vaccinia Virus Proteins A27L, B5R, and D8L Protects Mice From Lethal Vaccinia Virus Challenge. J. Virol. 82, 3517-3529. doi: 10.1128/JVI.01854-07

Bertoglio, F., Fühner, V., Ruschig, M., Heine, P. A., Abasi, L., Klünemann, T., et al. (2021a). A SARS-CoV-2 Neutralizing Antibody Selected From COVID-19 Patients by Phage Display Is Binding to the ACE2-RBD Interface and Is Tolerant to Most Known Recently Emerging RBD Mutations. bioRxiv 2020. doi: 10.1101/2020.12.03.409318

Bertoglio, F., Meier, D., Langreder, N., Steinke, S., Rand, U., Simonelli, L., et al. (2021b). SARS-CoV-2 Neutralizing Human Recombinant Antibodies Selected From Pre-Pandemic Healthy Donors Binding at RBD-ACE2 Interface. Nat. Commun. 12, 1577. doi: 10.1038/s41467-021-21609-2

Besse, N. G., Barre, L., Buhariwalla, C., Vignaud, M. L., Khamissi, E., Decourseulles, E., et al. (2010). The Overgrowth of Listeria Monocytogenes by Other Listeria Spp. In Food Samples Undergoing Enrichment Cultivation has a Nutritional Basis. Int. J. Food Microbiol. 136, 345-351. doi: 10.1016/ j.ijfoodmicro.2009.10.025

Björling, E., von Garrelts, E., Mörner, A., Ehnlund, M., and Persson, M. A. (1999). Human Neutralizing Human Immunodeficiency Virus Type 2-Specific Fab Molecules Generated by Phage Display. J. Gen. Virol. 80 (Pt 8), 1987-1993. doi: 10.1099/0022-1317-80-8-1987

Bliss, J. M., Sullivan, M. A., Malone, J., and Haidaris, C. G. (2003). Differentiation of Candida Albicans and Candida Dubliniensis by Using Recombinant Human Antibody Single-Chain Variable Fragments Specific for Hyphae. J. Clin. Microbiol. 41, 1152-1160. doi: 10.1128/JCM.41.3.1152-1160.2003

Boel, E., Bootsma, H., de Kruif, J., Jansze, M., Klingman, K. L., van Dijk, H., et al. (1998). Phage Antibodies Obtained by Competitive Selection on ComplementResistant Moraxella (Branhamella) Catarrhalis Recognize the High-MolecularWeight Outer Membrane Protein. Infect. Immun. 66, 83-88. doi: 10.1128/ IAI.66.1.83-88.1998

Bonaparte, M. I., Dimitrov, A. S., Bossart, K. N., Crameri, G., Mungall, B. A., Bishop, K. A., et al. (2005). Ephrin-B2 Ligand Is a Functional Receptor for Hendra Virus and Nipah Virus. Proc. Natl. Acad. Sci. U. S. A. 102, 1065210657. doi: $10.1073 /$ pnas. 0504887102

Boruah, B. M., Liu, D., Ye, D., Gu, T.-J., Jiang, C.-L., Qu, M., et al. (2013). Single Domain Antibody Multimers Confer Protection Against Rabies Infection. PLoS One 8, e71383. doi: 10.1371/journal.pone.0071383 
Bossart, K. N., Geisbert, T. W., Feldmann, H., Zhu, Z., Feldmann, F., Geisbert, J. B., et al. (2011). A Neutralizing Human Monoclonal Antibody Protects African Green Monkeys From Hendra Virus Challenge. Sci. Transl. Med. 3105ra103. doi: 10.1126/scitranslmed.3002901

Bossart, K. N., Zhu, Z., Middleton, D., Klippel, J., Crameri, G., Bingham, J., et al. (2009). A Neutralizing Human Monoclonal Antibody Protects Against Lethal Disease in a New Ferret Model of Acute Nipah Virus Infection. PLoS Pathog. 5, e1000642. doi: 10.1371/journal.ppat.1000642

Boulter-Bitzer, J. I., Lee, H., and Trevors, J. T. (2009). Single-Chain Variable Fragment Antibodies Selected by Phage Display Against the Sporozoite Surface Antigen P23 Of Cryptosporidium Parvum. J. Parasitol. 95, 75-81. doi: 10.1645/ GE-1634.1

Boulter-Bitzer, J. I., Lee, H., and Trevors, J. T. (2010). Single Chain Variable Fragment Antibodies Selected by Phage Display Against the Sporozoite Surface Antigen S16 of Cryptosporidium Parvum. Exp. Parasitol. 125, 124-129. doi: 10.1016/j.exppara.2010.01.001

Bracken, C. J., Lim, S. A., Solomon, P., Rettko, N. J., Nguyen, D. P., Zha, B. S., et al. (2021). Bi-Paratopic and Multivalent VH Domains Block ACE2 Binding and Neutralize SARS-CoV-2. Nat. Chem. Biol. 17, 113-121. doi: 10.1038/s41589020-00679-1

Bradbury, A. R. M., Trinklein, N. D., Thie, H., Wilkinson, I. C., Tandon, A. K., Anderson, S., et al. (2018). When Monoclonal Antibodies are Not Monospecific: Hybridomas Frequently Express Additional Functional Variable Regions. $m A b s$ 10, 539-546. doi: 10.1080/19420862.2018.1445456

Breitling, F., Dübel, S., Seehaus, T., Klewinghaus, I., and Little, M. (1991). A Surface Expression Vector for Antibody Screening. Gene 104, 147-153. doi: 10.1016/0378-1119(91)90244-6

Briggs, D. J. (2012). The Role of Vaccination in Rabies Prevention. Curr. Opin. Virol. 2, 309-314. doi: 10.1016/j.coviro.2012.03.007

Broderick, L. S., Conces, D. J., Tarver, R. D., Bergmann, C. A., and Bisesi, M. A. (1996). Pulmonary Aspergillosis: A Spectrum of Disease. Crit. Rev. Diagn. Imaging 37, 491-531.

Burioni, R., Bugli, F., Mancini, N., Rosa, D., Di Campli, C., Moroncini, G., et al. (2001). Nonneutralizing Human Antibody Fragments Against Hepatitis C Virus E2 Glycoprotein Modulate Neutralization of Binding Activity of Human Recombinant Fabs. Virology 288, 29-35. doi: 10.1006/viro.2001.1014

Burioni, R., Williamson, R. A., Sanna, P. P., Bloom, F. E., and Burton, D. R. (1994). Recombinant Human Fab to Glycoprotein D Neutralizes Infectivity and Prevents Cell-to-Cell Transmission of Herpes Simplex Viruses 1 and 2 In Vitro. Proc. Natl. Acad. Sci. U. S. A. 91, 355-359. doi: 10.1073/pnas.91.1.355

Burke, C. W., Froude, J. W., Miethe, S., Hülseweh, B., Hust, M., and Glass, P. J. (2018). Human-Like Neutralizing Antibodies Protect Mice From Aerosol Exposure With Western Equine Encephalitis Virus. Viruses 10. doi: 10.3390/v10040147

Busch, C., Hofmann, F., Selzer, J., Munro, S., Jeckel, D., and Aktories, K. (1998). A Common Motif of Eukaryotic Glycosyltransferases is Essential for the Enzyme Activity of Large Clostridial Cytotoxins. J. Biol. Chem. 273, 19566-19572. doi: 10.1074/jbc.273.31.19566

Cabezas, S., Rojas, G., Pavon, A., Alvarez, M., Pupo, M., Guillen, G., et al. (2008). Selection of Phage-Displayed Human Antibody Fragments on Dengue Virus Particles Captured by a Monoclonal Antibody: Application to the Four Serotypes. J. Virol. Methods 147, 235-243. doi: 10.1016/j.jviromet.2007.09.001

Cattani, P., Rossolini, G. M., Cresti, S., Santangelo, R., Burton, D. R., Williamson, R. A., et al. (1997). Detection and Typing of Herpes Simplex Viruses by Using Recombinant Immunoglobulin Fragments Produced in Bacteria. J. Clin. Microbiol. 35, 1504-1509. doi: 10.1128/jcm.35.6.1504-1509.1997

Chahboun, S., Hust, M., Liu, Y., Pelat, T., Miethe, S., Helmsing, S., et al. (2011). Isolation of a Nanomolar scFv Inhibiting the Endopeptidase Activity of Botulinum Toxin A, by Single-Round Panning of an Immune PhageDisplayed Library of Macaque Origin. BMC Biotechnol. 11, 113. doi: 10. 1186/1472-6750-11-113

Chan, S. W., Bye, J. M., Jackson, P., and Allain, J. P. (1996). Human Recombinant Antibodies Specific for Hepatitis C Virus Core and Envelope E2 Peptides From an Immune Phage Display Library. J. Gen. Virol. 77 (Pt 10), 2531-2539. doi: 10.1099/0022-1317-77-10-2531

Chassagne, S., Laffly, E., Drouet, E., Hérodin, F., Lefranc, M.-P., and Thullier, P. (2004). A High-Affinity Macaque Antibody Fab With Human-Like Framework Regions Obtained From a Small Phage Display Immune Library. Mol. Immunol. 41, 539-546. doi: 10.1016/j.molimm.2004.03.040
Chatenoud, L., and Bluestone, J. A. (2007). CD3-Specific Antibodies: A Portal to the Treatment of Autoimmunity. Nat. Rev. Immunol. 7, 622-632. doi: 10.1038/ nri2 134

Chauvin, D., Hust, M., Schütte, M., Chesnay, A., Parent, C., Moreira, G. M. S. G., et al. (2019). Targeting Aspergillus Fumigatus Crf Transglycosylases With Neutralizing Antibody Is Relevant But Not Sufficient to Erase Fungal Burden in a Neutropenic Rat Model. Front. Microbiol. 10, 600. doi: 10.3389/ fmicb.2019.00600

Chen, Z., Chumakov, K., Dragunsky, E., Kouiavskaia, D., Makiya, M., Neverov, A., et al. (2011). Chimpanzee-Human Monoclonal Antibodies for Treatment of Chronic Poliovirus Excretors and Emergency Postexposure Prophylaxis. J. Virol. 85, 4354-4362. doi: 10.1128/JVI.02553-10

Chen, Z., Earl, P., Americo, J., Damon, I., Smith, S. K., Zhou, Y.-H., et al. (2006). Chimpanzee/human Mabs to Vaccinia Virus B5 Protein Neutralize Vaccinia and Smallpox Viruses and Protect Mice Against Vaccinia Virus. Proc. Natl. Acad. Sci. U. S. A. 103, 1882-1887. doi: 10.1073/pnas.0510598103

Chen, G., Gorelik, L., Simon, K. J., Pavlenco, A., Cheung, A., Brickelmaier, M., et al. (2015). Synthetic Antibodies and Peptides Recognizing Progressive Multifocal Leukoencephalopathy-Specific Point Mutations in Polyomavirus JC Capsid Viral Protein 1. $m A$ bs 7, 681-692. doi: 10.1080/19420862.2015.1038447

Chen, G., Karauzum, H., Long, H., Carranza, D., Holtsberg, F. W., Howell, K. A., et al. (2019). Potent Neutralization of Staphylococcal Enterotoxin B In Vivo by Antibodies That Block Binding to the T-Cell Receptor. J. Mol. Biol. 431, 43544367. doi: 10.1016/j.jmb.2019.03.017

Chen, P., Nirula, A., Heller, B., Gottlieb, R. L., Boscia, J., Morris, J., et al. (2021). SARS-CoV-2 Neutralizing Antibody LY-CoV555 in Outpatients With Covid19. N. Engl. J. Med. 384, 229-237. doi: 10.1056/NEJMoa2029849

Chen, Z., Ren, X., Yang, J., Dong, J., Xue, Y., Sun, L., et al. (2017). An Elaborate Landscape of the Human Antibody Repertoire Against Enterovirus 71 Infection Is Revealed by Phage Display Screening and Deep Sequencing. $m A$ bs 9, 342-349. doi: 10.1080/19420862.2016.1267086

Chen, Z., Sosnovtsev, S. V., Bok, K., Parra, G. I., Makiya, M., Agulto, L., et al. (2013). Development of Norwalk Virus-Specific Monoclonal Antibodies With Therapeutic Potential for the Treatment of Norwalk Virus Gastroenteritis. J. Virol. 87, 9547-9557. doi: 10.1128/JVI.01376-13

Chen, Z., Zhang, L., Tang, A., Callahan, C., Pristatsky, P., Swoyer, R., et al. (2016). Discovery and Characterization of Phage Display-Derived Human Monoclonal Antibodies Against RSV F Glycoprotein. PLoS One 11, e0156798. doi: 10.1371/ journal.pone.0156798

Cherry, J. D. (2004). The Chronology of the 2002-2003 SARS Mini Pandemic. Paediatr. Respir. Rev. 5, 262-269. doi: 10.1016/j.prrv.2004.07.009

Chi, X., Liu, X., Wang, C., Zhang, X., Li, X., Hou, J., et al. (2020). Humanized Single Domain Antibodies Neutralize SARS-CoV-2 by Targeting the Spike Receptor Binding Domain. Nat. Commun. 11, 4528. doi: 10.1038/s41467-02018387-8

Chiliza, T. E., Van Wyngaardt, W., and Du Plessis, D. H. (2008). Single-Chain Antibody Fragments From a Display Library Derived From Chickens Immunized With a Mixture of Parasite and Viral Antigens. Hybrid 27, 413 421. doi: 10.1089/hyb.2008.0051

Choudhry, V., Zhang, M.-Y., Sidorov, I. A., Louis, J. M., Harris, I., Dimitrov, A. S., et al. (2007). Cross-Reactive HIV-1 Neutralizing Monoclonal Antibodies Selected by Screening of an Immune Human Phage Library Against an Envelope Glycoprotein (Gp140) Isolated From a Patient (R2) With Broadly HIV-1 Neutralizing Antibodies. Virology 363, 79-90. doi: 10.1016/ j.virol.2007.01.015

Chung, W. Y., Sack, M., Carter, R., Spiegel, H., Fischer, R., Hirst, T. R., et al. (2008). Phage-Display Derived Single-Chain Fragment Variable (scFv) Antibodies Recognizing Conformational Epitopes of Escherichia Coli Heat-Labile Enterotoxin B-Subunit. J. Immunol. Methods 339, 115-123. doi: 10.1016/ j.jim.2008.08.005

Chung, S.-Y., Schöttelndreier, D., Tatge, H., Fühner, V., Hust, M., Beer, L.-A., et al. (2018). The Conserved Cys-2232 in Clostridioides Difficile Toxin B Modulates Receptor Binding. Front. Microbiol. 9, 2314. doi: 10.3389/fmicb.2018.02314

Clackson, T., Hoogenboom, H. R., Griffiths, A. D., and Winter, G. (1991). Making Antibody Fragments Using Phage Display Libraries. Nature 352, 624-628. doi: $10.1038 / 352624 \mathrm{a} 0$

Close, D. W., Ferrara, F., Dichosa, A. E. K., Kumar, S., Daughton, A. R., Daligault, H. E., et al. (2013). Using Phage Display Selected Antibodies to Dissect 
Microbiomes for Complete De Novo Genome Sequencing of Low Abundance Microbes. BMC Microbiol. 13, 270. doi: 10.1186/1471-2180-13-270

Cole, S. P., Campling, B. G., Atlaw, T., Kozbor, D., and Roder, J. C. (1984). Human Monoclonal Antibodies. Mol. Cell. Biochem. 62, 109-120. doi: 10.1007/ BF00223301

Colwill, K., and Gräslund, S. (2011). A Roadmap to Generate Renewable Protein Binders to the Human Proteome. Nat. Methods 8, 551-558. doi: 10.1038/ nmeth. 1607

Conway, J. O., Sherwood, L. J., Collazo, M. T., Garza, J. A., and Hayhurst, A. (2010). Llama Single Domain Antibodies Specific for the 7 Botulinum Neurotoxin Serotypes as Heptaplex Immunoreagents. PLoS One 5, e8818. doi: 10.1371/journal.pone.0008818

Corti, D., Misasi, J., Mulangu, S., Stanley, D. A., Kanekiyo, M., Wollen, S., et al. (2016). Protective Monotherapy Against Lethal Ebola Virus Infection by a Potently Neutralizing Antibody. Science 351, 1339-1342. doi: 10.1126/ science.aad5224

Costa, L. E., Alves, P. T., Carneiro, A. P., Dias, A. C. S., Fujimura, P. T., Araujo, G. R., et al. (2019). Leishmania Infantum $\beta$-Tubulin Identified by Reverse Engineering Technology Through Phage Display Applied as Theranostic Marker for Human Visceral Leishmaniasis. Int. J. Mol. Sci. 20. doi: 10.3390/ ijms 20081812

Courtenay-Luck, N. S., Epenetos, A. A., Moore, R., Larche, M., Pectasides, D., Dhokia, B., et al. (1986). Development of Primary and Secondary Immune Responses to Mouse Monoclonal Antibodies Used in the Diagnosis and Therapy of Malignant Neoplasms. Cancer Res. 46, 6489-6493.

Cox-Singh, J., Davis, T. M. E., Lee, K.-S., Shamsul, S. S. G., Matusop, A., Ratnam, S., et al. (2008). Plasmodium Knowlesi Malaria in Humans Is Widely Distributed and Potentially Life Threatening. Clin. Infect. Dis. 46, 165-171. doi: $10.1086 / 524888$

Crowcroft, N. S., and Thampi, N. (2015). The Prevention and Management of Rabies. BMJ 350, g7827. doi: 10.1136/bmj.g7827

Daffis, S., Kontermann, R. E., Korimbocus, J., Zeller, H., Klenk, H.-D., and Ter Meulen, J. (2005). Antibody Responses Against Wild-Type Yellow Fever Virus and the 17D Vaccine Strain: Characterization With Human Monoclonal Antibody Fragments and Neutralization Escape Variants. Virology 337, 262272. doi: 10.1016/j.virol.2005.04.031

da Silva, F. A., Li, M., Rato, S., Maia, S., Malhó, R., Warren, K., et al. (2012). Recombinant Rabbit Single-Chain Antibodies Bind to the Catalytic and CTerminal Domains of HIV-1 Integrase Protein and Strongly Inhibit HIV-1 Replication. Biotechnol. Appl. Biochem. 59, 353-366. doi: 10.1002/bab.1034

Datta, A., and Burall, L. (2018). Current Trends in Foodborne Human Listeriosis. Food Saf. Tokyo Jpn. 6, 1-6. doi: 10.14252/foodsafetyfscj.2017020

de Alwis, R., Smith, S. A., Olivarez, N. P., Messer, W. B., Huynh, J. P., Wahala, W. M. P. B., et al. (2012). Identification of Human Neutralizing Antibodies That Bind to Complex Epitopes on Dengue Virions. Proc. Natl. Acad. Sci. U. S. A. 109, 7439-7444. doi: 10.1073/pnas.1200566109

de Carvalho Nicacio, C., Lundkvist, A., Sjölander, K. B., Plyusnin, A., Salonen, E. M., and Björling, E. (2000). A Neutralizing Recombinant Human Antibody Fab Fragment Against Puumala Hantavirus. J. Med. Virol. 60, 446-454. doi: 10.1002/(SICI) 1096-9071(200004)60:4<446::AID-JMV13>3.0.CO;2-V

de Carvalho Nicacio, C., Williamson, R. A., Parren, P. W. H. I., Lundkvist, A., Burton, D. R., and Björling, E. (2002). Neutralizing Human Fab Fragments Against Measles Virus Recovered by Phage Display. J. Virol. 76, 251-258. doi: 10.1128/JVI.76.1.251-258.2002

Deckers, N., Saerens, D., Kanobana, K., Conrath, K., Victor, B., Wernery, U., et al. (2009). Nanobodies, a Promising Tool for Species-Specific Diagnosis of Taenia Solium Cysticercosis. Int. J. Parasitol. 39, 625-633. doi: 10.1016/j.ijpara. 2008.10.012

De Coninck, B., Verheesen, P., Vos, C. M., Van Daele, I., De Bolle, M. F., Vieira, J. V., et al. (2017). Fungal Glucosylceramide-Specific Camelid Single Domain Antibodies Are Characterized by Broad Spectrum Antifungal Activity. Front. Microbiol. 8, 1059. doi: 10.3389/fmicb.2017.01059

de Haard, H. J., van Neer, N., Reurs, A., Hufton, S. E., Roovers, R. C., Henderikx, P., et al. (1999). A Large non-Immunized Human Fab Fragment Phage Library That Permits Rapid Isolation and Kinetic Analysis of High Affinity Antibodies. J. Biol. Chem. 274, 18218-18230. doi: 10.1074/jbc.274.26.18218

Delfin-Riela, T., Rossotti, M., Alvez-Rosado, R., Leizagoyen, C., and GonzálezSapienza, G. (2020). Highly Sensitive Detection of Zika Virus Nonstructural
Protein 1 in Serum Samples by a Two-Site Nanobody ELISA. Biomolecules. 10 (12), 1652. doi: 10.3390/biom10121652

Dembek, Z. F., Smith, L. A., and Rusnak, J. M. (2007). Botulism: Cause, Effects, Diagnosis, Clinical and Laboratory Identification, and Treatment Modalities. Disaster Med. Public Health Prep. 1, 122-134. doi: 10.1097/DMP.0b013 e318158c5fd

Depestel, D. D., and Aronoff, D. M. (2013). Epidemiology of Clostridium Difficile Infection. J. Pharm. Pract. 26, 464-475. doi: 10.1177/0897190013499521

Derman, Y., Selby, K., Miethe, S., Frenzel, A., Liu, Y., Rasetti-Escargueil, C., et al. (2016). Neutralization of Botulinum Neurotoxin Type E by a Humanized Antibody. Toxins 8 (9), 257. doi: 10.3390/toxins 8090257

de Wildt, R. M., Mundy, C. R., Gorick, B. D., and Tomlinson, I. M. (2000). Antibody Arrays for High-Throughput Screening of Antibody-Antigen Interactions. Nat. Biotechnol. 18, 989-994. doi: 10.1038/79494

Dezorzová-Tomanová, K., Molinková, D., Pekarová, M., Celer, V., and Smola, J. (2007). Isolation of Lawsonia Intracellularis Specific Single-Chain Fv Antibody Fragments From Phage Display Library. Res. Vet. Sci. 83, 85-90. doi: 10.1016/ j.rvsc.2006.11.002

Dietzschold, B., Gore, M., Casali, P., Ueki, Y., Rupprecht, C. E., Notkins, A. L., et al. (1990). Biological Characterization of Human Monoclonal Antibodies to Rabies Virus. J. Virol. 64, 3087-3090. doi: 10.1128/jvi.64.6.3087-3090.1990

Dixon, P., Davies, P., Hollingworth, W., Stoddart, M., and MacGowan, A. (2015). A Systematic Review of Matrix-Assisted Laser Desorption/Ionisation Time-ofFlight Mass Spectrometry Compared to Routine Microbiological Methods for the Time Taken to Identify Microbial Organisms From Positive Blood Cultures. Eur. J. Clin. Microbiol. Infect. Dis. Off. Publ. Eur. Soc Clin. Microbiol. 34, 863-876. doi: 10.1007/s10096-015-2322-0

Dolgikh, V. V., Tsarev, A. A., Senderskiy, I. V., and Timofeev, S. A. (2017). Production of Single Chain Fragment Variable (Scfv) Antibody Against Paranosema Locustae Alpha/Beta-Hydrolase and Immunolocalization Of Microsporidian Enzyme in The Infected Host Cell. Tsitologiia 59, 298-305.

Dong, S., Bo, Z., Zhang, C., Feng, J., and Liu, X. (2018). Screening for Single-Chain Variable Fragment Antibodies Against Multiple Cry1 Toxins From an Immunized Mouse Phage Display Antibody Library. Appl. Microbiol. Biotechnol. 102, 3363-3374. doi: 10.1007/s00253-018-8797-8

Dong, J., Otsuki, T., Kato, T., and Park, E. Y. (2014). Tracking Neospora Caninum Parasites Using Chimera Monoclonal Antibodies Against Its Surface AntigenRelated Sequences (Rncsrs2). J. Biosci. Bioeng. 117, 351-357. doi: 10.1016/ j.jbiosc.2013.09.003

Dong, J., Sakurai, A., Nomura, N., Park, E. Y., Shibasaki, F., and Ueda, H. (2013). Isolation of Recombinant Phage Antibodies Targeting the Hemagglutinin Cleavage Site of Highly Pathogenic Avian Influenza Virus. PLoS One 8, e61158. doi: 10.1371/journal.pone.0061158

Duan, T., Ferguson, M., Yuan, L., Xu, F., and Li, G. (2009). Human Monoclonal Fab Antibodies Against West Nile Virus and its Neutralizing Activity Analyzed in Vitro and in Vivo. J. Antivir. Antiretrovir. 1, 36-42. doi: 10.4172/jaa.1000005

Duan, H., Ma, Z., Xu, L., Zhang, A., Li, Z., and Xiao, S. (2020). A Novel Intracellularly Expressed NS5B-Specific Nanobody Suppresses Bovine Viral Diarrhea Virus Replication. Vet. Microbiol. 240, 108449. doi: 10.1016/ j.vetmic.2019.108449

Dübel, S., Stoevesandt, O., Taussig, M. J., and Hust, M. (2010). Generating Recombinant Antibodies to the Complete Human Proteome. Trends Biotechnol. 28, 333-339. doi: 10.1016/j.tibtech.2010.05.001

Duggan, J. M., Coates, D. M., and Ulaeto, D. O. (2001). Isolation of Single-Chain Antibody Fragments Against Venezuelan Equine Encephalomyelitis Virus From Two Different Immune Sources. Viral Immunol. 14, 263-273. doi: $10.1089 / 088282401753266774$

Du, T., Zhu, G., Wu, X., Fang, J., and Zhou, E.-M. (2019). Biotinylated SingleDomain Antibody-Based Blocking ELISA for Detection of Antibodies Against Swine Influenza Virus. Int. J. Nanomed. 14, 9337-9349. doi: 10.2147/ IJN.S218458

Earl, P. L., Americo, J. L., Wyatt, L. S., Eller, L. A., Whitbeck, J. C., Cohen, G. H., et al. (2004). Immunogenicity of a Highly Attenuated MVA Smallpox Vaccine and Protection Against Monkeypox. Nature 428, 182-185. doi: 10.1038/nature02331

Ebrahimizadeh, W., Mousavi Gargari, S., Rajabibazl, M., Safaee Ardekani, L., Zare, H., and Bakherad, H. (2013). Isolation and Characterization of Protective Anti-LPS Nanobody Against V. Cholerae O1 Recognizing Inaba and Ogawa Serotypes. Appl. Microbiol. Biotechnol. 97, 4457-4466. doi: 10.1007/s00253-012-4518-x 
Egerer, M., Giesemann, T., Jank, T., Satchell, K. J. F., and Aktories, K. (2007). AutoCatalytic Cleavage of Clostridium Difficile Toxins A and B Depends on Cysteine Protease Activity. J. Biol. Chem. 282, 25314-25321. doi: 10.1074/jbc.M703062200

Fahimi, F., Sarhaddi, S., Fouladi, M., Samadi, N., Sadeghi, J., Golchin, A., et al. (2018). Phage Display-Derived Antibody Fragments Against Conserved Regions of VacA Toxin of Helicobacter Pylori. Appl. Microbiol. Biotechnol. 102, 6899-6913. doi: 10.1007/s00253-018-9068-4

Fatima, A., Wang, H., Kang, K., Xia, L., Wang, Y., Ye, W., et al. (2014). Development of VHH Antibodies Against Dengue Virus Type 2 NS1 and Comparison With Monoclonal Antibodies for Use in Immunological Diagnosis. PLoS One 9, e95263. doi: 10.1371/journal.pone.0095263

Fehrsen, J., van Wyngaardt, W., Mashau, C., Potgieter, A. C., Chaudhary, V. K., Gupta, A., et al. (2005). Serogroup-Reactive and Type-Specific Detection of Bluetongue Virus Antibodies Using Chicken Scfvs in Inhibition ELISAs. J. Virol. Methods 129, 31-39. doi: 10.1016/j.jviromet.2005.04.015

Ferrara, F., Naranjo, L. A., Kumar, S., Gaiotto, T., Mukundan, H., Swanson, B., et al. (2012). Using Phage and Yeast Display to Select Hundreds of Monoclonal Antibodies: Application to Antigen 85, a Tuberculosis Biomarker. PLoS One 7, e49535. doi: 10.1371/journal.pone.0049535

Fishwild, D. M., O’Donnell, S. L., Bengoechea, T., Hudson, D. V., Harding, F., Bernhard, S. L., et al. (1996). High-Avidity Human IgG Kappa Monoclonal Antibodies From a Novel Strain of Minilocus Transgenic Mice. Nat. Biotechnol. 14, 845-851. doi: 10.1038/nbt0796-845

Flego, M., Frau, A., Accardi, L., Mallano, A., Ascione, A., Gellini, M., et al. (2019). Intracellular Human Antibody Fragments Recognizing the VP35 Protein of Zaire Ebola Filovirus Inhibit the Protein Activity. BMC Biotechnol. 19, 64. doi: 10.1186/s12896-019-0554-2

Fong, R. H., Banik, S. S. R., Mattia, K., Barnes, T., Tucker, D., Liss, N., et al. (2014). Exposure of Epitope Residues on the Outer Face of the Chikungunya Virus Envelope Trimer Determines Antibody Neutralizing Efficacy. J. Virol. 88, 14364-14379. doi: 10.1128/JVI.01943-14

Foord, A. J., Muller, J. D., Yu, M., Wang, L.-F., and Heine, H. G. (2007). Production and Application of Recombinant Antibodies to Foot-and-Mouth Disease Virus Non-Structural Protein 3ABC. J. Immunol. Methods 321, 142151. doi: 10.1016/j.jim.2007.01.014

Fouladi, M., Sarhadi, S., Tohidkia, M., Fahimi, F., Samadi, N., Sadeghi, J., et al. (2019). Selection of a Fully Human Single Domain Antibody Specific to Helicobacter Pylori Urease. Appl. Microbiol. Biotechnol. 103, 3407-3420. doi: 10.1007/s00253-019-09674-6

Franka, R., Carson, W. C., Ellison, J. A., Taylor, S. T., Smith, T. G., Kuzmina, N. A., et al. (2017). In Vivo Efficacy of a Cocktail of Human Monoclonal Antibodies (CL184) Against Diverse North American Bat Rabies Virus Variants. Trop. Med. Infect. Dis. 2 (3), 48. doi: 10.3390/tropicalmed2030048

Frenzel, A., Kügler, J., Helmsing, S., Meier, D., Schirrmann, T., Hust, M., et al. (2017). Designing Human Antibodies by Phage Display. Transfus. Med. Hemother. 44, 312-318. doi: 10.1159/000479633

Frenzel, A., Kügler, J., Wilke, S., Schirrmann, T., and Hust, M. (2014). Construction of Human Antibody Gene Libraries and Selection of Antibodies by Phage Display. Methods Mol. Biol. Clifton N. J. 1060, 215-243. doi: 10.1007/978-1-62703-586-6_12

Froude, J. W., Herbert, A. S., Pelat, T., Miethe, S., Zak, S. E., Brannan, J. M., et al. (2018). Post-Exposure Protection in Mice Against Sudan Virus by a Two Antibody Cocktail. Viruses 10 (6), 286. doi: 10.3390/v10060286

Froude, J. W., Pelat, T., Miethe, S., Zak, S. E., Wec, A. Z., Chandran, K., et al. (2017). Generation and Characterization of Protective Antibodies to Marburg Virus. $m A$ Abs 9, 696-703. doi: 10.1080/19420862.2017.1299848

Froude, J. W., Stiles, B., Pelat, T., and Thullier, P. (2011). Antibodies for Biodefense. $m A b s$ 3, 517-527. doi: 10.4161/mabs.3.6.17621

Fuchs, M., Kämpfer, S., Helmsing, S., Spallek, R., Oehlmann, W., Prilop, W., et al. (2014). Novel Human Recombinant Antibodies Against Mycobacterium Tuberculosis Antigen 85B. BMC Biotechnol. 14, 68. doi: 10.1186/1472-6750-14-68

Fu, L. M., and Fu-Liu, C. S. (2002). Is Mycobacterium Tuberculosis a Closer Relative to Gram-Positive or Gram-Negative Bacterial Pathogens? Tuberc. Edinb. Scotl. 82, 85-90. doi: 10.1054/tube.2002.0328

Fühner, V., Heine, P. A., Helmsing, S., Goy, S., Heidepriem, J., Loeffler, F. F., et al. (2018). Development of Neutralizing and Non-Neutralizing Antibodies Targeting Known and Novel Epitopes of TcdB of Clostridioides Difficile. Front. Microbiol. 9, 3389. doi: 10.3389/fmicb.2018.02908
Fu, Y., Shearing, L. N., Haynes, S., Crewther, P., Tilley, L., Anders, R. F., et al. (1997). Isolation From Phage Display Libraries of Single Chain Variable Fragment Antibodies That Recognize Conformational Epitopes in the Malaria Vaccine Candidate, Apical Membrane Antigen-1. J. Biol. Chem. 272, 25678-25684. doi: 10.1074/jbc.272.41.25678

Gai, J., Ma, L., Li, G., Zhu, M., Qiao, P., Li, X., et al. (2021). A Potent Neutralizing Nanobody Against SARS-CoV-2 With Inhaled Delivery Potential. MedComm 2, 101-113. doi: $10.1002 / \mathrm{mco} 2.60$

Garaicoechea, L., Aguilar, A., Parra, G. I., Bok, M., Sosnovtsev, S. V., Canziani, G., et al. (2015). Llama Nanoantibodies With Therapeutic Potential Against Human Norovirus Diarrhea. PLoS One 10, e0133665. doi: 10.1371/ journal.pone.0133665

Gasanov, U., Hughes, D., and Hansbro, P. M. (2005). Methods for the Isolation and Identification of Listeria Spp. And Listeria Monocytogenes: A Review. FEMS Microbiol. Rev. 29, 851-875. doi: 10.1016/j.femsre.2004.12.002

Geisbert, T. W., Mire, C. E., Geisbert, J. B., Chan, Y.-P., Agans, K. N., Feldmann, F., et al. (2014). Therapeutic Treatment of Nipah Virus Infection in Nonhuman Primates With a Neutralizing Human Monoclonal Antibody. Sci. Transl. Med. 6, 242ra82. doi: 10.1126/scitranslmed.3008929

Gene, R. W., Kumaran, J., Aroche, C., van Faassen, H., Hall, J. C., MacKenzie, C. R., et al. (2015). High Affinity Anti-Internalin B VHH Antibody Fragments Isolated From Naturally and Artificially Immunized Repertoires. J. Immunol. Methods 416, 29-39. doi: 10.1016/j.jim.2014.10.009

Genisyuerek, S., Papatheodorou, P., Guttenberg, G., Schubert, R., Benz, R., and Aktories, K. (2011). Structural Determinants for Membrane Insertion, Pore Formation and Translocation of Clostridium Difficile Toxin B. Mol. Microbiol. 79, 1643-1654. doi: 10.1111/j.1365-2958.2011.07549.x

Gerstenbruch, S., Brooks, C. L., Kosma, P., Brade, L., Mackenzie, C. R., Evans, S. V., et al. (2010). Analysis of Cross-Reactive and Specific Anti-Carbohydrate Antibodies Against Lipopolysaccharide From Chlamydophila Psittaci. Glycobiology 20, 461-472. doi: 10.1093/glycob/cwp198

Ge, S., Xu, L., Li, B., Zhong, F., Liu, X., and Zhang, X. (2020). Canine Parvovirus Is Diagnosed and Neutralized by Chicken IgY-scFv Generated Against the Virus Capsid Protein. Vet. Res. 51, 110. doi: 10.1186/s13567-020-00832-7

Ghannam, A., Kumari, S., Muyldermans, S., and Abbady, A. Q. (2015). Camelid Nanobodies With High Affinity for Broad Bean Mottle Virus: A Possible Promising Tool to Immunomodulate Plant Resistance Against Viruses. Plant Mol. Biol. 87, 355-369. doi: 10.1007/s11103-015-0282-5

Glab-Ampai, K., Chulanetra, M., Malik, A. A., Juntadech, T., Thanongsaksrikul, J., Srimanote, P., et al. (2017). Human Single Chain-Transbodies That Bound to Domain-I of Non-Structural Protein 5A (NS5A) of Hepatitis C Virus. Sci. Rep. 7, 15042. doi: 10.1038/s41598-017-14886-9

Glamann, J., Burton, D. R., Parren, P. W., Ditzel, H. J., Kent, K. A., Arnold, C., et al. (1998). Simian Immunodeficiency Virus (SIV) Envelope-Specific Fabs With High-Level Homologous Neutralizing Activity: Recovery From a LongTerm-Nonprogressor SIV-Infected Macaque. J. Virol. 72, 585-592. doi: 10.1128/JVI.72.1.585-592.1998

Glanville, J., Zhai, W., Berka, J., Telman, D., Huerta, G., Mehta, G. R., et al. (2009). Precise Determination of the Diversity of a Combinatorial Antibody Library Gives Insight Into the Human Immunoglobulin Repertoire. Proc. Natl. Acad. Sci. U. S. A. 106, 20216-20221. doi: 10.1073/pnas.0909775106

Godakova, S. A., Noskov, A. N., Vinogradova, I. D., Ugriumova, G. A., Solovyev, A. I., Esmagambetov, I. B., et al. (2019). Camelid VHHs Fused to Human Fc Fragments Provide Long Term Protection Against Botulinum Neurotoxin A in Mice. Toxins 11. doi: 10.3390/toxins11080464

Gogtay, N. J., Munshi, R., Ashwath Narayana, D. H., Mahendra, B. J., Kshirsagar, V., Gunale, B., et al. (2018). Comparison of a Novel Human Rabies Monoclonal Antibody to Human Rabies Immunoglobulin for Postexposure Prophylaxis: A Phase 2/3, Randomized, Single-Blind, Noninferiority, Controlled Study. Clin. Infect. Dis. Off. Publ. Infect. Dis. Soc Am. 66, 387-395. doi: 10.1093/cid/cix791 Golden, A., Stevens, E. J., Yokobe, L., Faulx, D., Kalnoky, M., Peck, R., et al. (2016). A Recombinant Positive Control for Serology Diagnostic Tests Supporting Elimination of Onchocerca Volvulus. PLoS Negl. Trop. Dis. 10, e0004292. doi: 10.1371/journal.pntd.0004292

Goncalvez, A. P., Chien, C.-H., Tubthong, K., Gorshkova, I., Roll, C., Donau, O., et al. (2008). Humanized Monoclonal Antibodies Derived From Chimpanzee Fabs Protect Against Japanese Encephalitis Virus In Vitro and In Vivo. J. Virol. 82, 7009-7021. doi: 10.1128/JVI.00291-08 
Gong, X., Zhu, M., Li, G., Lu, X., and Wan, Y. (2016). Specific Determination of Influenza H7N2 Virus Based on Biotinylated Single-Domain Antibody From a PhageDisplayed Library. Anal. Biochem. 500, 66-72. doi: 10.1016/j.ab.2015.09.020

Goodchild, S. A., Dooley, H., Schoepp, R. J., Flajnik, M., and Lonsdale, S. G. (2011). Isolation and Characterisation of Ebolavirus-Specific Recombinant Antibody Fragments From Murine and Shark Immune Libraries. Mol. Immunol. 48, 2027-2037. doi: 10.1016/j.molimm.2011.06.437

Goudsmit, J., Marissen, W. E., Weldon, W. C., Niezgoda, M., Hanlon, C. A., Rice, A. B., et al. (2006). Comparison of an Anti-Rabies Human Monoclonal Antibody Combination With Human Polyclonal Anti-Rabies Immune Globulin. J. Infect. Dis. 193, 796-801. doi: 10.1086/500470

Gould, L. H., Sui, J., Foellmer, H., Oliphant, T., Wang, T., Ledizet, M., et al. (2005). Protective and Therapeutic Capacity of Human Single-Chain Fv-Fc Fusion Proteins Against West Nile Virus. J. Virol. 79, 14606-14613. doi: 10.1128/ JVI.79.23.14606-14613.2005

Griep, R. A., van Twisk, C., van Beckhoven, J. R., van der Wolf, J. M., and Schots, A. (1998). Development of Specific Recombinant Monoclonal Antibodies Against the Lipopolysaccharide of Ralstonia Solanacearum Race 3. Phytopathology 88, 795-803. doi: 10.1094/PHYTO.1998.88.8.795

Griffiths, A. D., Williams, S. C., Hartley, O., Tomlinson, I. M., Waterhouse, P., Crosby, W. L., et al. (1994). Isolation of High Affinity Human Antibodies Directly From Large Synthetic Repertoires. EMBO J. 13, 3245-3260. doi: 10.1002/j.1460-2075.1994.tb06626.x

Grilo, A. L., and Mantalaris, A. (2019). The Increasingly Human and Profitable Monoclonal Antibody Market. Trends Biotechnol. 37, 9-16. doi: 10.1016/ j.tibtech.2018.05.014

Grippo, V., Niborski, L. L., Gomez, K. A., and Levin, M. J. (2011). Human Recombinant Antibodies Against Trypanosoma Cruzi Ribosomal P2 $\beta$ Protein. Parasitology 138, 736-747. doi: 10.1017/S0031182011000175

Guan, Y., Zheng, B. J., He, Y. Q., Liu, X. L., Zhuang, Z. X., Cheung, C. L., et al. (2003). Isolation and Characterization of Viruses Related to the SARS Coronavirus From Animals in Southern China. Science 302, 276-278. doi: 10.1126/science.1087139

Gustchina, E., Louis, J. M., Lam, S. N., Bewley, C. A., and Clore, G. M. (2007). A Monoclonal Fab Derived From a Human Nonimmune Phage Library Reveals a New Epitope on Gp41 and Neutralizes Diverse Human Immunodeficiency Virus Type 1 Strains. J. Virol. 81, 12946-12953. doi: 10.1128/JVI.01260-07

Haidaris, C. G., Malone, J., Sherrill, L. A., Bliss, J. M., Gaspari, A. A., Insel, R. A., et al. (2001). Recombinant Human Antibody Single Chain Variable Fragments Reactive With Candida Albicans Surface Antigens. J. Immunol. Methods 257, 185-202. doi: 10.1016/S0022-1759(01)00463-X

Halpin, K., Hyatt, A. D., Fogarty, R., Middleton, D., Bingham, J., Epstein, J. H., et al. (2011). Pteropid Bats Are Confirmed as the Reservoir Hosts of Henipaviruses: A Comprehensive Experimental Study of Virus Transmission. Am. J. Trop. Med. Hyg. 85, 946-951. doi: 10.4269/ajtmh.2011.10-0567

Halstead, S. B. (2014). Dengue Antibody-Dependent Enhancement: Knowns and Unknowns. Microbiol. Spectr. 2. doi: 10.1128/microbiolspec.AID-0022-2014

Hamidon, N. H., Suraiya, S., Sarmiento, M. E., Acosta, A., Norazmi, M. N., and Lim, T. S. (2018). Immune TB Antibody Phage Display Library as a Tool To Study B Cell Immunity in TB Infections. Appl. Biochem. Biotechnol. 184, 852868. doi: 10.1007/s12010-017-2582-5

Hammond, P. W. (2010). Accessing the Human Repertoire for Broadly Neutralizing HIV Antibodies. mAbs 2, 157-164. doi: 10.4161/mabs.2.2.11301

Hansen, J., Baum, A., Pascal, K. E., Russo, V., Giordano, S., Wloga, E., et al. (2020). Studies in Humanized Mice and Convalescent Humans Yield a SARS-CoV-2 Antibody Cocktail. Science. doi: 10.1126/science.abd0827

Harmsen, M. M., Seago, J., Perez, E., Charleston, B., Eblé, P. L., and Dekker, A. (2017). Isolation of Single-Domain Antibody Fragments That Preferentially Detect Intact (146s) Particles of Foot-And-Mouth Disease Virus for Use in Vaccine Quality Control. Front. Immunol. 8, 3389. doi: 10.3389/fimmu. 2017.00960

Hayashi, N., Welschof, M., Zewe, M., Braunagel, M., Dübel, S., Breitling, F., et al. (1994). Simultaneous Mutagenesis of Antibody CDR Regions by Overlap Extension and PCR. BioTechniques 17310 312, 314-315.

Hayhurst, A., Happe, S., Mabry, R., Koch, Z., Iverson, B. L., and Georgiou, G. (2003). Isolation and Expression of Recombinant Antibody Fragments to the Biological Warfare Pathogen Brucella Melitensis. J. Immunol. Methods 276, 185-196. doi: 10.1016/S0022-1759(03)00100-5
He, L., Lin, X., de Val, N., Saye-Francisco, K. L., Mann, C. J., Augst, R., et al. (2017). Hidden Lineage Complexity of Glycan-Dependent HIV-1 Broadly Neutralizing Antibodies Uncovered by Digital Panning and Native-Like Gp140 Trimer. Front. Immunol. 8, 3389. doi: 10.3389/fimmu.2017.01025

Henderson, D. A., Inglesby, T. V., Bartlett, J. G., Ascher, M. S., Eitzen, E., Jahrling, P. B., et al. (1999). Smallpox as a Biological Weapon: Medical and Public Health Management. Working Group on Civilian Biodefense. JAMA 281, 2127-2137. doi: 10.1001/jama.281.22.2127

Henning, L. N., Carpenter, S., Stark, G. V., and Serbina, N. V. (2018). Development of Protective Immunity in New Zealand White Rabbits Challenged With Bacillus Anthracis Spores and Treated With Antibiotics and Obiltoxaximab, A Monoclonal Antibody Against Protective Antigen. Antimicrob. Agents Chemother. 62 (2), e01590-17. doi: 10.1128/AAC.01590-17

Herbert, A. S., Froude, J. W., Ortiz, R. A., Kuehne, A. I., Dorosky, D. E., Bakken, R. R., et al. (2020). Development of an Antibody Cocktail for Treatment of Sudan Virus Infection. Proc. Natl. Acad. Sci. U. S. A. 117, 3768-3778. doi: 10.1073/pnas.1914985117

He, T., Wang, Y., Li, P., Zhang, Q., Lei, J., Zhang, Z., et al. (2014). NanobodyBased Enzyme Immunoassay for Aflatoxin in Agro-Products With High Tolerance to Cosolvent Methanol. Anal. Chem. 86, 8873-8880. doi: 10.1021/ ac502390c

Higo-Moriguchi, K., Shirato, H., Someya, Y., Kurosawa, Y., Takeda, N., and Taniguchi, K. (2014). Isolation of Cross-Reactive Human Monoclonal Antibodies That Prevent Binding of Human Noroviruses to Histo-Blood Group Antigens. J. Med. Virol. 86, 558-567. doi: 10.1002/jmv.23734

Hirano, D., Ohshima, N., Kubota-Koketsu, R., Yamasaki, A., Kurosawa, G., Okuno, Y., et al. (2018). Three Types of Broadly Reacting Antibodies Against Influenza B Viruses Induced by Vaccination With Seasonal Influenza Viruses. J. Immunol. Res. 2018, 7251793. doi: 10.1155/2018/7251793

Hirose, Y., Matsuhira, S., Batanova, T. A., Goo, Y.-K., Terkawi, M. A., Nishikawa, Y., et al. (2009). Detection of Babesia Gibsoni by Reaction of Phage Display Single Chain Antibodies With P50 Proteins. J. Vet. Med. Sci. Jpn. Soc Vet. Sci. 71, 1133-1136. doi: 10.1292/jvms.71.1133

Hoet, R. M., Cohen, E. H., Kent, R. B., Rookey, K., Schoonbroodt, S., Hogan, S., et al. (2005). Generation of High-Affinity Human Antibodies by Combining Donor-Derived and Synthetic Complementarity-Determining-Region Diversity. Nat. Biotechnol. 23, 344-348. doi: 10.1038/nbt1067

Hoe, L.-N., Wan, K.-L., and Nathan, S. (2005). Construction and Characterization of Recombinant Single-Chain Variable Fragment Antibodies Against Toxoplasma Gondii MIC2 Protein. Parasitology 131, 759-768. doi: 10.1017/ S0031182005008450

Holt, L. J., Herring, C., Jespers, L. S., Woolven, B. P., and Tomlinson, I. M. (2003). Domain Antibodies: Proteins for Therapy. Trends Biotechnol. 21, 484-490. doi: 10.1016/j.tibtech.2003.08.007

Hosking, C. G., Driguez, P., McWilliam, H. E. G., Ilag, L. L., Gladman, S., Li, Y., et al. (2015a). Using the Local Immune Response From the Natural Buffalo Host to Generate an Antibody Fragment Library That Binds the Early Larval Stages of Schistosoma Japonicum. Int. J. Parasitol. 45, 729-740. doi: 10.1016/ j.ijpara.2015.05.002

Hosking, C. G., McWilliam, H. E. G., Driguez, P., Piedrafita, D., Li, Y., McManus, D. P., et al. (2015b). Generation of a Novel Bacteriophage Library Displaying scFv Antibody Fragments From the Natural Buffalo Host to Identify Antigens From Adult Schistosoma Japonicum for Diagnostic Development. PLoS Negl. Trop. Dis. 9, e0004280. doi: 10.1371/journal.pntd.0004280

Houimel, M. (2014). The Analysis of VH and VL Genes Repertoires of Fab Library Built From Peripheral B Cells of Human Rabies Virus Vaccinated Donors. Hum. Immunol. 75, 745-755. doi: 10.1016/j.humimm.2014.05.005

Hsu, F.-Y., Chou, L.-F., Hor, L.-I., and Chang, H.-Y. (2011). A Human SingleChain Variable Fragment Targeting to Vibrio Vulnificus RtxA Toxin. J. Microbiol. Methods 84, 94-100. doi: 10.1016/j.mimet.2010.11.006

Huang, W., Samanta, M., Crawford, S. E., Estes, M. K., Neill, F. H., Atmar, R. L., et al. (2014). Identification of Human Single-Chain Antibodies With Broad Reactivity for Noroviruses. Protein Eng. Des. Sel. PEDS 27, 339-349. doi: 10.1093/protein/gzu023

Hufton, S. E., Risley, P., Ball, C. R., Major, D., Engelhardt, O. G., and Poole, S. (2014). The Breadth of Cross Sub-Type Neutralisation Activity of a Single Domain Antibody to Influenza Hemagglutinin can be Increased by Antibody Valency. PLoS One 9, e103294. doi: 10.1371/journal.pone.0103294 
Hu, W.-G., Jager, S., Chau, D., Mah, D., and Nagata, L. P. (2010). Generation of a Recombinant Full-Length Human Antibody Binding to Botulinum Neurotoxin A. Appl. Biochem. Biotechnol. 160, 1206-1216. doi: 10.1007/s12010-009-8657-1

Hu, Z.-Q., Liu, J.-L., Li, H.-P., Xing, S., Xue, S., Zhang, J.-B., et al. (2012). Generation of a Highly Reactive Chicken-Derived Single-Chain Variable Fragment Against Fusarium Verticillioides by Phage Display. Int. J. Mol. Sci. 13, 7038-7056. doi: 10.3390/ijms 13067038

Hu, Z.-Q., Li, H.-P., Zhang, J.-B., Huang, T., Liu, J.-L., Xue, S., et al. (2013). A Phage-Displayed Chicken Single-Chain Antibody Fused to Alkaline Phosphatase Detects Fusarium Pathogens and Their Presence in Cereal Grains. Anal. Chim. Acta 764, 84-92. doi: 10.1016/j.aca.2012.12.022

Hülseweh, B., Rülker, T., Pelat, T., Langermann, C., Frenzel, A., Schirrmann, T., et al. (2014). Human-Like Antibodies Neutralizing Western Equine Encephalitis Virus. $m A b s$ 6, 717-726. doi: 10.4161/mabs.28170

Hunt, A. R., Frederickson, S., Maruyama, T., Roehrig, J. T., and Blair, C. D. (2010). The First Human Epitope Map of the Alphaviral E1 and E2 Proteins Reveals a New E2 Epitope With Significant Virus Neutralizing Activity. PLoS Negl. Trop. Dis. 4, e739. doi: 10.1371/journal.pntd.0000739

Hurwitz, A. M., Huang, W., Kou, B., Estes, M. K., Atmar, R. L., and Palzkill, T. (2017). Identification and Characterization of Single-Chain Antibodies That Specifically Bind GI Noroviruses. PLoS One 12, e0170162. doi: 10.1371/ journal.pone. 0170162

Hussack, G., Arbabi-Ghahroudi, M., van Faassen, H., Songer, J. G., Ng, K. K.-S., MacKenzie, R., et al. (2011). Neutralization of Clostridium Difficile Toxin A With Single-Domain Antibodies Targeting the Cell Receptor Binding Domain. J. Biol. Chem. 286, 8961-8976. doi: 10.1074/jbc.M110.198754

Hussein, A. H., Davis, E. M., Halperin, S. A., and Lee, S. F. (2007). Construction and Characterization of Single-Chain Variable Fragment Antibodies Directed Against the Bordetella Pertussis Surface Adhesins Filamentous Hemagglutinin and Pertactin. Infect. Immun. 75, 5476-5482. doi: 10.1128/IAI.00494-07

Hust, M., Maiss, E., Jacobsen, H.-J., and Reinard, T. (2002). The Production of a Genus-Specific Recombinant Antibody (scFv) Using a Recombinant Potyvirus Protease. J. Virol. Methods 106, 225-233. doi: 10.1016/S0166-0934(02)00166-0

Hust, M., Meyer, T., Voedisch, B., Rülker, T., Thie, H., El-Ghezal, A., et al. (2011). A Human scFv Antibody Generation Pipeline for Proteome Research. J. Biotechnol. 152, 159-170. doi: 10.1016/j.jbiotec.2010.09.945

Imam, M., Singh, S., Kaushik, N. K., and Chauhan, V. S. (2014). Plasmodium Falciparum Merozoite Surface Protein 3: Oligomerization, Self-Assembly, and Heme Complex Formation. J. Biol. Chem. 289, 3856-3868. doi: 10.1074/ jbc.M113.520239

Imamura, T. (2003). The Role of Gingipains in the Pathogenesis of Periodontal Disease. J. Periodontol. 74, 111-118. doi: 10.1902/jop.2003.74.1.111

Indrawattana, N., Sookrung, N., Kulkeaw, K., Seesuay, W., Kongngoen, T., Chongsa-nguan, M., et al. (2010). Human Monoclonal ScFv That Inhibits Cellular Entry and Metalloprotease Activity of Tetanus Neurotoxin. Asian Pac. J. Allergy Immunol. Launched Allergy Immunol. Soc. Thail. 28, 85-93.

Inglesby, T. V., O’Toole, T., Henderson, D. A., Bartlett, J. G., Ascher, M. S., Eitzen, E., et al. (2002). Anthrax as a Biological Weapo: Updated Recommendations for Management. JAMA J. Am. Med. Assoc. 287, 2236-2252. doi: 10.1001/ jama.287.17.2236

Ita, S., Agostinho, M. R., Sullivan, K., Yub Han, S., Akleh, R., Johnson, W. E., et al. (2017). Analysis of SIVmac Envelope-Specific Antibodies Selected Through Phage Display. AIDS Res. Hum. Retroviruses 33, 869-879. doi: 10.1089/AID.2016.0247

Jacobsen, A., Hendriksen, R. S., Aaresturp, F. M., Ussery, D. W., and Friis, C. (2011). The Salmonella Enterica Pan-Genome. Microb. Ecol. 62, 487-504. doi: 10.1007/s00248-011-9880-1

Jäger, V., Büssow, K., Wagner, A., Weber, S., Hust, M., Frenzel, A., et al. (2013). High Level Transient Production of Recombinant Antibodies and Antibody Fusion Proteins in HEK293 Cells. BMC Biotechnol. 13, 52. doi: 10.1186/1472-6750-13-52 Jakobovits, A. (1995). Production of Fully Human Antibodies by Transgenic Mice. Curr. Opin. Biotechnol. 6, 561-566. doi: 10.1016/0958-1669(95)80093-X

Jang, S., Kim, G., Oh, J., Lee, ,. S., Kim, D., Kim, K.-H., et al. (2017). Molecular Characterization of a Single-Chain Antibody Variable Fragment (scFv) Specific for PspA From Streptococcus Pneumoniae. Biochem. Biophys. Res. Commun. 482, 141-146. doi: 10.1016/j.bbrc.2016.10.150

Jiang, S., Zhang, X., Yang, Y., Hotez, P. J., and Du, L. (2020). Neutralizing Antibodies for the Treatment of COVID-19. Nat. Biomed. Eng. 4, 1134-1139. doi: 10.1038/s41551-020-00660-2
Jittavisutthikul, S., Seesuay, W., Thanongsaksrikul, J., Thueng-In, K., Srimanote, P., Werner, R. G., et al. (2016). Human Transbodies to HCV NS3/4A Protease Inhibit Viral Replication and Restore Host Innate Immunity. Front. Immunol. 7, 3389. doi: 10.3389/fimmu.2016.00318

Johnson, S., and Gerding, D. N. (2019). Bezlotoxumab. Clin. Infect. Dis. Off. Publ. Infect. Dis. Soc. Am. 68, 699-704. doi: 10.1093/cid/ciy577

Johnson, K. M., and Martin, D. H. (1974). Venezuelan Equine Encephalitis. Adv. Vet. Sci. Comp. Med. 18, 79-116.

Josewski, J., Buchmeier, S., Frenzel, A., Tinnefeld, P., Dübel, S., and Rau, U. (2017). Generation of Recombinant Antibodies Against the Beta-(1,6)-Branched Beta$(1,3)$-D-Glucan Schizophyllan From Immunized Mice via Phage Display. Biotechnol. Res. Int. 2017, 8791359. doi: 10.1155/2017/8791359

Just, I., Wilm, M., Selzer, J., Rex, G., von Eichel-Streiber, C., Mann, M., et al. (1995). The Enterotoxin From Clostridium Difficile (ToxA) Monoglucosylates the Rho Proteins. J. Biol. Chem. 270, 13932-13936. doi: 10.1074/jbc. 270.23.13932

Kandalaft, H., Hussack, G., Aubry, A., van Faassen, H., Guan, Y., ArbabiGhahroudi, M., et al. (2015). Targeting Surface-Layer Proteins With SingleDomain Antibodies: A Potential Therapeutic Approach Against Clostridium Difficile-Associated Disease. Appl. Microbiol. Biotechnol. 99, 8549-8562. doi: 10.1007/s00253-015-6594-1

Kandeil, A., Gomaa, M., Nageh, A., Shehata, M. M., Kayed, A. E., Sabir, J. S. M., et al. (2019). Middle East Respiratory Syndrome Coronavirus (MERS-CoV) in Dromedary Camels in Africa and Middle East. Viruses 11 (8), 717. doi: $10.3390 / \mathrm{v} 11080717$

Kang, X., Yang, B.-A., Hu, Y., Zhao, H., Xiong, W., Yang, Y., et al. (2006). Human Neutralizing Fab Molecules Against Severe Acute Respiratory Syndrome Coronavirus Generated by Phage Display. Clin. Vaccine Immunol. CVI 13, 953-957. doi: 10.1128/CVI.00037-06

Kaplon, H., and Reichert, J. M. (2021). Antibodies to Watch in 2021. mAbs 13, 1860476. doi: 10.1080/19420862.2020.1860476

Kawasaki, M., Echiverri, C., Raymond, L., Cadena, E., Reside, E., Gler, M. T., et al. (2019). Lipoarabinomannan in Sputum to Detect Bacterial Load and Treatment Response in Patients With Pulmonary Tuberculosis: Analytic Validation and Evaluation in Two Cohorts. PLoS Med. 16, e1002780. doi: 10.1371/journal.pmed.1002780

Keilman, L. J. (2019). Seasonal Influenza (Flu). Nurs. Clin. North Am. 54, 227-243. doi: 10.1016/j.cnur.2019.02.009

Khalili, E., Lakzaei, M., Rasaee, M. J., and Aminian, M. (2015). Production of Recombinant Human scFv Against Tetanus Toxin Heavy Chain by Phage Display Technology. Monoclon. Antibodies Immunodiagn. Immunother. 34, 303-309. doi: 10.1089/mab.2015.0020

Khlusevich, Y., Matveev, A., Baykov, I., Bulychev, L., Bormotov, N., Ilyichev, I., et al. (2018). Phage Display Antibodies Against Ectromelia Virus That Neutralize Variola Virus: Selection and Implementation for P35 Neutralizing Epitope Mapping. Antiviral Res. 152, 18-25. doi: 10.1016/j.antiviral.2018.02.006

Kim, D., Jang, S., Oh, J., Han, S., Park, S., Ghosh, P., et al. (2018). Molecular Characterization of Single-Chain Antibody Variable Fragments (scFv) Specific to Pep27 From Streptococcus Pneumoniae. Biochem. Biophys. Res. Commun. 501, 718-723. doi: 10.1016/j.bbrc.2018.05.054

Kim, H.-Y., Lee, J.-H., Kim, M. J., Park, S. C., Choi, M., Lee, W., et al. (2021). Development of a SARS-CoV-2-Specific Biosensor for Antigen Detection Using scFv-Fc Fusion Proteins. Biosens. Bioelectron. 175, 112868. doi: 10. 1016/j.bios.2020.112868

Kim, Y., Lee, H., Park, K., Park, S., Lim, J.-H., So, M. K., et al. (2019). Selection and Characterization of Monoclonal Antibodies Targeting Middle East Respiratory Syndrome Coronavirus Through a Human Synthetic Fab Phage Display Library Panning. Antibodies Basel Switz. 8 (3), 42. doi: 10.3390/antib8030042

Kirsch, M., Hülseweh, B., Nacke, C., Rülker, T., Schirrmann, T., Marschall, H.-J., et al. (2008). Development of Human Antibody Fragments Using Antibody Phage Display for the Detection and Diagnosis of Venezuelan Equine Encephalitis Virus (VEEV). BMC Biotechnol. 8, 66. doi: 10.1186/1472-6750-8-66

Knappik, A., Ge, L., Honegger, A., Pack, P., Fischer, M., Wellnhofer, G., et al. (2000). Fully Synthetic Human Combinatorial Antibody Libraries (HuCAL) Based on Modular Consensus Frameworks and CDRs Randomized With Trinucleotides. J. Mol. Biol. 296, 57-86. doi: 10.1006/jmbi.1999.3444

Koch, K., Kalusche, S., Torres, J. L., Stanfield, R. L., Danquah, W., Khazanehdari, K., et al. (2017). Selection of Nanobodies With Broad Neutralizing Potential Against 
Primary HIV-1 Strains Using Soluble Subtype C Gp140 Envelope Trimers. Sci. Rep. 7, 8390. doi: 10.1038/s41598-017-08273-7

Koch, J., Liang, M., Queitsch, I., Kraus, A. A., and Bautz, E. K. F. (2003). Human Recombinant Neutralizing Antibodies Against Hantaan Virus G2 Protein. Virology 308, 64-73. doi: 10.1016/s0042-6822(02)00094-6

Köhler, G., and Milstein, C. (1975). Continuous Cultures of Fused Cells Secreting Antibody of Predefined Specificity. Nature 256, 495-497. doi: 10.1038/ $256495 \mathrm{a} 0$

Kourea, H., and Kotoula, V. (2016). Towards Tumor Immunodiagnostics. Ann. Transl. Med. 4, 263. doi: 10.21037/atm.2016.07.07

Kramer, R. A., Marissen, W. E., Goudsmit, J., Visser, T. J., Clijsters-Van der Horst, M., Bakker, A. Q., et al. (2005). The Human Antibody Repertoire Specific for Rabies Virus Glycoprotein as Selected From Immune Libraries. Eur. J. Immunol. 35, 2131-2145. doi: 10.1002/eji.200526134

Krammer, F., and Palese, P. (2013). Influenza Virus Hemagglutinin Stalk-Based Antibodies and Vaccines. Curr. Opin. Virol. 3, 521-530. doi: 10.1016/ j.coviro.2013.07.007

Ksiazek, T. G., Erdman, D., Goldsmith, C. S., Zaki, S. R., Peret, T., Emery, S., et al. (2003). A Novel Coronavirus Associated With Severe Acute Respiratory Syndrome. N. Engl. J. Med. 348, 1953-1966. doi: 10.1056/NEJMoa030781

Kügler, J., Wilke, S., Meier, D., Tomszak, F., Frenzel, A., Schirrmann, T., et al. (2015). Generation and Analysis of the Improved Human HAL9/10 Antibody Phage Display Libraries. BMC Biotechnol. 15, 10. doi: 10.1186/s12896-015-0125-0

Kuhn, K. G., Falkenhorst, G., Ceper, T. H., Dalby, T., Ethelberg, S., Mølbak, K., et al. (2012). Detecting Non-Typhoid Salmonella in Humans by ELISAs: A Literature Review. J. Med. Microbiol. 61, 1-7. doi: 10.1099/jmm.0.034447-0

Kuhn, P., Fühner, V., Unkauf, T., Moreira, G. M. S. G., Frenzel, A., Miethe, S., et al. (2016). Recombinant Antibodies for Diagnostics and Therapy Against Pathogens and Toxins Generated by Phage Display. Proteomics Clin. Appl. 10, 922-948. doi: 10.1002/prca.201600002

Kuhn, P., Thiem, S., Steinert, M., Purvis, D., Lugmayr, V., Treutlein, U., et al. (2017). Human Anti-Lipopolysaccharid (LPS) Antibodies Against Legionella With High Species Specificity. Hum. Antibodies 26, 29-38. doi: 10.3233/HAB-170318

Kulkarni, A., Mochnáčová, E., Majerova, P., Čurlík, J., Bhide, K., Mertinková, P., et al. (2020). Single Domain Antibodies Targeting Receptor Binding Pockets of NadA Restrain Adhesion of Neisseria Meningitidis to Human Brain Microvascular Endothelial Cells. Front. Mol. Biosci. 7, 3389. doi: 10.3389/ fmolb.2020.573281

Kumar, N., and Carter, R. (1984). Biosynthesis of the Target Antigens of Antibodies Blocking Transmission of Plasmodium Falciparum. Mol. Biochem. Parasitol. 13, 333-342. doi: 10.1016/0166-6851(84)90124-5

Kumar, S., Kumar, R., Khan, L., Makhdoomi, M. A., Thiruvengadam, R., Mohata, M., et al. (2017). CD4-Binding Site Directed Cross-Neutralizing scFv Monoclonals From HIV-1 Subtype C Infected Indian Children. Front. Immunol. 8, 3389. doi: 10.3389/fimmu.2017.01568

Kummerfeldt, C. E. (2014). Raxibacumab: Potential Role in the Treatment of Inhalational Anthrax. Infect. Drug Resist. 7, 101-109. doi: 10.2147/IDR.S47305

Ku, Z., Xie, X., Davidson, E., Ye, X., Su, H., Menachery, V. D., et al. (2021). Molecular Determinants and Mechanism for Antibody Cocktail Preventing SARS-CoV-2 Escape. Nat. Commun. 12, 469. doi: 10.1038/s41467-020-20789-7

Laforce-Nesbitt, S. S., Sullivan, M. A., Hoyer, L. L., and Bliss, J. M. (2008). Inhibition of Candida Albicans Adhesion by Recombinant Human Antibody Single-Chain Variable Fragment Specific for Als3p. FEMS Immunol. Med. Microbiol. 54, 195-202. doi: 10.1111/j.1574-695X.2008.00465.x

Larkin, E. A., Stiles, B. G., and Ulrich, R. G. (2010). Inhibition of Toxic Shock by Human Monoclonal Antibodies Against Staphylococcal Enterotoxin B. PLoS One 5, e13253. doi: 10.1371/journal.pone.0013253

Latgé, J. P. (1999). Aspergillus Fumigatus and Aspergillosis. Clin. Microbiol. Rev. 12, 310-350. doi: 10.1128/CMR.12.2.310

Lauer, B., Ottleben, I., Jacobsen, H.-J., and Reinard, T. (2005). Production of a Single-Chain Variable Fragment Antibody Against Fumonisin B1. J. Agric. Food Chem. 53, 899-904. doi: 10.1021/jf048651s

Laustsen, A. H., Karatt-Vellatt, A., Masters, E. W., Arias, A. S., Pus, U., Knudsen, C., et al. (2018). In Vivo Neutralization of Dendrotoxin-Mediated Neurotoxicity of Black Mamba Venom by Oligoclonal Human IgG Antibodies. Nat. Commun. 9, 3928. doi: 10.1038/s41467-018-06086-4

Lebani, K., Jones, M. L., Watterson, D., Ranzoni, A., Traves, R. J., Young, P. R., et al. (2017). Isolation of Serotype-Specific Antibodies Against Dengue Virus non-
Structural Protein 1 Using Phage Display and Application in a Multiplexed Serotyping Assay. PLoS One 12, e0180669. doi: 10.1371/journal.pone.0180669

Lee, Y.-C., Leu, S.-J. C., Hu, C.-J., Shih, N.-Y., Huang, I.-J., Wu, H.-H., et al. (2007). Chicken Single-Chain Variable Fragments Against the SARS-CoV Spike Protein. J. Virol. Methods 146, 104-111. doi: 10.1016/j.jviromet.2007.06.010

Leivo, J., Vehniäinen, M., and Lamminmäki, U. (2020). Phage Display Selection of an Anti-Idiotype-Antibody With Broad-Specificity to Deoxynivalenol Mycotoxins. Toxins 13 (1), 18. doi: 10.3390/toxins 13010018

Leow, C. H., Fischer, K., Leow, C. Y., Braet, K., Cheng, Q., and McCarthy, J. (2018). Isolation and Characterization of Malaria PfHRP2 Specific VNAR Antibody Fragments From Immunized Shark Phage Display Library. Malar. J. 17, 383. doi: 10.1186/s12936-018-2531-y

Leow, C. H., Jones, M., Cheng, Q., Mahler, S., and McCarthy, J. (2014). Production and Characterization of Specific Monoclonal Antibodies Binding the Plasmodium Falciparum Diagnostic Biomarker, Histidine-Rich Protein 2. Malar. J. 13, 277. doi: 10.1186/1475-2875-13-277

Levenhagen, M. A., de Almeida Araújo Santos, F., Fujimura, P. T., Caneiro, A. P., Costa-Cruz, J. M., and Goulart, L. R. (2015). Structural and Functional Characterization of a Novel scFv Anti-HSP60 of Strongyloides Sp. Sci. Rep. 5, 10447. doi: 10.1038/srep10447

Liang, F., Browne, D. J., Gray, M. J., Gartlan, K. H., Smith, D. D., Barnard, R. T., et al. (2018). Development of a Multiplexed Microsphere PCR for Culture-Free Detection and Gram-Typing of Bacteria in Human Blood Samples. ACS Infect. Dis. 4, 837-844. doi: 10.1021/acsinfecdis.7b00277

Liang, M., Dübel, S., Li, D., Queitsch, I., Li, W., and Bautz, E. K. (2001). Baculovirus Expression Cassette Vectors for Rapid Production of Complete Human IgG From Phage Display Selected Antibody Fragments. J. Immunol. Methods 247, 119-130. doi: 10.1016/S0022-1759(00)00322-7

Liang, M.-F., Du, R.-L., Liu, J.-Z., Li, C., Zhang, Q.-F., Han, L.-L., et al. (2005). SARS Patients-Derived Human Recombinant Antibodies to $\mathrm{S}$ and M Proteins Efficiently Neutralize SARS-Coronavirus Infectivity. Biomed. Environ. Sci. BES $18,363-374$.

Li, T.-W., Cheng, S.-F., Tseng, Y.-T., Yang, Y.-C., Liu, W.-C., Wang, S.-C., et al. (2016). Development of Single-Chain Variable Fragments (scFv) Against Influenza Virus Targeting Hemagglutinin Subunit 2 (HA2). Arch. Virol. 161, 19-31. doi: 10.1007/s00705-015-2625-6

Li, W., Drelich, A., Martinez, D. R., Gralinski, L., Chen, C., Sun, Z., et al. (2020a). Rapid Selection of a Human Monoclonal Antibody That Potently Neutralizes SARS-CoV-2 in Two Animal Models. bioRxiv. doi: 10.1101/2020.05.13.093088

Li, W., Schäfer, A., Kulkarni, S. S., Liu, X., Martinez, D. R., Chen, C., et al. (2020b). High Potency of a Bivalent Human VH Domain in SARS-CoV-2 Animal Models. Cell 183, 429-441.e16. doi: 10.1016/j.cell.2020.09.007

Li, T., Huang, M., Xiao, H., Zhang, G., Ding, J., Wu, P., et al. (2017). Selection and Characterization of Specific Nanobody Against Bovine Virus Diarrhea Virus (BVDV) E2 Protein. PLoS One 12, e0178469. doi: 10.1371/journal.pone.0178469

Lillo, A. M., Ayriss, J. E., Shou, Y., Graves, S. W., and Bradbury, A. R. M. (2011). Development of Phage-Based Single Chain Fv Antibody Reagents for Detection of Yersinia Pestis. PLoS One 6, e27756. doi: 10.1371/journal.pone.0027756

Lima, M. I. S., Capparelli, F. E., Dias Oliveira, J., das, D., Fujimura, P. T., Moraes, E. C. D. S., et al. (2020). Biotechnological and Immunological Platforms Based on PGL-I Carbohydrate-Like Peptide of Mycobacterium Leprae for Antibodies Detection Among Leprosy Clinical Forms. Front. Microbiol. 11, 3389. doi: $10.3389 /$ fmicb.2020.00429

Lim, A. P. C., Chan, C. E. Z., Wong, S. K. K., Chan, A. H. Y., Ooi, E. E., and Hanson, B. J. (2008). Neutralizing Human Monoclonal Antibody Against H5N1 Influenza HA Selected From a Fab-Phage Display Library. Virol. J. 5, 130. doi: 10.1186/1743-422X-5-130

Lim, B. N., Chin, C. F., Choong, Y. S., Ismail, A., and Lim, T. S. (2016). Generation of a Naïve Human Single Chain Variable Fragment (scFv) Library for the Identification of Monoclonal scFv Against Salmonella Typhi Hemolysin E Antigen. Toxicon 117, 94-101. doi: 10.1016/j.toxicon.2016.04.032

Lim, S. S. Y., Chua, K. H., Nölke, G., Spiegel, H., Goh, W. L., Chow, S. C., et al. (2018). Plant-Derived Chimeric Antibodies Inhibit the Invasion of Human Fibroblasts by Toxoplasma Gondii. PeerJ 6, e5780. doi: 10.7717/peerj.5780

Lim, S. A., Gramespacher, J. A., Pance, K., Rettko, N. J., Solomon, P., Jin, J., et al. (2021). Bispecific VH/Fab Antibodies Targeting Neutralizing and NonNeutralizing Spike Epitopes Demonstrate Enhanced Potency Against SARSCoV-2. mAbs 13, 1893426. doi: 10.1080/19420862.2021.1893426 
Lim, C. C., Woo, P. C. Y., and Lim, T. S. (2019). Development of a Phage Display Panning Strategy Utilizing Crude Antigens: Isolation of MERS-CoV Nucleoprotein Human Antibodies. Sci. Rep. 9, 6088. doi: 10.1038/s41598019-42628-6

Lindquist, E. A., Marks, J. D., Kleba, B. J., and Stephens, R. S. (2002). PhageDisplay Antibody Detection of Chlamydia Trachomatis-Associated Antigens. Microbiol. Read. Engl. 148, 443-451. doi: 10.1099/00221287-148-2-443

Liu, H., Liang, C., Duan, H., Zhang, X., Wang, X., Xiao, S., et al. (2016). Intracellularly Expressed Nanobodies Against non-Structural Protein 4 of Porcine Reproductive and Respiratory Syndrome Virus Inhibit Virus Replication. Biotechnol. Lett. 38, 1081-1088. doi: 10.1007/s10529-016-2086-3

Liu, S., Moayeri, M., and Leppla, S. H. (2014). Anthrax Lethal and Edema Toxins in Anthrax Pathogenesis. Trends Microbiol. 22, 317-325. doi: 10.1016/ j.tim.2014.02.012

Liu, J. L., Shriver-Lake, L. C., Anderson, G. P., Zabetakis, D., and Goldman, E. R. (2017). Selection, Characterization, and Thermal Stabilization of Llama Single Domain Antibodies Towards Ebola Virus Glycoprotein. Microb. Cell Factories 16, 223. doi: 10.1186/s12934-017-0837-z

Liu, J. L., Shriver-Lake, L. C., Zabetakis, D., Anderson, G. P., and Goldman, E. R. (2019). Selection and Characterization of Protective Anti-Chikungunya Virus Single Domain Antibodies. Mol. Immunol. 105, 190-197. doi: 10.1016/ j.molimm.2018.11.016

Liu, J. L., Shriver-Lake, L. C., Zabetakis, D., Goldman, E. R., and Anderson, G. P. (2018). Selection of Single-Domain Antibodies Towards Western Equine Encephalitis Virus. Antibodies Basel Switz. 7 (4), 44. doi: 10.3390/antib7040044

Liu, H., Wang, Y., Duan, H., Zhang, A., Liang, C., Gao, J., et al. (2015). An Intracellularly Expressed Nsp9-Specific Nanobody in MARC-145 Cells Inhibits Porcine Reproductive and Respiratory Syndrome Virus Replication. Vet. Microbiol. 181, 252-260. doi: 10.1016/j.vetmic.2015.10.021

Liu, H., Zheng, X., Shi, X., Yu, L., Jia, P., Wang, J., et al. (2014). Selection and Characterization of Single-Chain Recombinant Antibodies Against Infectious Haematopoietic Necrosis Virus From Mouse Phage Display Library. J. Virol. Methods 205C, 61-67. doi: 10.1016/j.jviromet.2014.04.008

Lloyd, C., Lowe, D., Edwards, B., Welsh, F., Dilks, T., Hardman, C., et al. (2009). Modelling the Human Immune Response: Performance of a 1011 Human Antibody Repertoire Against a Broad Panel of Therapeutically Relevant Antigens. Protein Eng. Des. Sel. PEDS 22, 159-168. doi: 10.1093/protein/gzn058

Lo, K.-M., Leger, O., and Hock, B. (2014). Antibody Engineering. Microbiol. Spectr. 2, AID-0007-2012. doi: 10.1128/microbiolspec.AID-0007-12

Lo, A. W. H., Moonens, K., De Kerpel, M., Brys, L., Pardon, E., Remaut, H., et al. (2014). The Molecular Mechanism of Shiga Toxin Stx2e Neutralization by a Single-Domain Antibody Targeting the Cell Receptor-Binding Domain. J. Biol. Chem. 289, 25374-25381. doi: 10.1074/jbc.M114.566257

Lonberg, N., and Huszar, D. (1995). Human Antibodies From Transgenic Mice. Int. Rev. Immunol. 13, 65-93. doi: 10.3109/08830189509061738

Lundquist, R., Nielsen, L. K., Jafarshad, A., Soesoe, D., Christensen, L. H., Druilhe, P., et al. (2006). Human Recombinant Antibodies Against Plasmodium Falciparum Merozoite Surface Protein 3 Cloned From Peripheral Blood Leukocytes of Individuals With Immunity to Malaria Demonstrate Antiparasitic Properties. Infect. Immun. 74, 3222-3231. doi: 10.1128/ IAI.00928-05

Lutje Hulsik, D., Liu, Y., Strokappe, N. M., Battella, S., El Khattabi, M., McCoy, L. E., et al. (2013). A Gp41 MPER-Specific Llama VHH Requires a Hydrophobic CDR3 for Neutralization But Not for Antigen Recognition. PLoS Pathog. 9, e1003202. doi: 10.1371/journal.ppat.1003202

Lu, X., Xiao, H., Li, S., Pang, X., Song, J., Liu, S., et al. (2019). Double Lock of a Human Neutralizing and Protective Monoclonal Antibody Targeting the Yellow Fever Virus Envelope. Cell Rep. 26, 438-446.e5. doi: 10.1016/ j.celrep.2018.12.065

Luz, D., Chen, G., Maranhão, A. Q., Rocha, L. B., Sidhu, S., and Piazza, R. M. F. (2015). Development and Characterization of Recombinant Antibody Fragments That Recognize and Neutralize In Vitro Stx2 Toxin From Shiga Toxin-Producing Escherichia Coli. PLoS One 10, e0120481. doi: 10.1371/ journal.pone.0120481

Lu, R., Zhao, X., Li, J., Niu, P., Yang, B., Wu, H., et al. (2020). Genomic Characterisation and Epidemiology of 2019 Novel Coronavirus: Implications for Virus Origins and Receptor Binding. Lancet Lond. Engl. 395, 565-574. doi: $10.1016 /$ S0140-6736(20)30251-8
Malik, A. A., Imtong, C., Sookrung, N., Katzenmeier, G., Chaicumpa, W., and Angsuthanasombat, C. (2016). Structural Characterization of Humanized Nanobodies With Neutralizing Activity Against the Bordetella Pertussis CyaA-Hemolysin: Implications for a Potential Epitope of Toxin-Protective Antigen. Toxins 8, 99. doi: 10.3390/toxins8040099

Malkin, A. J., McPherson, A., and Gershon, P. D. (2003). Structure of Intracellular Mature Vaccinia Virus Visualized by In Situ Atomic Force Microscopy. J. Virol. 77, 6332-6340. doi: 10.1128/jvi.77.11.6332-6340.2003

Malley, R., DeVincenzo, J., Ramilo, O., Dennehy, P. H., Meissner, H. C., Gruber, W. C., et al. (1998). Reduction of Respiratory Syncytial Virus (RSV) in Tracheal Aspirates in Intubated Infants by Use of Humanized Monoclonal Antibody to RSV F Protein. J. Infect. Dis. 178, 1555-1561. doi: 10.1086/314523

Maneewatch, S., Thanongsaksrikul, J., Songserm, T., Thueng-In, K., Kulkeaw, K., Thathaisong, U., et al. (2009). Human Single-Chain Antibodies That Neutralize Homologous and Heterologous Strains and Clades of Influenza A Virus Subtype H5N1. Antivir. Ther. 14, 221-230.

Marozsan, A. J., Ma, D., Nagashima, K. A., Kennedy, B. J., Kang, Y. K., Arrigale, R. R., et al. (2012). Protection Against Clostridium Difficile Infection With Broadly Neutralizing Antitoxin Monoclonal Antibodies. J. Infect. Dis. 206, 706-713. doi: 10.1093/infdis/jis416

Maruyama, T., Parren, P. W., Sanchez, A., Rensink, I., Rodriguez, L. L., Khan, A. S., et al. (1999a). Recombinant Human Monoclonal Antibodies to Ebola Virus. J. Infect. Dis. 179 (Suppl 1), S235-S239. doi: 10.1086/514280

Maruyama, T., Rodriguez, L. L., Jahrling, P. B., Sanchez, A., Khan, A. S., Nichol, S. T., et al. (1999b). Ebola Virus can be Effectively Neutralized by Antibody Produced in Natural Human Infection. J. Virol. 73, 6024-6030. doi: 10.1128/ JVI.73.7.6024-6030.1999

Ma, Z., Wang, T., Li, Z., Guo, X., Tian, Y., Li, Y., et al. (2019). A Novel Biotinylated Nanobody-Based Blocking ELISA for the Rapid and Sensitive Clinical Detection of Porcine Epidemic Diarrhea Virus. J. Nanobiotechnol. 17, 96. doi: 10.1186/s12951-019-0531-x

Ma, H., Zeng, W., Meng, X., Huang, X., Yang, Y., Zhao, D., et al. (2021). Potent Neutralization of SARS-CoV-2 by Hetero-Bivalent Alpaca Nanobodies Targeting the Spike Receptor-Binding Domain. J. Virol. 95 (10), e02438-20. doi: 10.1128/ JVI.02438-20

Mazumdar, S. (2009). Raxibacumab. mAbs 1, 531-538. doi: 10.4161/ mabs.1.6.10195

Mazzega, E., Beran, A., Cabrini, M., and de Marco, A. (2019). In Vitro Isolation of Nanobodies for Selective Alexandrium Minutum Recognition: A Model for Convenient Development of Dedicated Immuno-Reagents to Study and Diagnostic Toxic Unicellular Algae. Harmful Algae 82, 44-51. doi: 10.1016/ j.hal.2019.01.002

McCafferty, J., Griffiths, A. D., Winter, G., and Chiswell, D. J. (1990). Phage Antibodies: Filamentous Phage Displaying Antibody Variable Domains. Nature 348, 552-554. doi: 10.1038/348552a0

McElhiney, J., Lawton, L. A., and Porter, A. J. (2000). Detection and Quantification of Microcystins (Cyanobacterial Hepatotoxins) With Recombinant Antibody Fragments Isolated From a Naïve Human Phage Display Library. FEMS Microbiol. Lett. 193, 83-88. doi: 10.1111/j.1574-6968.2000.tb09406.x

Mechaly, A., Elia, U., Alcalay, R., Cohen, H., Epstein, E., Cohen, O., et al. (2019). Inhibition of Francisella Tularensis Phagocytosis Using a Novel Anti-LPS scFv Antibody Fragment. Sci. Rep. 9, 11418. doi: 10.1038/s41598019-47931-w

Mechaly, A., Zahavy, E., and Fisher, M. (2008). Development and Implementation of a Single-Chain Fv Antibody for Specific Detection of Bacillus Anthracis Spores. Appl. Environ. Microbiol. 74, 818-822. doi: 10.1128/AEM.01244-07

Memish, Z. A., Perlman, S., Van Kerkhove, M. D., and Zumla, A. (2020). Middle East Respiratory Syndrome. Lancet Lond. Engl. 395, 1063-1077. doi: 10.1016/ S0140-6736(19)33221-0

Men, R., Yamashiro, T., Goncalvez, A. P., Wernly, C., Schofield, D. J., Emerson, S. U., et al. (2004). Identification of Chimpanzee Fab Fragments by Repertoire Cloning and Production of a Full-Length Humanized Immunoglobulin G1 Antibody That is Highly Efficient for Neutralization of Dengue Type 4 Virus. J. Virol. 78, 4665-4674. doi: 10.1128/JVI.78.9.4665-4674.2004

Meyer, T., Schirrmann, T., Frenzel, A., Miethe, S., Stratmann-Selke, J., Gerlach, G. F., et al. (2012). Identification of Immunogenic Proteins and Generation of Antibodies Against Salmonella Typhimurium Using Phage Display. BMC Biotechnol. 12, 29. doi: $10.1186 / 1472-6750-12-29$ 
Meyer, T., Stratmann-Selke, J., Meens, J., Schirrmann, T., Gerlach, G. F., Frank, R., et al. (2011). Isolation of scFv Fragments Specific to OmpD of Salmonella Typhimurium. Vet. Microbiol. 147, 162-169. doi: 10.1016/j.vetmic.2010.06.023

Miethe, S., Mazuet, C., Liu, Y., Tierney, R., Rasetti-Escargueil, C., Avril, A., et al. (2016). Development of Germline-Humanized Antibodies Neutralizing Botulinum Neurotoxin A and B. PLoS One 11, e0161446. doi: 10.1371/ journal.pone. 0161446

Miethe, S., Rasetti-Escargueil, C., Avril, A., Liu, Y., Chahboun, S., Korkeala, H., et al. (2015). Development of Human-Like scFv-Fc Neutralizing Botulinum Neurotoxin E. PLoS One 10, e0139905. doi: 10.1371/journal.pone.0139905

Miethe, S., Rasetti-Escargueil, C., Liu, Y., Chahboun, S., Pelat, T., Avril, A., et al. (2014). Development of Neutralizing scFv-Fc Against Botulinum Neurotoxin A Light Chain From a Macaque Immune Library. mAbs 6, 446-459. doi: 10.4161/mabs.27773

Miller, M. D., Geleziunas, R., Bianchi, E., Lennard, S., Hrin, R., Zhang, H., et al. (2005). A Human Monoclonal Antibody Neutralizes Diverse HIV-1 Isolates by Binding a Critical Gp41 Epitope. Proc. Natl. Acad. Sci. U. S. A. 102, 1475914764. doi: $10.1073 /$ pnas. 0506927102

Mire, C. E., Satterfield, B. A., Geisbert, J. B., Agans, K. N., Borisevich, V., Yan, L., et al. (2016). Pathogenic Differences Between Nipah Virus Bangladesh and Malaysia Strains in Primates: Implications for Antibody Therapy. Sci. Rep. 6:30916. doi: 10.1038/srep30916

Moayeri, M., Leysath, C. E., Tremblay, J. M., Vrentas, C., Crown, D., Leppla, S. H., et al. (2015). A Heterodimer of a VHH (Variable Domains of Camelid Heavy Chain-Only) Antibody That Inhibits Anthrax Toxin Cell Binding Linked to a VHH Antibody That Blocks Oligomer Formation Is Highly Protective in an Anthrax Spore Challenge Model. J. Biol. Chem. 290, 6584-6595. doi: 10.1074/ jbc.M114.627943

Moazen, B., Ebrahimi, E., and Nejatollahi, F. (2016). Single Chain Antibodies Against Gp55 of Human Cytomegalovirus (HCMV) for Prophylaxis and Treatment of HCMV Infections. Jundishapur J. Microbiol. 9, e16241. doi: $10.5812 /$ jjm. 16241

Mohammadzadeh, S., Rajabibazl, M., Fourozandeh, M., Rasaee, M. J., Rahbarizadeh, F., and Mohammadi, M. (2014). Production of Recombinant scFv Against P24 of Human Immunodeficiency Virus Type 1 by Phage Display Technology. Monoclon. Antibodies Immunodiagn. Immunother. 33, 28-33. doi: $10.1089 / \mathrm{mab} .2013 .0059$

Mohd Ali, M. R., Sum, J. S., Aminuddin Baki, N. N., Choong, Y. S., Nor Amdan, N. A., Amran, F., et al. (2021). Development of Monoclonal Antibodies Against Recombinant LipL21 Protein of Pathogenic Leptospira Through Phage Display Technology. Int. J. Biol. Macromol. 168, 289-300. doi: 10.1016/ j.ijbiomac.2020.12.062

Monedero, V., Rodríguez-Díaz, J., Viana, R., Buesa, J., and Pérez-Martínez, G. (2004). Selection of Single-Chain Antibodies Against the VP8* Subunit of Rotavirus VP4 Outer Capsid Protein and Their Expression in Lactobacillus Casei. Appl. Environ. Microbiol. 70, 6936-6939. doi: 10.1128/AEM.70.11.69366939.2004

Moreira, G. M. S. G., Köllner, S. M. S., Helmsing, S., Jänsch, L., Meier, A., Gronow, S., et al. (2020). Pyruvate Dehydrogenase Complex-Enzyme 2, A New Target for Listeria Spp. Detection Identified Using Combined Phage Display Technologies. Sci. Rep. 10, 15267. doi: 10.1038/s41598-020-72159-4

Moreland, N. J., Susanto, P., Lim, E., Tay, M. Y. F., Rajamanonmani, R., Hanson, B. J., et al. (2012). Phage Display Approaches for the Isolation of Monoclonal Antibodies Against Dengue Virus Envelope Domain III From Human and Mouse Derived Libraries. Int. J. Mol. Sci. 13, 2618-2635. doi: 10.3390/ijms13032618

Moreland, N. J., Tay, M. Y. F., Lim, E., Paradkar, P. N., Doan, D. N. P., Yau, Y. H., et al. (2010). High Affinity Human Antibody Fragments to Dengue Virus NonStructural Protein 3. PLoS Negl. Trop. Dis. 4, e881. doi: 10.1371/journal. pntd.0000881

Muerhoff, A. S., Birkenmeyer, L. G., Coffey, R., Dille, B. J., Barnwell, J. W., Collins, W. E., et al. (2010). Detection of Plasmodium Falciparum, P. Vivax, P. Ovale and P. Malariae Merozoite Surface Protein 1-P19 Antibodies in Human Malaria Patients and Experimentally Infected Nonhuman Primates. Clin. Vaccine Immunol. CVI 17, 1631-1638. doi: 10.1128/CVI.00196-10

Mu, Y., Jia, C., Zheng, X., Zhu, H., Zhang, X., Xu, H., et al. (2021). A NanobodyHorseradish Peroxidase Fusion Protein-Based Competitive ELISA for Rapid Detection of Antibodies Against Porcine Circovirus Type 2. J. Nanobiotechnol. 19, 34. doi: 10.1186/s12951-021-00778-8
Mulangu, S., Dodd, L. E., Davey, R. T., Tshiani Mbaya, O., Proschan, M., Mukadi, D., et al. (2019). A Randomized, Controlled Trial of Ebola Virus Disease Therapeutics. N. Engl. J. Med. 381, 2293-2303. doi: 10.1056/NEJMoa1910993

Murphy, J. R. (1996). "Corynebacterium Diphtheriae," in Medical Microbiology. Ed. S. Baron (Galveston, TX: University of Texas Medical Branch at Galveston).

Muyldermans, S. (2001). Single Domain Camel Antibodies: Current Status. J. Biotechnol. 74, 277-302. doi: 10.1016/S1389-0352(01)00021-6

Muyldermans, S., Baral, T. N., Retamozzo, V. C., De Baetselier, P., De Genst, E., Kinne, J., et al. (2009). Camelid Immunoglobulins and Nanobody Technology. Vet. Immunol. Immunopathol. 128, 178-183. doi: 10.1016/j.vetimm. 2008.10.299

Mwale, P. F., Lee, C.-H., Lin, L.-T., Leu, S.-J., Huang, Y.-J., Chiang, L.-C., et al. (2020). Expression, Purification, and Characterization of Anti-Zika Virus Envelope Protein: Polyclonal and Chicken-Derived Single Chain Variable Fragment Antibodies. Int. J. Mol. Sci. 21 (2), 492. doi: 10.3390/ijms21020492

Naranjo, L., Ferrara, F., Blanchard, N., Demangel, C., D’Angelo, S., Erasmus, M. F., et al. (2019). Recombinant Antibodies Against Mycolactone. Toxins 11. doi: $10.3390 /$ toxins 11060346

Natarajan, M., Walk, S. T., Young, V. B., and Aronoff, D. M. (2013). A Clinical and Epidemiological Review of Non-Toxigenic Clostridium Difficile. Anaerobe 22, 1-5. doi: 10.1016/j.anaerobe.2013.05.005

Navaratnarajah, C. K., Generous, A. R., Yousaf, I., and Cattaneo, R. (2020). Receptor-Mediated Cell Entry of Paramyxoviruses: Mechanisms, and Consequences for Tropism and Pathogenesis. J. Biol. Chem. 295, 2771-2786. doi: 10.1074/jbc.REV119.009961

Neelakantam, B., Sridevi, N. V., Shukra, A. M., Sugumar, P., Samuel, S., and Rajendra, L. (2014). Recombinant Human Antibody Fragment Against Tetanus Toxoid Produced by Phage Display. Eur. J. Microbiol. Immunol. 4, 45-55. doi: 10.1556/EuJMI.4.2014.1.4

Negrete, O. A., Levroney, E. L., Aguilar, H. C., Bertolotti-Ciarlet, A., Nazarian, R., Tajyar, S., et al. (2005). EphrinB2 is the Entry Receptor for Nipah Virus, an Emergent Deadly Paramyxovirus. Nature 436, 401-405. doi: 10.1038/ nature 03838

Negrete, O. A., Wolf, M. C., Aguilar, H. C., Enterlein, S., Wang, W., Mühlberger, E., et al. (2006). Two Key Residues in Ephrinb3 Are Critical for its Use as an Alternative Receptor for Nipah Virus. PLoS Pathog. 2, e7. doi: 10.1371/ journal.ppat.0020007

Nejatollahi, F., Hodgetts, S. J., Vallely, P. J., and Burnie, J. P. (2002). Neutralising Human Recombinant Antibodies to Human Cytomegalovirus Glycoproteins gB and gH. FEMS Immunol. Med. Microbiol. 34, 237-244. doi: 10.1111/j.1574695X.2002.tb00630.x

Nelson, A. L., Dhimolea, E., and Reichert, J. M. (2010). Development Trends for Human Monoclonal Antibody Therapeutics. Nat. Rev. Drug Discov. 9, 767774. doi: $10.1038 / \mathrm{nrd} 3229$

Neri, P., Shigemori, N., Hamada-Tsutsumi, S., Tsukamoto, K., Arimitsu, H., Shimizu, T., et al. (2011). Single Chain Variable Fragment Antibodies Against Shiga Toxins Isolated From a Human Antibody Phage Display Library. Vaccine 29, 5340-5346. doi: 10.1016/j.vaccine.2011.05.093

Nian, S., Wu, T., Ye, Y., Wang, X., Xu, W., and Yuan, Q. (2016). Development and Identification of Fully Human scFv-Fcs Against Staphylococcus Aureus. BMC Immunol. 17, 8. doi: 10.1186/s12865-016-0146-z

Norbis, L., Alagna, R., Tortoli, E., Codecasa, L. R., Migliori, G. B., and Cirillo, D. M. (2014). Challenges and Perspectives in the Diagnosis of Extrapulmonary Tuberculosis. Expert Rev. Anti Infect. Ther. 12, 633-647. doi: 10.1586/ 14787210.2014 .899900

Norbury, L. J., Basałaj, K., Baska, P., Kalinowska, A., Zawistowska-Deniziak, A., Yap, H. Y., et al. (2019a). Construction of a Novel Phage Display Antibody Library Against Fasciola Hepatica, and Generation of a Single-Chain Variable Fragment Specific for F. Hepatica Cathepsin L1. Exp. Parasitol. 198, 87-94. doi: 10.1016/j.exppara.2019.02.001

Norbury, L. J., Basałaj, K., Backa, P., Zawistowska-Deniziak, A., Kalinowska, A., Wilkowski, P., et al. (2019b). Generation of a Single-Chain Variable Fragment Phage Display Antibody Library From Naïve Mice Panned Against Fasciola Hepatica Antigens. Exp. Parasitol. 205, 107737. doi: 10.1016/j.exppara. 2019.107737

Noy-Porat, T., Makdasi, E., Alcalay, R., Mechaly, A., Levy, Y., Bercovich-Kinori, A., et al. (2020). A Panel of Human Neutralizing Mabs Targeting SARS-CoV-2 
Spike at Multiple Epitopes. Nat. Commun. 11, 4303. doi: 10.1038/s41467-020$18159-4$

Nuttall, S. D., Humberstone, K. S., Krishnan, U. V., Carmichael, J. A., Doughty, L., Hattarki, M., et al. (2004). Selection and Affinity Maturation of IgNAR Variable Domains Targeting Plasmodium Falciparum AMA1. Proteins 55, 187-197. doi: $10.1002 /$ prot.20005

Nuttall, S. D., Krishnan, U. V., Hattarki, M., De Gori, R., Irving, R. A., and Hudson, P. J. (2001). Isolation of the New Antigen Receptor From Wobbegong Sharks, and Use as a Scaffold for the Display of Protein Loop Libraries. Mol. Immunol. 38, 313-326. doi: 10.1016/S0161-5890(01)00057-8

Nzuma, R. M., Liu, F., and Grant, I. R. (2018). Generation and Characterization of a Novel Recombinant scFv Antibody Specific for Campylobacter Jejuni. Appl. Microbiol. Biotechnol. 102, 4873-4885. doi: 10.1007/s00253-018-8949-x

Obishakin, E., Stijlemans, B., Santi-Rocca, J., Vandenberghe, I., Devreese, B., Muldermans, S., et al. (2014). Generation of a Nanobody Targeting the Paraflagellar Rod Protein of Trypanosomes. PLoS One 9, e115893. doi: 10.1371/journal.pone.0115893

Oeuvray, C., Bouharoun-Tayoun, H., Gras-Masse, H., Bottius, E., Kaidoh, T., Aikawa, M., et al. (1994). Merozoite Surface Protein-3: A Malaria Protein Inducing Antibodies That Promote Plasmodium Falciparum Killing by Cooperation With Blood Monocytes. Blood 84, 1594-1602. doi: 10.1182/ blood.V84.5.1594.1594

Oncü, S., Oncü, S., and Sakarya, S. (2003). Anthrax-An Overview. Med. Sci. Monit. Int. Med. J. Exp. Clin. Res. 9, RA276-RA283.

Ono, H. K., Omoe, K., Imanishi, K., Iwakabe, Y., Hu, D.-L., Kato, H., et al. (2008). Identification and Characterization of Two Novel Staphylococcal Enterotoxins, Types S and T. Infect. Immun. 76, 4999-5005. doi: 10.1128/IAI.00045-08

Orecchia, M., Nölke, G., Saldarelli, P., Dell'Orco, M., Uhde-Holzem, K., Sack, M., et al. (2008). Generation and Characterization of a Recombinant Antibody Fragment That Binds to the Coat Protein of Grapevine Leafroll-Associated Virus 3. Arch. Virol. 153, 1075-1084. doi: 10.1007/s00705-008-0100-3

Oswald, W. B., Geisbert, T. W., Davis, K. J., Geisbert, J. B., Sullivan, N. J., Jahrling, P. B., et al. (2007). Neutralizing Antibody Fails to Impact the Course of Ebola Virus Infection in Monkeys. PLoS Pathog. 3, e9. doi: 10.1371/ journal.ppat.0030009

Parmley, S. F., and Smith, G. P. (1988). Antibody-Selectable Filamentous Fd Phage Vectors: Affinity Purification of Target Genes. Gene 73, 305-318. doi: 10.1016/ 0378-1119(88)90495-7

Parray, H. A., Chiranjivi, A. K., Asthana, S., Yadav, N., Shrivastava, T., Mani, S., et al. (2020). Identification of an Anti-SARS-CoV-2 Receptor-Binding Domain-Directed Human Monoclonal Antibody From a Naïve Semisynthetic Library. J. Biol. Chem. 295, 12814-12821. doi: 10.1074/ jbc.AC120.014918

Parren, P. W. H. I., Geisbert, T. W., Maruyama, T., Jahrling, P. B., and Burton, D. R. (2002). Pre- and Postexposure Prophylaxis of Ebola Virus Infection in an Animal Model by Passive Transfer of a Neutralizing Human Antibody. J. Virol. 76, 6408-6412. doi: 10.1128/JVI.76.12.6408-6412.2002

Parvari, R., Avivi, A., Lentner, F., Ziv, E., Tel-Or, S., Burstein, Y., et al. (1988). Chicken Immunoglobulin Gamma-Heavy Chains: Limited VH Gene Repertoire, Combinatorial Diversification by D Gene Segments and Evolution of the Heavy Chain Locus. EMBO J. 7, 739-744. doi: 10.1002/ j.1460-2075.1988.tb02870.x

Pascal, K. E., Dudgeon, D., Trefry, J. C., Anantpadma, M., Sakurai, Y., Murin, C. D., et al. (2018). Development of Clinical-Stage Human Monoclonal Antibodies That Treat Advanced Ebola Virus Disease in Nonhuman Primates. J. Infect. Dis. 218, S612-S626. doi: 10.1093/infdis/jiy285

Pauza, M. E., Rehmann, J. A., and LeBien, T. W. (1993). Unusual Patterns of Immunoglobulin Gene Rearrangement and Expression During Human B Cell Ontogeny: Human B Cells can Simultaneously Express Cell Surface Kappa and Lambda Light Chains. J. Exp. Med. 178, 139-149. doi: 10.1084/jem.178.1.139

Payandeh, Z., Rasooli, I., Mousavi Gargari, S. L., Rajabi Bazl, M., and Ebrahimizadeh, W. (2014). Immunoreaction of a Recombinant Nanobody From Camelid Single Domain Antibody Fragment With Acinetobacter Baumannii. Trans. R. Soc Trop. Med. Hyg. 108, 92-98. doi: 10.1093/trstmh/trt114

Peeters, M., Price, T., and Van Laethem, J.-L. (2009). Anti-Epidermal Growth Factor Receptor Monotherapy in the Treatment of Metastatic Colorectal Cancer: Where Are We Today? Oncol. 14, 29-39. doi: 10.1634/ theoncologist.2008-0167
Pelat, T., Hust, M., Hale, M., Lefranc, M.-P., Dübel, S., and Thullier, P. (2009). Isolation of a Human-Like Antibody Fragment (scFv) That Neutralizes Ricin Biological Activity. BMC Biotechnol. 9, 60. doi: 10.1186/1472-6750-9-60

Pelat, T., Hust, M., Laffly, E., Condemine, F., Bottex, C., Vidal, D., et al. (2007). High-Affinity, Human Antibody-Like Antibody Fragment (Single-Chain Variable Fragment) Neutralizing the Lethal Factor (LF) of Bacillus Anthracis by Inhibiting Protective Antigen-LF Complex Formation. Antimicrob. Agents Chemother. 51, 2758-2764. doi: 10.1128/AAC.01528-06

Pereira, S. S., Moreira-Dill, L. S., Morais, M. S. S., Prado, N. D. R., Barros, M. L., Koishi, A. C., et al. (2014). Novel Camelid Antibody Fragments Targeting Recombinant Nucleoprotein of Araucaria Hantavirus: A Prototype for an Early Diagnosis of Hantavirus Pulmonary Syndrome. PLoS One 9, e108067. doi: 10.1371/journal.pone.0108067

Peschen, D., Li, H.-P., Fischer, R., Kreuzaler, F., and Liao, Y.-C. (2004). Fusion Proteins Comprising a Fusarium-Specific Antibody Linked to Antifungal Peptides Protect Plants Against a Fungal Pathogen. Nat. Biotechnol. 22, 732738. doi: $10.1038 / \mathrm{nbt} 970$

Phanthong, S., Densumite, J., Seesuay, W., Thanongsaksrikul, J., Teimoori, S., Sookrung, N., et al. (2020). Human Antibodies to VP4 Inhibit Replication of Enteroviruses Across Subgenotypes and Serotypes, and Enhance Host Innate Immunity. Front. Microbiol. 11, 3389. doi: 10.3389/fmicb.2020.562768

Pini, A., Viti, F., Santucci, A., Carnemolla, B., Zardi, L., Neri, P., et al. (1998). Design and Use of a Phage Display Library. Human Antibodies With Subnanomolar Affinity Against a Marker of Angiogenesis Eluted From a Two-Dimensional Gel. J. Biol. Chem. 273, 21769-21776. doi: 10.1074/ jbc.273.34.21769

Pitaksajjakul, P., Lekcharoensuk, P., Upragarin, N., Barbas, C. F., Ibrahim, M. S., Ikuta, K., et al. (2010). Fab MAbs Specific to HA of Influenza Virus With H5N1 Neutralizing Activity Selected From Immunized Chicken Phage Library. Biochem. Biophys. Res. Commun. 395, 496-501. doi: 10.1016/j.bbrc. 2010.04.040

Playford, E. G., Munro, T., Mahler, S. M., Elliott, S., Gerometta, M., Hoger, K. L., et al. (2020). Safety, Tolerability, Pharmacokinetics, and Immunogenicity of a Human Monoclonal Antibody Targeting the G Glycoprotein of Henipaviruses in Healthy Adults: A First-in-Human, Randomised, Controlled, Phase 1 Study. Lancet Infect. Dis. 20, 445-454. doi: 10.1016/S1473-3099(19)30634-6

Popovici, J., and Ménard, D. (2015). Challenges in Antimalarial Drug Treatment for Vivax Malaria Control. Trends Mol. Med. 21, 776-788. doi: 10.1016/ j.molmed.2015.10.004

Postel, S., Deredge, D., Bonsor, D. A., Yu, X., Diederichs, K., Helmsing, S., et al. (2016). Bacterial Flagellar Capping Proteins Adopt Diverse Oligomeric States. eLife 5. doi: 10.7554/eLife.18857

Poungpair, O., Bangphoomi, K., Chaowalit, P., Sawasdee, N., Saokaew, N., Choowongkomon, K., et al. (2014). Generation of Human Single-Chain Variable Fragment Antibodies Specific to Dengue Virus non-Structural Protein 1 That Interfere With the Virus Infectious Cycle. mAbs 6, 474-482. doi: $10.4161 /$ mabs.27874

Rahumatullah, A., Abdul Karim, I. Z., Noordin, R., and Lim, T. S. (2017). Antibody-Based Protective Immunity Against Helminth Infections: Antibody Phage Display Derived Antibodies Against BmR1 Antigen. Int. J. Mol. Sci. 18. doi: 10.3390/ijms18112376

Rahumatullah, A., Ahmad, A., Noordin, R., Lai, J. Y., Baharudeen, Z., and Lim, T. S. (2020). Applicability of Brugia Malayi Immune Antibody Library for the Isolation of a Human Recombinant Monoclonal Antibody to Echinococcus Granulosus Antigen B. Exp. Parasitol. 219, 108029. doi: 10.1016/j.exppara. 2020.108029

Rahumatullah, A., Ahmad, A., Noordin, R., and Lim, T. S. (2015). Delineation of BmSXP Antibody V-Gene Usage From a Lymphatic Filariasis Based Immune scFv Antibody Library. Mol. Immunol. 67, 512-523. doi: 10.1016/j.molimm. 2015.07.040

Rahumatullah, A., Balachandra, D., Noordin, R., Baharudeen, Z., Lim, Y. Y., Choong, Y. S., et al. (2021). Broad Specificity of Immune Helminth scFv Library to Identify Monoclonal Antibodies Targeting Strongyloides. Sci. Rep. 11, 2502. doi: 10.1038/s41598-021-82125-3

Rahumatullah, A., Lim, T. S., Yunus, M. H., and Noordin, R. (2019). Development of an Antigen Detection ELISA for Bancroftian Filariasis Using BmSXPSpecific Recombinant Monoclonal Antibody. Am. J. Trop. Med. Hyg. 101, 436-440. doi: 10.4269/ajtmh.19-0034 
Rajput, R., Sharma, G., Rawat, V., Gautam, A., Kumar, B., Pattnaik, B., et al. (2015). Diagnostic Potential of Recombinant scFv Antibodies Generated Against Hemagglutinin Protein of Influenza A Virus. Front. Immunol. 6, 3389. doi: 10.3389/fimmu.2015.00440

Ramage, W., Gaiotto, T., Ball, C., Risley, P., Carnell, G. W., Temperton, N., et al. (2019). Cross-Reactive and Lineage-Specific Single Domain Antibodies Against Influenza B Hemagglutinin. Antibodies Basel Switz. 8. doi: 10.3390/antib8010014

Rasetti-Escargueil, C., Avril, A., Chahboun, S., Tierney, R., Bak, N., Miethe, S., et al. (2015). Development of Human-Like scFv-Fc Antibodies Neutralizing Botulinum Toxin Serotype B. mAbs 7, 1161-1177. doi: 10.1080/19420862.2015.1082016

Rasetti-Escargueil, C., Avril, A., Miethe, S., Mazuet, C., Derman, Y., Selby, K., et al. (2017). The European AntibotABE Framework Program and Its Update: Development of Innovative Botulinum Antibodies. Toxins 9. doi: 10.3390/ toxins 9100309

Ray, K., Embleton, M. J., Jailkhani, B. L., Bhan, M. K., and Kumar, R. (2001). Selection of Single Chain Variable Fragments ( $\mathrm{scFv}$ ) Against the Glycoprotein Antigen of the Rabies Virus From a Human Synthetic scFv Phage Display Library and Their Fusion With the Fc Region of Human Igg1. Clin. Exp. Immunol. 125, 94-101. doi: 10.1046/j.1365-2249.2001.01515.x

Reason, D. C., Wagner, T. C., and Lucas, A. H. (1997). Human Fab Fragments Specific for the Haemophilus Influenzae B Polysaccharide Isolated From a Bacteriophage Combinatorial Library Use Variable Region Gene Combinations and Express an Idiotype That Mirrors In Vivo Expression. Infect. Immun. 65, 261-266. doi: 10.1128/iai.65.1.261-266.1997

Rehman, Z. U., Deng, Q., Umair, S., Savoian, M. S., Knight, J. S., Pernthaner, A., et al. (2016). Excretory/secretory Products of Adult Haemonchus Contortus and Teladorsagia Circumcincta Which Increase the Permeability of Caco-2 Cell Monolayers are Neutralised by Antibodies From Immune Hosts. Vet. Parasitol. 221, 104-110. doi: 10.1016/j.vetpar.2016.03.017

Reiche, N., Jung, A., Brabletz, T., Vater, T., Kirchner, T., and Faller, G. (2002). Generation and Characterization of Human Monoclonal scFv Antibodies Against Helicobacter Pylori Antigens. Infect. Immun. 70, 4158-4164. doi: 10.1128/IAI.70.8.4158-4164.2002

Reineke, J., Tenzer, S., Rupnik, M., Koschinski, A., Hasselmayer, O., Schrattenholz, A., et al. (2007). Autocatalytic Cleavage of Clostridium Difficile Toxin B. Nature 446, 415-419. doi: 10.1038/nature05622

Rener, J., Graves, P. M., Carter, R., Williams, J. L., and Burkot, T. R. (1983). Target Antigens of Transmission-Blocking Immunity on Gametes of Plasmodium Falciparum. J. Exp. Med. 158, 976-981. doi: 10.1084/jem.158.3.976

Ribeiro, V., da, S., Araújo, T. G., Gonzaga, H. T., Nascimento, R., Goulart, L. R., et al. (2013). Development of Specific scFv Antibodies to Detect Neurocysticercosis Antigens and Potential Applications in Immunodiagnosis. Immunol. Lett. 156, 59-67. doi: 10.1016/j.imlet.2013.09.005

Rizzo, S., Imperato, P., Mora-Cárdenas, E., Konstantinidou, S., Marcello, A., and Sblattero, D. (2020). Selection and Characterization of Highly Specific Recombinant Antibodies Against West Nile Virus E Protein. J. Biotechnol. 311, 35-43. doi: 10.1016/j.jbiotec.2020.02.004

Rodríguez-Díaz, J., Monedero, V., Pérez-Martínez, G., and Buesa, J. (2004). SingleChain Variable Fragment ( $\mathrm{scFv}$ ) Antibodies Against Rotavirus NSP4 Enterotoxin Generated by Phage Display. J. Virol. Methods 121, 231-238. doi: 10.1016/j.jviromet.2004.07.002

Roeffen, W. F., Raats, J. M., Teelen, K., Hoet, R. M., Eling, W. M., van Venrooij, W. J., et al. (2001). Recombinant Human Antibodies Specific for the Pfs $48 / 45$ Protein of the Malaria Parasite Plasmodium Falciparum. J. Biol. Chem. 276, 19807-19811. doi: 10.1074/jbc.M100562200

Rohrbeck, A., Fühner, V., Schröder, A., Hagemann, S., Vu, X.-K., Berndt, S., et al. (2016). Detection and Quantification of ADP-Ribosylated RhoA/B by Monoclonal Antibody. Toxins 8, 100. doi: 10.3390/toxins 8040100

Rukkawattanakul, T., Sookrung, N., Seesuay, W., Onlamoon, N., Diraphat, P., Chaicumpa, W., et al. (2017). Human Scfvs That Counteract Bioactivities of Staphylococcus Aureus TSST-1. Toxins 9. doi: 10.3390/toxins9020050

Rülker, T., Voß, L., Thullier, P., O’ Brien, L. M., Pelat, T., Perkins, S. D., et al. (2012). Isolation and Characterisation of a Human-Like Antibody Fragment (scFv) That Inactivates VEEV In Vitro and In Vivo. PLoS One 7, e37242. doi: 10.1371/journal.pone.0037242

Rüping, M. J. G. T., Vehreschild, J. J., and Cornely, O. A. (2008). Patients at High Risk of Invasive Fungal Infections: When and How to Treat. Drugs 68, 19411962. doi: 10.2165/00003495-200868140-00002
Rupnik, M., Wilcox, M. H., and Gerding, D. N. (2009). Clostridium Difficile Infection: New Developments in Epidemiology and Pathogenesis. Nat. Rev. Microbiol. 7, 526-536. doi: 10.1038/nrmicro2164

Russo, G., Meier, D., Helmsing, S., Wenzel, E., Oberle, F., Frenzel, A., et al. (2018). Parallelized Antibody Selection in Microtiter Plates. Methods Mol. Biol. Clifton N. J. 1701, 273-284. doi: 10.1007/978-1-4939-7447-4_14

Sabin, C., Corti, D., Buzon, V., Seaman, M. S., Lutje Hulsik, D., Hinz, A., et al. (2010). Crystal Structure and Size-Dependent Neutralization Properties of HK20, a Human Monoclonal Antibody Binding to the Highly Conserved Heptad Repeat 1 of Gp41. PLoS Pathog. 6, e1001195. doi: 10.1371/ journal.ppat.1001195

Sabir, J. S. M., Lam, T. T.-Y., Ahmed, M. M. M., Li, L., Shen, Y., Abo-Aba, S. E. M., et al. (2016). Co-Circulation of Three Camel Coronavirus Species and Recombination of MERS-CoVs in Saudi Arabia. Science 351, 81-84. doi: $10.1126 /$ science.aac 8608

Sadreddini, S., Seifi-Najmi, M., Ghasemi, B., Kafil, H. S., Alinejad, V., Sadreddini, S., et al. (2015). Design and Construction of Immune Phage Antibody Library Against Tetanus Neurotoxin: Production of Single Chain Antibody Fragments. Hum. Antibodies 23, 73-79. doi: 10.3233/HAB-150287

Saerens, D., Stijlemans, B., Baral, T. N., Nguyen Thi, G. T., Wernery, U., Magez, S., et al. (2008). Parallel Selection of Multiple Anti-Infectome Nanobodies Without Access to Purified Antigens. J. Immunol. Methods 329, 138-150. doi: 10.1016/j.jim.2007.10.005

Saldarelli, P., Keller, H., Dell'Orco, M., Schots, A., Elicio, V., and Minafra, A. (2005). Isolation of Recombinant Antibodies (Scfvs) to Grapevine Virus B. J. Virol. Methods 124, 191-195. doi: 10.1016/j.jviromet.2004.11.021

Salem, R., El-Kholy, A. A., and Ibrahim, M. (2019). Eight Novel Single Chain Antibody Fragments Recognising VP2 of Foot-and-Mouth Disease Virus Serotypes A, O, and SAT 2. Virology 533, 145-154. doi: 10.1016/j.virol. 2019.05.012

Salhi, I., Bessalah, S., Snoun, D., Khorchani, T., and Hammadi, M. (2020). Construction of a Nanobodies Phage Display Library From an Escherichia Coli Immunized Dromedary. Iran. J. Biotechnol. 18, e2247. doi: 10.30498/ IJB.2020.127753.2247

Salonen, E. M., Parren, P. W., Graus, Y. F., Lundkvist, A., Fisicaro, P., Vapalahti, O., et al. (1998). Human Recombinant Puumala Virus Antibodies: CrossReaction With Other Hantaviruses and Use in Diagnostics. J. Gen. Virol. 79 (Pt 4), 659-665. doi: 10.1099/0022-1317-79-4-659

Sanna, P. P., Williamson, R. A., De Logu, A., Bloom, F. E., and Burton, D. R. (1995). Directed Selection of Recombinant Human Monoclonal Antibodies to Herpes Simplex Virus Glycoproteins From Phage Display Libraries. Proc. Natl. Acad. Sci. U. S. A. 92, 6439-6443. doi: 10.1073/pnas.92.14.6439

Santajit, S., Seesuay, W., Mahasongkram, K., Sookrung, N., Ampawong, S., Reamtong, O., et al. (2019). Human Single-Chain Antibodies That Neutralize Pseudomonas Aeruginosa-Exotoxin A-Mediated Cellular Apoptosis. Sci. Rep. 9, 14928. doi: 10.1038/s41598-019-51089-w

Saokaew, N., Poungpair, O., Panya, A., Tarasuk, M., Sawasdee, N., Limjindaporn, T., et al. (2014). Human Monoclonal Single-Chain Antibodies Specific to Dengue Virus Envelope Protein. Lett. Appl. Microbiol. 58, 270-277. doi: 10.1111/lam.12186

Sawyer, C., Embleton, J., and Dean, C. (1997). Methodology for Selection of Human Antibodies to Membrane Proteins From a Phage-Display Library. J. Immunol. Methods 204, 193-203. doi: 10.1016/S0022-1759(97)00048-3

Schmiedl, A., Zimmermann, J., Scherberich, J. E., Fischer, P., and Dübel, S. (2006). Recombinant Variants of Antibody $138 \mathrm{H} 11$ Against Human GammaGlutamyltransferase for Targeting Renal Cell Carcinoma. Hum. Antibodies 15, 81-94. doi: 10.3233/HAB-2006-15303

Schoenenwald, A. K. J., Gwee, C. P., Stiasny, K., Hermann, M., Vasudevan, S. G., and Skern, T. (2020). Development and Characterization of Specific AntiUsutu Virus Chicken-Derived Single Chain Variable Fragment Antibodies. Protein Sci. Publ. Protein Soc 29, 2175-2188. doi: 10.1002/pro.3937

Schofield, D. J., Glamann, J., Emerson, S. U., and Purcell, R. H. (2000). Identification by Phage Display and Characterization of Two Neutralizing Chimpanzee Monoclonal Antibodies to the Hepatitis E Virus Capsid Protein. J. Virol. 74, 5548-5555. doi: 10.1128/JVI.74.12.5548-5555.2000

Schofield, D. J., Pope, A. R., Clementel, V., Buckell, J., Chapple, S. D., Clarke, K. F., et al. (2007). Application of Phage Display to High Throughput Antibody Generation and Characterization. Genome Biol. 8, R254. doi: 10.1186/gb-2007$8-11-\mathrm{r} 254$ 
Schofield, D. J., Satterfield, W., Emerson, S. U., and Purcell, R. H. (2002). Four Chimpanzee Monoclonal Antibodies Isolated by Phage Display Neutralize Hepatitis a Virus. Virology 292, 127-136. doi: 10.1006/viro.2001.1252

Schütte, M., Thullier, P., Pelat, T., Wezler, X., Rosenstock, P., Hinz, D., et al. (2009). Identification of a Putative Crf Splice Variant and Generation of Recombinant Antibodies for the Specific Detection of Aspergillus Fumigatus. PLoS One 4, e6625. doi: 10.1371/journal.pone.0006625

Seah, Y. F. S., Hu, H., and Merten, C. A. (2018). Microfluidic Single-Cell Technology in Immunology and Antibody Screening. Mol. Aspects Med. 59, 47-61. doi: 10.1016/j.mam.2017.09.004

Seesuay, W., Jittavisutthikul, S., Sae-Lim, N., Sookrung, N., Sakolvaree, Y., and Chaicumpa, W. (2018). Human Transbodies That Interfere With the Functions of Ebola Virus VP35 Protein in Genome Replication and Transcription and Innate Immune Antagonism. Emerg. Microbes Infect. 7, 41. doi: 10.1038/s41426-018-0031-3

Seidel-Greven, M., Addai-Mensah, O., Spiegel, H., Chiegoua Dipah, G. N., Schmitz, S., Breuer, G., et al. (2021). Isolation and Light Chain Shuffling of a Plasmodium Falciparum AMA1-Specific Human Monoclonal Antibody With Growth Inhibitory Activity. Malar. J. 20, 37. doi: 10.1186/s12936-020-03548-3

Selke, M., Meens, J., Springer, S., Frank, R., and Gerlach, G.-F. (2007). Immunization of Pigs to Prevent Disease in Humans: Construction and Protective Efficacy of a Salmonella Enterica Serovar Typhimurium Live Negative-Marker Vaccine. Infect. Immun. 75, 2476-2483. doi: 10.1128/ IAI.01908-06

Sengupta, D., Shaikh, A., Bhatia, S., Pateriya, A. K., Khandia, R., Sood, R., et al. (2014). Development of Single-Chain Fv Against the Nucleoprotein of Type A Influenza Virus and Its Use in ELISA. J. Virol. Methods 208, 129-137. doi: 10.1016/j.jviromet.2014.08.009

Shadman, Z., Farajnia, S., Pazhang, M., Tohidkia, M., Rahbarnia, L., Najavand, S., et al. (2021). Isolation and Characterizations of a Novel Recombinant scFv Antibody Against Exotoxin A of Pseudomonas Aeruginosa. BMC Infect. Dis. 21, 300. doi: 10.1186/s12879-021-05969-0

Shali, A., Hasannia, S., Gashtasbi, F., Abdous, M., Shahangian, S. S., and Jalili, S. (2018). Generation and Screening of Efficient Neutralizing Single Domain Antibodies (VHHs) Against the Critical Functional Domain of Anthrax Protective Antigen (PA). Int. J. Biol. Macromol. 114, 1267-1278. doi: 10.1016/j.ijbiomac.2018.03.034

Sheets, M. D., Amersdorfer, P., Finnern, R., Sargent, P., Lindquist, E., Schier, R., et al. (1998). Efficient Construction of a Large Nonimmune Phage Antibody Library: The Production of High-Affinity Human Single-Chain Antibodies to Protein Antigens. Proc. Natl. Acad. Sci. U. S. A. 95, 6157-6162. doi: 10.1073/ pnas.95.11.6157

Shin, Y. W., Chang, K.-H., Hong, G.-W., Yeo, S.-G., Jee, Y., Kim, J.-H., et al. (2019). Selection of Vaccinia Virus-Neutralizing Antibody From a PhageDisplay Human-Antibody Library. J. Microbiol. Biotechnol. 29, 651-657. doi: $10.4014 /$ jmb.1812.12024

Shingarova, L. N., Tikunova, N. V., Iun, T. E., Chepurnov, A. A., Aliev, T. K., Batanova, T. A., et al. (2007). [Recombinant Full-Size Human Antibody to Ebola Virus]. Bioorg. Khim. 33, 598-605. doi: 10.1134/S1068162007060040

Shirvan, A. N., and Aitken, R. (2016). Isolation of Recombinant Antibodies Directed Against Surface Proteins of Clostridium Difficile. Braz. J. Microbiol. Publ. Braz. Soc. Microbiol. doi: 10.1016/j.bjm.2016.01.017

Shi, R., Shan, C., Duan, X., Chen, Z., Liu, P., Song, J., et al. (2020). A Human Neutralizing Antibody Targets the Receptor Binding Site of SARS-CoV-2. Nature. doi: 10.1038/s41586-020-2381-y

Shriver-Lake, L. C., Liu, J. L., Zabetakis, D., Sugiharto, V. A., Lee, C.-R., Defang, G. N., et al. (2018). Selection and Characterization of Anti-Dengue NS1 Single Domain Antibodies. Sci. Rep. 8, 18086. doi: 10.1038/s41598-018-35923-1

Shriver-Lake, L. C., Zabetakis, D., Goldman, E. R., and Anderson, G. P. (2017). Evaluation of Anti-Botulinum Neurotoxin Single Domain Antibodies With Additional Optimization for Improved Production and Stability. Toxicon Off. 135, 51-58. doi: 10.1016/j.toxicon.2017.06.002

Siddiqui, R., Kulsoom, H., Lalani, S., and Khan, N. A. (2016). Isolation of Balamuthia Mandrillaris-Specific Antibody Fragments From a Bacteriophage Antibody Display Library. Exp. Parasitol. 166, 94-96. doi: 10.1016/ j.exppara.2016.04.001

Singh, P. K., Agrawal, R., Kamboj, D. V., Gupta, G., Boopathi, M., Goel, A. K., et al. (2010). Construction of a Single-Chain Variable-Fragment Antibody Against the Superantigen Staphylococcal Enterotoxin B. Appl. Environ. Microbiol. 76, 8184-8191. doi: 10.1128/AEM.01441-10

Sixholo, J., Van Wyngaardt, W., Mashau, C., Frischmuth, J., Du Plessis, D. H., and Fehrsen, J. (2011). Improving the Characteristics of a Mycobacterial $16 \mathrm{kDa}-$ Specific Chicken scFv. Biol. J. Int. Assoc. Biol. Stand. 39, 110-116. doi: 10.1016/ j.biologicals.2011.01.007

Skottrup, P. D., Leonard, P., Kaczmarek, J. Z., Veillard, F., Enghild, J. J., O'Kennedy, R., et al. (2011). Diagnostic Evaluation of a Nanobody With Picomolar Affinity Toward the Protease RgpB From Porphyromonas Gingivalis. Anal. Biochem. 415, 158-167. doi: 10.1016/j.ab.2011.04.015

Slezak, T., and Kossiakoff, A. A. (2021). Engineered Ultra-High Affinity Synthetic Antibodies for SARS-CoV-2 Neutralization and Detection. J. Mol. Biol. 433:166956. doi: 10.1016/j.jmb.2021.166956

Smith, G. P. (1985). Filamentous Fusion Phage: Novel Expression Vectors That Display Cloned Antigens on the Virion Surface. Science 228, 1315-1317. doi: 10.1126/science.4001944

Socransky, S. S., Haffajee, A. D., Cugini, M. A., Smith, C., and Kent, R. L. (1998), Microbial Complexes in Subgingival Plaque. J. Clin. Periodontol. 25, 134-144. doi: 10.1111/j.1600-051X.1998.tb02419.x

Songsivilai, S., and Dharakul, T. (1998). Genetically Engineered Single-Chain Fvs of Human Immunoglobulin Against Hepatitis C Virus Nucleocapsid Protein Derived From Universal Phage Display Library. Asian Pac. J. Allergy Immunol. Launched Allergy Immunol. Soc. Thail. 16, 31-41.

Sowa, K. M., Cavanagh, D. R., Creasey, A. M., Raats, J., McBride, J., Sauerwein, R., et al. (2001). Isolation of a Monoclonal Antibody From a Malaria PatientDerived Phage Display Library Recognising the Block 2 Region of Plasmodium Falciparum Merozoite Surface Protein-1. Mol. Biochem. Parasitol. 112, 143147. doi: 10.1016/S0166-6851(00)00348-0

Spencer, D. A., Shapiro, M. B., Haigwood, N. L., and Hessell, A. J. (2021). Advancing HIV Broadly Neutralizing Antibodies: From Discovery to the Clinic. Front. Public Health 9, 3389. doi: 10.3389/fpubh.2021.690017

Strokappe, N., Szynol, A., Aasa-Chapman, M., Gorlani, A., Forsman Quigley, A., Hulsik, D. L., et al. (2012). Llama Antibody Fragments Recognizing Various Epitopes of the CD4bs Neutralize a Broad Range of HIV-1 Subtypes A, B and C. PLoS One 7, e33298. doi: 10.1371/journal.pone.0033298

Sui, J., Hwang, W. C., Perez, S., Wei, G., Aird, D., Chen, L., et al. (2009). Structural and Functional Bases for Broad-Spectrum Neutralization of Avian and Human Influenza A Viruses. Nat. Struct. Mol. Biol. 16, 265-273. doi: 10.1038/nsmb.1566

Sui, J., Li, W., Murakami, A., Tamin, A., Matthews, L. J., Wong, S. K., et al. (2004). Potent Neutralization of Severe Acute Respiratory Syndrome (SARS) Coronavirus by a Human mAb to S1 Protein That Blocks Receptor Association. Proc. Natl. Acad. Sci. U. S. A. 101, 2536-2541. doi: 10.1073/ pnas.0307140101

Sun, Z., Chen, C., Li, W., Martinez, D. R., Drelich, A., Baek, D.-S., et al. (2020). Potent Neutralization of SARS-CoV-2 by Human Antibody Heavy-Chain Variable Domains Isolated From a Large Library With a New Stable Scaffold. $m A b s$ 12, 1778435. doi: 10.1080/19420862.2020.1778435

Sun, L., Chen, Z., Yu, L., Wei, J., Li, C., Jin, J., et al. (2012). Generation and Characterization of Neutralizing Human Recombinant Antibodies Against Antigenic Site II of Rabies Virus Glycoprotein. Appl. Microbiol. Biotechnol. 96, 357-366. doi: 10.1007/s00253-012-4171-4

Sun, L., Lu, X., Li, C., Wang, M., Liu, Q., Li, Z., et al. (2009). Generation, Characterization and Epitope Mapping of Two Neutralizing and Protective Human Recombinant Antibodies Against Influenza A H5N1 Viruses. PLoS One 4, e5476. doi: 10.1371/journal.pone.0005476

Sun, Y., Qiao, Y., Zhu, Y., Chong, H., and He, Y. (2017). Identification of a Novel HIV-1-Neutralizing Antibody From a CRF07_BC-Infected Chinese Donor. Oncotarget 8, 63047-63063. doi: 10.18632/oncotarget.18594

Sun, T., Zhao, Z., Liu, W., Xu, Z., He, H., Ning, B., et al. (2020). Development of Sandwich Chemiluminescent Immunoassay Based on an Anti-Staphylococcal Enterotoxin B Nanobody-Alkaline Phosphatase Fusion Protein for Detection of Staphylococcal Enterotoxin B. Anal. Chim. Acta 1108, 28-36. doi: 10.1016/ j.aca.2020.01.032

Taylor, A., Foo, S.-S., Bruzzone, R., Dinh, L. V., King, N. J. C., and Mahalingam, S. (2015). Fc Receptors in Antibody-Dependent Enhancement of Viral Infections. Immunol. Rev. 268, 340-364. doi: 10.1111/imr.12367

Ten Haaf, A., Kohl, J., Pscherer, S., Hamann, H.-P., Eskens, H. U., Bastian, M., et al. (2017). Development of a Monoclonal Sandwich ELISA for Direct 
Detection of Bluetongue Virus 8 in Infected Animals. J. Virol. Methods 243, 172-176. doi: 10.1016/j.jviromet.2017.02.003

Thanongsaksrikul, J., Srimanote, P., Maneewatch, S., Choowongkomon, K., Tapchaisri, P., Makino, S., et al. (2010). A V H H That Neutralizes the Zinc Metalloproteinase Activity of Botulinum Neurotoxin Type A. J. Biol. Chem. 285, 9657-9666. doi: 10.1074/jbc.M109.073163

Thanongsaksrikul, J., Srimanote, P., Tongtawe, P., Glab-Ampai, K., Malik, A. A., Supasorn, O., et al. (2018). Identification and Production of Mouse scFv to Specific Epitope of Enterovirus-71 Virion Protein-2 (VP2). Arch. Virol. 163, 1141-1152. doi: 10.1007/s00705-018-3731-z

Thomas, D. Y., Jarraud, S., Lemercier, B., Cozon, G., Echasserieau, K., Etienne, J., et al. (2006). Staphylococcal Enterotoxin-Like Toxins U2 and V, Two New Staphylococcal Superantigens Arising From Recombination Within the Enterotoxin Gene Cluster. Infect. Immun. 74, 4724-4734. doi: 10.1128/ IAI.00132-06

Throsby, M., van den Brink, E., Jongeneelen, M., Poon, L. L. M., Alard, P., Cornelissen, L., et al. (2008). Heterosubtypic Neutralizing Monoclonal Antibodies Cross-Protective Against H5N1 and H1N1 Recovered From Human IgM+ Memory B Cells. PLoS One 3, e3942. doi: 10.1371/ journal.pone.0003942

Thueng-in, K., Thanongsaksrikul, J., Jittavisutthikul, S., Seesuay, W., Chulanetra, M., Sakolvaree, Y., et al. (2014). Interference of HCV Replication by Cell Penetrable Human Monoclonal scFv Specific to NS5B Polymerase. mAbs 6, 1327-1339. doi: 10.4161/mabs.29978

Tikunova, N., Dubrovskaya, V., Morozova, V., Yun, T., Khlusevich, Y., Bormotov, N., et al. (2012). The Neutralizing Human Recombinant Antibodies to Pathogenic Orthopoxviruses Derived From a Phage Display Immune Library. Virus Res. 163, 141-150. doi: 10.1016/j.virusres.2011.09.008

Tiller, T., Schuster, I., Deppe, D., Siegers, K., Strohner, R., Herrmann, T., et al. (2013). A Fully Synthetic Human Fab Antibody Library Based on Fixed VH/ VL Framework Pairings With Favorable Biophysical Properties. $m A b s 5$, 445470. doi: $10.4161 / \mathrm{mabs} .24218$

Tillib, S. V., Morgunova, E. Y., Ivanova, T. I., Koroleva, E. A., Rutovskaya, M. V., and Zigangirova, N. A. (2017). [Single-Domain Adapted Antibodies Against Chlamydia Trachomatis, Preserving the Development of Chlamidic Infection In Vitro]. Biomeditsinskaia Khimiia 63, 461-466. doi: 10.18097/PBMC20176305461

Tolle, M. A. (2009). Mosquito-Borne Diseases. Curr. Probl. Pediatr. Adolesc. Health Care 39, 97-140. doi: 10.1016/j.cppeds.2009.01.001

Tremblay, J. M., Mukherjee, J., Leysath, C. E., Debatis, M., Ofori, K., Baldwin, K., et al. (2013). A Single VHH-Based Toxin-Neutralizing Agent and an Effector Antibody Protect Mice Against Challenge With Shiga Toxins 1 and 2. Infect. Immun. 81, 4592-4603. doi: 10.1128/IAI.01033-13

Trombetta, C., Piccirella, S., Perini, D., Kistner, O., and Montomoli, E. (2015). Emerging Influenza Strains in the Last Two Decades: A Threat of a New Pandemic? Vaccines 3, 172-185. doi: 10.3390/vaccines3010172

Trott, M., Wei $\beta$, ,. S., Antoni, S., Koch, J., von Briesen, H., Hust, M., et al. (2014). Functional Characterization of Two scFv-Fc Antibodies From an HIV Controller Selected on Soluble HIV-1 Env Complexes: A Neutralizing V3and a Trimer-Specific Gp41 Antibody. PLoS One 9, e97478. doi: 10.1371/ journal.pone.0097478

Tu, Z., Chen, Q., Li, Y., Xiong, Y., Xu, Y., Hu, N., et al. (2016). Identification and Characterization of Species-Specific Nanobodies for the Detection of Listeria Monocytogenes in Milk. Anal. Biochem. 493, 1-7. doi: 10.1016/j.ab.2015.09.023

Tunghirun, C., Narkthong, V., Chaicumpa, W., and Chimnaronk, S. (2020). Interference of Dengue Replication by Blocking the Access of 3' SL RNA to the Viral RNA-Dependent RNA Polymerase. Antiviral Res. 182, 104921. doi: 10.1016/j.antiviral.2020.104921

Unger, M., Eichhoff, A. M., Schumacher, L., Strysio, M., Menzel, S., Schwan, C., et al. (2015). Selection of Nanobodies That Block the Enzymatic and Cytotoxic Activities of the Binary Clostridium Difficile Toxin CDT. Sci. Rep. 5, 7850. doi: 10.1038/srep07850

Urushibata, Y., Itoh, K., Ohshima, M., and Seto, Y. (2010). Generation of Fab Fragment-Like Molecular Recognition Proteins Against Staphylococcal Enterotoxin B by Phage Display Technology. Clin. Vaccine Immunol. CVI 17, 1708-1717. doi: 10.1128/CVI.00229-10

Valldorf, B., Hinz, S. C., Russo, G., Pekar, L., Mohr, L., Klemm, J., et al. (2021). Antibody Display Technologies: Selecting the Cream of the Crop. Biol. Chem. doi: 10.1515/hsz-2020-0377 van Wyngaardt, W., Malatji, T., Mashau, C., Fehrsen, J., Jordaan, F., Miltiadou, D., et al. (2004). A Large Semi-Synthetic Single-Chain Fv Phage Display Library Based on Chicken Immunoglobulin Genes. BMC Biotechnol. 4, 6. doi: 10.1186/ 1472-6750-4-6

Vashisht, S., Verma, S., and Salunke, D. M. (2019). Cross-Clade Antibody Reactivity may Attenuate the Ability of Influenza Virus to Evade the Immune Response. Mol. Immunol. 114, 149-161. doi: 10.1016/ j.molimm.2019.07.010

Vaughan, T. J., Williams, A. J., Pritchard, K., Osbourn, J. K., Pope, A. R., Earnshaw, J. C., et al. (1996). Human Antibodies With Sub-Nanomolar Affinities Isolated From a Large non-Immunized Phage Display Library. Nat. Biotechnol. 14, 309-314. doi: 10.1038/nbt0396-309

Velappan, N., Martinez, J. S., Valero, R., Chasteen, L., Ponce, L., Bondu-Hawkins, V., et al. (2007). Selection and Characterization of scFv Antibodies Against the Sin Nombre Hantavirus Nucleocapsid Protein. J. Immunol. Methods 321, 6069. doi: 10.1016/j.jim.2007.01.011

Velappan, N., Micheva-Viteva, S., Adikari, S. H., Waldo, G. S., Lillo, A. M., and Bradbury, A. R. M. (2020). Selection and Verification of Antibodies Against the Cytoplasmic Domain of M2 of Influenza, a Transmembrane Protein. $m A$ s s 12, 1843754. doi: 10.1080/19420862.2020.1843754

Vermeulen, A. N., Ponnudurai, T., Beckers, P. J., Verhave, J. P., Smits, M. A., and Meuwissen, J. H. (1985). Sequential Expression of Antigens on Sexual Stages of Plasmodium Falciparum Accessible to Transmission-Blocking Antibodies in the Mosquito. J. Exp. Med. 162, 1460-1476. doi: 10.1084/jem.162.5.1460

von Behring, E., and Kitasato, S. (1890). Über Das Zustandekommen Der Diphtherie-Immunität Und Der Tetanus-Immunität Bei Thieren. Dtsch. Med. Wochenzeitschrift 16, 1113-1114. doi: 10.1055/s-0029-1207589

von Eichel-Streiber, C., Sauerborn, M., and Kuramitsu, H. K. (1992). Evidence for a Modular Structure of the Homologous Repetitive C-Terminal CarbohydrateBinding Sites of Clostridium Difficile Toxins and Streptococcus Mutans Glucosyltransferases. J. Bacteriol. 174, 6707-6710. doi: 10.1128/jb.174.20. 6707-6710.1992

Vrentas, C. E., Moayeri, M., Keefer, A. B., Greaney, A. J., Tremblay, J., O’Mard, D., et al. (2016). A Diverse Set of Single-Domain Antibodies (VHHs) Against the Anthrax Toxin Lethal and Edema Factors Provides a Basis for Construction of a Bispecific Agent That Protects Against Anthrax Infection. J. Biol. Chem. 291, 21596-21606. doi: 10.1074/jbc.M116.749184

Vukovic, P., Chen, K., Qin Liu, X., Foley, M., Boyd, A., Kaslow, D., et al. (2002). Single-Chain Antibodies Produced by Phage Display Against the C-Terminal $19 \mathrm{kDa}$ Region of Merozoite Surface Protein-1 of Plasmodium Yoelii Reduce Parasite Growth Following Challenge. Vaccine 20, 2826-2835. doi: 10.1016/ S0264-410X(02)00197-4

Walper, S. A., Anderson, G. P., Brozozog Lee, P. A., Glaven, R. H., Liu, J. L., Bernstein, R. D., et al. (2012). Rugged Single Domain Antibody Detection Elements for Bacillus Anthracis Spores and Vegetative Cells. PLoS One 7, e32801. doi: 10.1371/journal.pone.0032801

Walper, S. A., Liu, J. L., Zabetakis, D., Anderson, G. P., and Goldman, E. R. (2014). Development and Evaluation of Single Domain Antibodies for Vaccinia and the L1 Antigen. PLoS One 9, e106263. doi: 10.1371/journal.pone.0106263

Wang, Q., Chang, C.-S., Pennini, M., Pelletier, M., Rajan, S., Zha, J., et al. (2016). Target-Agnostic Identification of Functional Monoclonal Antibodies Against Klebsiella Pneumoniae Multimeric MrkA Fimbrial Subunit. J. Infect. Dis. 213, 1800-1808. doi: 10.1093/infdis/jiw021

Wang, Y., Cui, P., Zhu, S., Meng, T., Hao, F., Zhu, G., et al. (2018). Preparation of Single-Chain Antibody Against VP3 Protein of Duck Hepatitis Virus Type 1 by Phage Display Technology. J. Virol. Methods 257, 73-78. doi: 10.1016/ j.jviromet.2018.04.010

Wang, R., Fang, S., Wu, D., Lian, J., Fan, J., Zhang, Y., et al. (2012). Screening for a Single-Chain Variable-Fragment Antibody That Can Effectively Neutralize the Cytotoxicity of the Vibrio Parahaemolyticus Thermolabile Hemolysin. Appl. Environ. Microbiol. 78, 4967-4975. doi: 10.1128/AEM.00435-12

Wang, R., Fang, S., Xiang, S., Ling, S., Yuan, J., and Wang, S. (2014). Generation and Characterization of a scFv Antibody Against T3SS Needle of Vibrio Parahaemolyticus. Indian J. Microbiol. 54, 143-150. doi: 10.1007/s12088-013-0428-6

Wang, X., Gray, M. C., Hewlett, E. L., and Maynard, J. A. (2015). The Bordetella Adenylate Cyclase Repeat-in-Toxin (RTX) Domain Is Immunodominant and Elicits Neutralizing Antibodies. J. Biol. Chem. 290, 3576-3591. doi: 10.1074/ jbc.M114.585281 
Wang, P., Li, G., Yan, J., Hu, Y., Zhang, C., Liu, X., et al. (2014). Bactrian Camel Nanobody-Based Immunoassay for Specific and Sensitive Detection of Cry1Fa Toxin. Toxicon 92, 186-192. doi: 10.1016/j.toxicon.2014.10.024

Wang, T., Li, P., Zhang, Q., Zhang, W., Zhang, Z., Wang, ,. T., et al. (2017). Determination of Aspergillus Pathogens in Agricultural Products by a Specific Nanobody-Polyclonal Antibody Sandwich ELISA. Sci. Rep. 7, 4348. doi: 10.1038/s41598-017-04195-6

Wang, Y., Rowley, K. J., Booth, B. J., Sloan, S. E., Ambrosino, D. M., and Babcock, G. J. (2011). G Glycoprotein Amino Acid Residues Required for Human Monoclonal Antibody RAB1 Neutralization are Conserved in Rabies Virus Street Isolates. Antiviral Res. 91, 187-194. doi: 10.1016/j.antiviral.2011.06.002

Wang, D., Yang, S., Yin, S., Shang, Y., Du, P., Guo, J., et al. (2015). Characterization of Single-Domain Antibodies Against Foot and Mouth Disease Virus (FMDV) Serotype O From a Camelid and Imaging of FMDV in Baby Hamster Kidney-21 Cells With Single-Domain Antibody-Quantum Dots Probes. BMC Vet. Res. 11, 120. doi: 10.1186/s12917-015-0437-2

Wang, D., Yue, Y., Wu, G., Tian, Y., Liu, Y., Yu, J., et al. (2017). Preparation and Characterization of a Human scFv Against the Clostridium Perfringens Type A Alpha-Toxin. Toxicon 130, 79-86. doi: 10.1016/j.toxicon.2017.02.021

Wang, H., Yu, R., Fang, T., Yu, T., Chi, X., Zhang, X., et al. (2016). Tetanus Neurotoxin Neutralizing Antibodies Screened From a Human Immune scFv Antibody Phage Display Library. Toxins 8. doi: 10.3390/toxins 8090266

Wang, M., Zhang, Y., Li, B., and Zhu, J. (2015). Construction of scFv That Bind Both Fibronectin-Binding Protein A and Clumping Factor A of Stapylococcus Aureus. Res. Vet. Sci. 100, 109-114. doi: 10.1016/j.rvsc.2015.02.012

Wang, Y., Zhang, X., Zhang, C., Liu, Y., and Liu, X. (2012). Isolation of Single Chain Variable Fragment (scFv) Specific for CrylC Toxin From Human Single Fold scFv Libraries. Toxicon 60, 1290-1297. doi: 10.1016/j.toxicon.2012.08.014

Wang, M., Zhang, Y., and Zhu, J. (2016). Anti-Staphylococcus Aureus SingleChain Variable Region Fragments Provide Protection Against Mastitis in Mice. Appl. Microbiol. Biotechnol. 100, 2153-2162. doi: 10.1007/s00253-015-7045-8

Weatherman, S., Feldmann, H., and de Wit, E. (2018). Transmission of Henipaviruses. Curr. Opin. Virol. 28, 7-11. doi: 10.1016/j.coviro.2017.09.004

Weaver, S. C., Ferro, C., Barrera, R., Boshell, J., and Navarro, J.-C. (2004). Venezuelan Equine Encephalitis. Annu. Rev. Entomol. 49, 141-174. doi: 10.1146/annurev.ento.49.061802.123422

Webster, R. G., and Govorkova, E. A. (2014). Continuing Challenges in Influenza. Ann. N. Y. Acad. Sci. 1323, 115-139. doi: 10.1111/nyas. 12462

Weir, D. L., Coggins, S. A., Vu, B. K., Coertse, J., Yan, L., Smith, I. L., et al. (2021). Isolation and Characterization of Cross-Reactive Human Monoclonal Antibodies That Potently Neutralize Australian Bat Lyssavirus Variants and Other Phylogroup 1 Lyssaviruses. Viruses 13. doi: 10.3390/v13030391

Welch, B. D., Paduch, M., Leser, G. P., Bergman, Z., Kors, C. A., Paterson, R. G., et al. (2014). Probing the Functions of the Paramyxovirus Glycoproteins F and HN With a Panel of Synthetic Antibodies. J. Virol. 88, 11713-11725. doi: 10.1128/JVI.01707-14

Wemmer, S., Mashau, C., Fehrsen, J., van Wyngaardt, W., and du Plessis, D. H. (2010). Chicken Scfvs and Bivalent scFv-C(H) Fusions Directed Against HSP65 of Mycobacterium Bovis. Biol. J. Int. Assoc. Biol. Stand. 38, 407-414. doi: 10.1016/j.biologicals.2010.02.002

Wenzel, E. V., Bosnak, M., Tierney, R., Schubert, M., Brown, J., Dübel, S., et al. (2020a). Human Antibodies Neutralizing Diphtheria Toxin In Vitro and In Vivo. . Sci. Rep. 10:571. doi: 10.1038/s41598-019-57103-5

Wenzel, E. V., Roth, K. D. R., Russo, G., Fühner, V., Helmsing, S., Frenzel, A., et al. (2020b). Antibody Phage Display: Antibody Selection in Solution Using Biotinylated Antigens. Methods Mol. Biol. Clifton N. J. 2070, 143-155. doi: 10.1007/978-1-4939-9853-1_8

Wiker, H. G., and Harboe, M. (1992). The Antigen 85 Complex: A Major Secretion Product of Mycobacterium Tuberculosis. Microbiol. Rev. 56, 648-661. doi: 10.1128/mr.56.4.648-661.1992

Wiker, H. G., Nagai, S., Harboe, M., and Ljungqvist, L. (1992). A Family of CrossReacting Proteins Secreted by Mycobacterium Tuberculosis. Scand. J. Immunol. 36, 307-319. doi: 10.1111/j.1365-3083.1992.tb03104.x

Williams, J. V., Chen, Z., Cseke, G., Wright, D. W., Keefer, C. J., Tollefson, S. J., et al. (2007). A Recombinant Human Monoclonal Antibody to Human Metapneumovirus Fusion Protein That Neutralizes Virus In Vitro and is Effective Therapeutically In Vivo. J. Virol. 81, 8315-8324. doi: 10.1128/ JVI.00106-07
Winter, G., Griffiths, A. D., Hawkins, R. E., and Hoogenboom, H. R. (1994). Making Antibodies by Phage Display Technology. Annu. Rev. Immunol. 12, 433-455. doi: 10.1146/annurev.iy.12.040194.002245

Winter, G., and Milstein, C. (1991). Man-Made Antibodies. Nature 349, 293-299. doi: 10.1038/349293a0

Wong, K. T., and Tan, C. T. (2012). Clinical and Pathological Manifestations of Human Henipavirus Infection. Curr. Top. Microbiol. Immunol. 359, 95-104. doi: 10.1007/82_2012_205

World Health Organization (2021). Available at: https://www.who.int/healthtopics/tuberculosis\#tab=tab_1 (accessed July 02, 2021).

Wu, Y., Li, S., Du, L., Wang, C., Zou, P., Hong, B., et al. (2017). Neutralization of Zika Virus by Germline-Like Human Monoclonal Antibodies Targeting Cryptic Epitopes on Envelope Domain III. Emerg. Microbes Infect. 6, e89. doi: 10.1038/emi.2017.79

Wu, J., Zeng, X.-Q., Zhang, H.-B., Ni, H.-Z., Pei, L., Zou, L.-R., et al. (2014). Novel Phage Display-Derived H5N1-Specific Scfvs With Potential Use in Rapid Avian Flu Diagnosis. J. Microbiol. Biotechnol. 24, 704-713. doi: 10.4014/jmb.1311.11107

Wyrzucki, A., Dreyfus, C., Kohler, I., Steck, M., Wilson, I. A., and Hangartner, L. (2014). Alternative Recognition of the Conserved Stem Epitope in Influenza A Virus Hemagglutinin by a VH3-30-Encoded Heterosubtypic Antibody. J. Virol. 88, 7083-7092. doi: 10.1128/JVI.00178-14

Xiao, X., Feng, Y., Vu, B. K., Ishima, R., and Dimitrov, D. S. (2009). A Large Library Based on a Novel (CH2) Scaffold: Identification of HIV-1 Inhibitors. Biochem. Biophys. Res. Commun. 387, 387-392. doi: 10.1016/j.bbrc.2009.07.044

Xue, W., Zhao, Q., Li, P., Zhang, R., Lan, J., Wang, J., et al. (2019). Identification and Characterization of a Novel Nanobody Against Duck Hepatitis A Virus Type 1. Virology 528, 101-109. doi: 10.1016/j.virol.2018.12.013

Xu, C., Liu, ,. X., Zhang, C., Zhang, X., Zhong, J., Liu, Y., et al. (2017a). Establishment of a Sensitive Time-Resolved Fluoroimmunoassay for Detection of Bacillus Thuringiensis Crylle Toxin Based Nanobody From a Phage Display Library. Anal. Biochem. 518, 53-59. doi: 10.1016/j.ab.2016.11.006

Xu, C., Miao, W., He, Y., Zu, Y., Liu, ,. X., Li, J., et al. (2019). Construction of an Immunized Rabbit Phage Display Antibody Library for Screening MicrocystinLR High Sensitive Single-Chain Antibody. Int. J. Biol. Macromol. 123, 369-378. doi: 10.1016/j.ijbiomac.2018.11.122

Xu, H., Xia, A., Wang, D., Zhang, Y., Deng, S., Lu, W., et al. (2020). An Ultraportable and Versatile Point-of-Care DNA Testing Platform. Sci. Adv. 6, eaaz7445. doi: 10.1126/sciadv.aaz7445

Xu, C., Yang, Y., Liu, L., Li, J., Liu, ,. X., Zhang, X., et al. (2018). Microcystin-LR Nanobody Screening From an Alpaca Phage Display Nanobody Library and its Expression and Application. Ecotoxicol. Environ. Saf. 151, 220-227. doi: 10.1016/j.ecoenv.2018.01.003

Xu, C., Zhang, C., Zhong, J., Hu, H., Luo, S., Liu, ,. X., et al. (2017b). Construction of an Immunized Rabbit Phage Display Library for Selecting High Activity Against Bacillus Thuringiensis Cry1F Toxin Single-Chain Antibodies. J. Agric. Food Chem. 65, 6016-6022. doi: 10.1021/acs.jafc.7b01985

Yamanaka, A., Imad, H. A., Phumratanaprapin, W., Phadungsombat, J., Konishi, E., and Shioda, T. (2021). Antibody-Dependent Enhancement Representing In Vitro Infective Progeny Virus Titer Correlates With the Viremia Level in Dengue Patients. Sci. Rep. 11, 12354. doi: 10.1038/s41598-021-91793-0

Yang, Z., Schmidt, D., Liu, W., Li, S., Shi, L., Sheng, J., et al. (2014). A Novel Multivalent, Single-Domain Antibody Targeting TcdA and TcdB Prevents Fulminant Clostridium Difficile Infection in Mice. J. Infect. Dis. 210, 964-972. doi: 10.1093/infdis/jiu196

Yang, B., Yajima, W., Das, D., Suresh, M. R., and Kav, N. N. V. (2009). Isolation, Expression and Characterization of Two Single-Chain Variable Fragment Antibodies Against an Endo-Polygalacturonase Secreted by Sclerotinia Sclerotiorum. Protein Expr. Purif. 64, 237-243. doi: 10.1016/j.pep.2008.12.007

Yan, Z.-H., Zhao, B., Pang, Y., Wang, X.-J., Yi, L., Wang, H.-L., et al. (2020). Generation of Mycobacterial Lipoarabinomannan-Specific Monoclonal Antibodies and Their Ability to Identify Mycobacterium Isolates. J. Microbiol. Immunol. Infect. Wei Mian Yu Gan Ran Za Zhi. doi: 10.1016/j.jmii.2020.02.005

Yodsheewan, R., Maneewatch, S., Srimanote, P., Thueng-In, K., Songserm, T., Dong-Din-On, F., et al. (2013). Human Monoclonal ScFv Specific to NS1 Protein Inhibits Replication of Influenza Viruses Across Types and Subtypes. Antiviral Res. 100, 226-237. doi: 10.1016/j.antiviral.2013.07.019

Yuan, L., Zhang, X., Xiao, N., Dai, L., Chen, W., Jia, C., et al. (2006). Identification of a WSSV Neutralizing scFv Antibody by Phage Display Technology and In Vitro Screening. Dis. Aquat. Organ. 72, 93-99. doi: 10.3354/dao072093 
Yu, J., Sun, Z., Sun, X., Sun, X., Wei, H., Jia, W., et al. (2020). Selection and Characterization of a Vibrio Parahaemolyticus OmpU Antibody by Phage Display. Microb. Pathog. 143, 104136. doi: 10.1016/j.micpath.2020.104136

Zaki, A. M., van Boheemen, S., Bestebroer, T. M., Osterhaus, A. D. M. E., and Fouchier, R. A. M. (2012). Isolation of a Novel Coronavirus From a Man With Pneumonia in Saudi Arabia. N. Engl. J. Med. 367, 1814-1820. doi: 10.1056/NEJMoa1211721

Zanganeh, S., Rouhani Nejad, H., Mehrabadi, J. F., Hosseini, R., Shahi, B., Tavassoli, Z., et al. (2019). Rapid and Sensitive Detection of Staphylococcal Enterotoxin B by Recombinant Nanobody Using Phage Display Technology. Appl. Biochem. Biotechnol. 187, 493-505. doi: 10.1007/s12010-018-2762-y

Zeng, X., Li, L., Lin, J., Li, X., Liu, B., Kong, Y., et al. (2020). Isolation of a Human Monoclonal Antibody Specific for the Receptor Binding Domain of SARSCoV-2 Using a Competitive Phage Biopanning Strategy. Antib. Ther. doi: 10.1093/abt/tbaa008

Zhang, F., Chen, Y., Ke, Y., Zhang, L., Zhang, B., Yang, L., et al. (2019a). Single Chain Fragment Variable (scFv) Antibodies Targeting the Spike Protein of Porcine Epidemic Diarrhea Virus Provide Protection Against Viral Infection in Piglets. Viruses 11. doi: 10.3390/v11010058

Zhang, F., Chen, Y., Yang, L., and Zhu, J. (2019b). Construction and Characterization of Porcine Single-Chain Fragment Variable Antibodies That Neutralize Transmissible Gastroenteritis Virus In Vitro. Arch. Virol. 164, 983-994. doi: 10.1007/s00705-019-04156-6

Zhang, J.-L., Gou, J.-J., Zhang, Z.-Y., Jing, Y.-X., Zhang, L., Guo, R., et al. (2006). Screening and Evaluation of Human Single-Chain Fragment Variable Antibody Against Hepatitis B Virus Surface Antigen. Hepatobiliary Pancreat. Dis. Int. HBPD Int. 5, 237-241.

Zhang, D., Mao, Y., Cao, Q., Xiong, L., Wen, J., Chen, R., et al. (2013). Generation and Characterization of a Novel Recombinant Antibody Against LMP1-TES1 of Epstein-Barr Virus Isolated by Phage Display. Viruses 5, 1131-1142. doi: 10.3390/v5041131

Zhang, Y., Sun, X., Qian, Y., Yi, H., Song, K., Zhu, H., et al. (2019). A Potent AntiSpuE Antibody Allosterically Inhibits Type III Secretion System and Attenuates Virulence of Pseudomonas Aeruginosa. J. Mol. Biol. 431, 48824896. doi: 10.1016/j.jmb.2019.10.026

Zhang, X., Sun, C., Xiao, X., Pang, L., Shen, S., Zhang, J., et al. (2016). Phage DisplayDerived Cross-Reactive Neutralizing Antibody Against Enterovirus 71 and Coxsackievirus A16. Jpn. J. Infect. Dis. 69, 66-74. doi: 10.7883/yoken.JJID.2015.060

Zhang, J. Y., Wang, J. G., Wu, Y. S., Li, M., Li, A. H., and Gong, X. L. (2006). A Combined Phage Display ScFv Library Against Myxobolus Rotundus Infecting Crucian Carp, Carassius Auratus Auratus (L.), in China. J. Fish Dis. 29, 1-7. doi: 10.1111/j.1365-2761.2005.00666.x

Zhang, L., Zheng, B., Gao, X., Zhang, L., Pan, H., Qiao, Y., et al. (2020). Development of Patient-Derived Human Monoclonal Antibodies Against Nucleocapsid Protein of Severe Acute Respiratory Syndrome Coronavirus 2 for Coronavirus Disease 2019 Diagnosis. Front. Immunol. 11, 3389. doi: 10.3389/fimmu.2020.595970

Zhao, Y., Moreland, N. J., Tay, M. Y. F., Lee, C. C., Swaminathan, K., and Vasudevan, S. G. (2014). Identification and Molecular Characterization of
Human Antibody Fragments Specific for Dengue NS5 Protein. Virus Res. 179, 225-230. doi: 10.1016/j.virusres.2013.11.010

Zhong, W., Li, G., Yu, X., Zhu, M., Gong, L., and Wan, Y. (2018). Sensitive Detection of Bacillus Thuringiensis Cry1B Toxin Based on Camel Single-Domain Antibodies. MicrobiologyOpen 7, e00581. doi: 10.1002/ mbo3.581

Zhou, D., Chan, J. F.-W., Zhou, B., Zhou, R., Li, S., Shan, S., et al. (2021). Robust SARS-CoV-2 Infection in Nasal Turbinates After Treatment With Systemic Neutralizing Antibodies. Cell Host Microbe 29, 551-563.e5. doi: 10.1016/ j.chom.2021.02.019

Zhou, P., Yang, X.-L., Wang, X.-G., Hu, B., Zhang, L., Zhang, W., et al. (2020). A Pneumonia Outbreak Associated With a New Coronavirus of Probable Bat Origin. Nature 579, 270-273. doi: 10.1038/s41586-020-2012-7

Zhu, Z., Bossart, K. N., Bishop, K. A., Crameri, G., Dimitrov, A. S., McEachern, J. A., et al. (2008). Exceptionally Potent Cross-Reactive Neutralization of Nipah and Hendra Viruses by a Human Monoclonal Antibody. J. Infect. Dis. 197, 846-853. doi: 10.1086/528801

Zhu, Z., Dimitrov, A. S., Bossart, K. N., Crameri, G., Bishop, K. A., Choudhry, V., et al. (2006). Potent Neutralization of Hendra and Nipah Viruses by Human Monoclonal Antibodies. J. Virol. 80, 891-899. doi: 10.1128/JVI.80.2.891899.2006

Zhu, M., Gong, X., Hu, Y., Ou, W., and Wan, Y. (2014). Streptavidin-Biotin-Based Directional Double Nanobody Sandwich ELISA for Clinical Rapid and Sensitive Detection of Influenza H5N1. J. Transl. Med. 12, 352. doi: 10.1186/ s12967-014-0352-5

Ziegler, A., Torrance, L., Macintosh, S. M., Cowan, G. H., and Mayo, M. A. (1995). Cucumber Mosaic Cucumovirus Antibodies From a Synthetic Phage Display Library. Virology 214, 235-238. doi: 10.1006/viro.1995.9935

Zúñiga-Navarrete, F., Gómez, I., Peña, G., Amaro, I., Ortíz, E., Becerril, B., et al. (2015). Identification of Bacillus Thuringiensis Cry3Aa Toxin Domain II Loop 1 as the Binding Site of Tenebrio Molitor Cadherin Repeat CR12. Insect Biochem. Mol. Biol. 59, 50-57. doi: 10.1016/j.ibmb.2015.02.002

Conflict of Interest: EW, GR, and SD are shareholders of Abcalis GmbH. AF, TS, $\mathrm{SD}$, and $\mathrm{MH}$ are shareholders of YUMAB GmbH.

The remaining authors declare that the research was conducted in the absence of any commercial or financial relationships that could be construed as a potential conflict of interest.

Copyright (C) 2021 Roth, Wenzel, Ruschig, Steinke, Langreder, Heine, Schneider, Ballmann, Fühner, Kuhn, Schirrmann, Frenzel, Dübel, Schubert, Moreira, Bertoglio, Russo and Hust. This is an open-access article distributed under the terms of the Creative Commons Attribution License (CC BY). The use, distribution or reproduction in other forums is permitted, provided the original author(s) and the copyright owner(s) are credited and that the original publication in this journal is cited, in accordance with accepted academic practice. No use, distribution or reproduction is permitted which does not comply with these terms. 